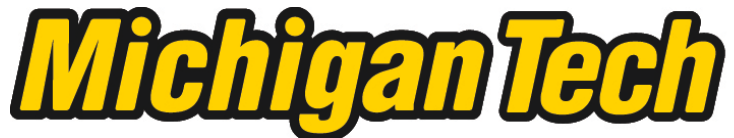 \\ Michigan Technological University Create the Future Digital Commons @ Michigan Tech
}

Integrated solar energy and absorption cooling model for HVAC (heating, ventilating, and air conditioning) applications in buildings

Sharizal Shaik Ahmedullah

Michigan Technological University

Follow this and additional works at: https://digitalcommons.mtu.edu/etds

Part of the Mechanical Engineering Commons

Copyright 2006 Sharizal Shaik Ahmedullah

Recommended Citation

Ahmedullah, Sharizal Shaik, "Integrated solar energy and absorption cooling model for HVAC (heating, ventilating, and air conditioning) applications in buildings", Dissertation, Michigan Technological University, 2006.

https://doi.org/10.37099/mtu.dc.etds/344

Follow this and additional works at: https://digitalcommons.mtu.edu/etds

Part of the Mechanical Engineering Commons 
INTEGRATED SOLAR ENERGY

AND ABSORPTION COOLING MODEL

FOR HVAC (HEATING, VENTILATING, AND AIR CONDITIONING)

APPLICATIONS IN BUILDINGS

By

Sharizal Shaik Ahmedullah

\begin{abstract}
A DISSERTATION
Submitted in partial fulfillment of the requirements

for the degree of

DOCTOR OF PHILOSOPHY

Mechanical Engineering-Engineering Mechanics
\end{abstract}

Michigan Technological University

2006 
This dissertation, "Integrated Solar Energy and Absorption Cooling Model for HVAC (Heating, Ventilating, and Air Conditioning) Applications in Buildings", is hereby approved in partial fulfillment of the requirements for the degree of DOCTOR OF PHILOSOPHY in the field of Mechanical Engineering-Engineering Mechanics.

DEPARTMENT: Mechanical Engineering-Engineering Mechanics

\section{Signatures:}

Dissertation co-advisor:

Dr. Oner Arici

Dissertation co-advisor:

Dr. Donna J. Michalek

Department Chair:

Dr. William W. Predebon

Date: 


\title{
Integrated Solar Energy and Absorption Cooling Model for HVAC (Heating, Ventilating, and Air Conditioning) Applications in Buildings
}

\begin{abstract}
The demands in production and associate costs at power generation through non renewable resources are increasing at an alarming rate. Solar energy is one of the renewable resource that has the potential to minimize this increase. Utilization of solar energy have been concentrated mainly on heating application. The use of solar energy in cooling systems in building would benefit greatly achieving the goal of non-renewable energy minimization.
\end{abstract}

The approaches of solar energy heating system research done by initiation such as University of Wisconsin at Madison and building heat flow model research conducted by Oklahoma State University can be used to develop and optimize solar cooling building system.

The research uses two approaches to develop a Graphical User Interface (GUI) software for an integrated solar absorption cooling building model, which is capable of simulating and optimizing the absorption cooling system using solar energy as the main energy source to drive the cycle. 
The software was then put through a number of litmus test to verify its integrity. The litmus test was conducted on various building cooling system data sets of similar applications around the world. The output obtained from the software developed were identical with established experimental results from the data sets used.

Software developed by other research are catered for advanced users. The software developed by this research is not only reliable in its code integrity but also through its integrated approach which is catered for new entry users.

Hence, this dissertation aims to correctly model a complete building with the absorption cooling system in appropriate climate as a cost effective alternative to conventional vapor compression system. 


\section{Acknowledgements}

This research was introduced by Dr. Oner Arici after 6 months I started my graduate studies at Michigan Technological University. Throughout his experience in research and teachings for more than 20 years, he always dreamed of an independent solar energy home that can provide cooling needs as an addition to the solar water heating. With his full guidance and encouragements, I was able to study in a lot deeper and analyzed this integrated solar energy and absorption cooling model in buildings. Thanks a million to you not only as my advisor but also in resolving other problems that arises during all those while...you are like a father to me.

Thanks to Dr. Donna Michalek for your support as the co-advisor. I really appreciate your willingness to be my mentor and to provide professional supervision that can support my journey which is a very challenging one.

I am also grateful to Dr. Amitabh Narain and Dr. Tony Rogers who served on my doctoral committee and for being very understanding especially during the proposal defense when I had to postponed it due to some unavoidable circumstances. Thank you.

Thank you to the MEEM Department Chair, Dr. William Predebon for the funding that I have received from this department and also for his personal attention to some of my requests.

Ahmad Faisal Bakar, Thanks so much for your time and willingness to review the dissertation. Thanks for being there for me. 
Thank you to all my friends for your support and the time we spent especially Anne Hartingh, Lucas Phan, Zainal Aroha, Azreen, Sean Wagner, Laura Kruger, Jessica Dorvinen, Paul Hunter, Egel Urip, Simon Tseng, and Barbara Zackal. I wish you all the best of luck

Thank you very much to all the persons that I have known for sharing the knowledge and spending the time and hopefully we will see each other again.

To my family, especially my parents, thanks for all the support and love that you've given me. I wouldn't got this far without you.

To my wife, Zuraizam Yusoff, I would like to give this very special thanks for always being there and for all the patience, love and encouragement that you never failed to give. I couldn't mentioned your sincere help that got me out of my miserable life.

And most of all, to God, I wouldn't have any strength without you and "Thank You God" for everything. 


\section{Table of Contents}

page

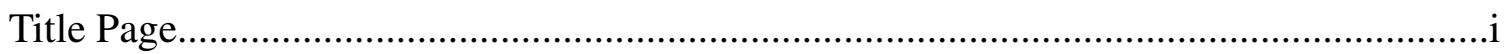

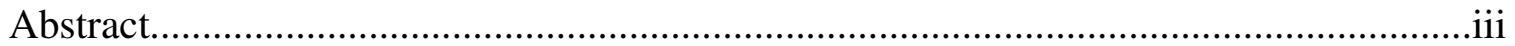

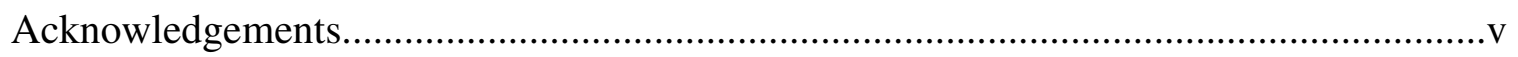

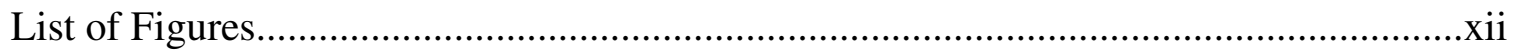

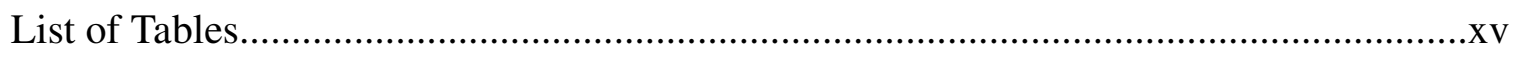

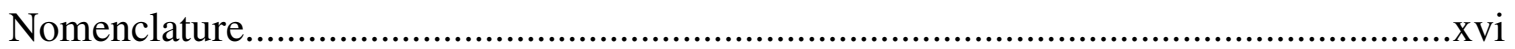

Chapter 1 Introduction

1.1 Motivation and Objectives............................................................................

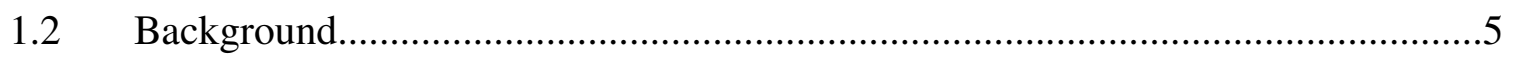

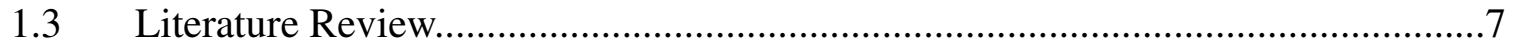

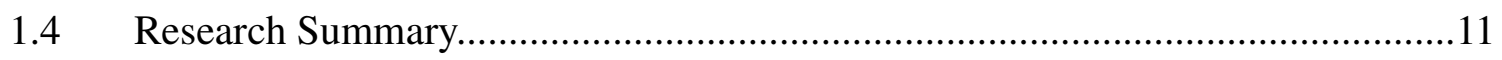

Chapter 2 Building Cooling Model

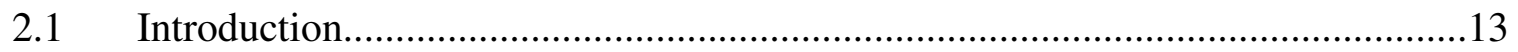

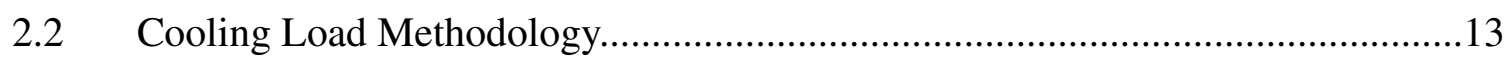

2.3 Cooling Load and Heat Gain Overview........................................................14

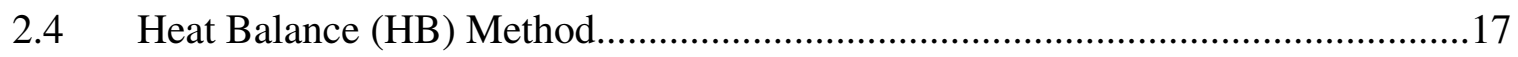

2.4.1 HB Method - Overview........................................................... 17 
2.4.2 HB Method - Formulation............................................................19

2.5 Radiant Time Series (RTS) Method.............................................................23

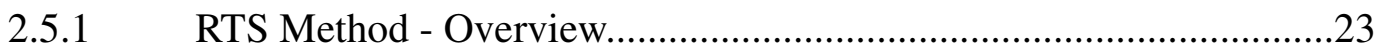

2.5.2 Calculating Heat Gains..............................................................25

2.5.3 Calculating Hourly Cooling Load.....................................................22

2.5.4 Validation / Sample Calculations.......................................................30

Chapter 3 Absorption System Model

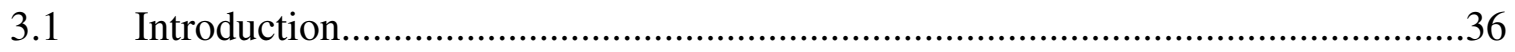

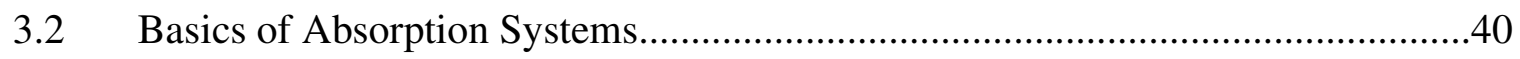

3.3 Absorption Cycle Description.....................................................................43

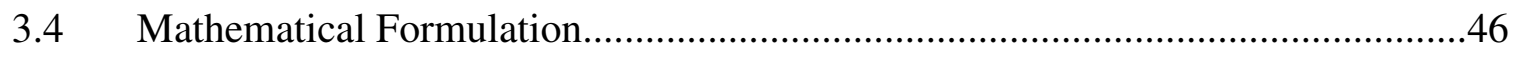

3.4.1 Desorber/Generator/Concentrator..............................................47

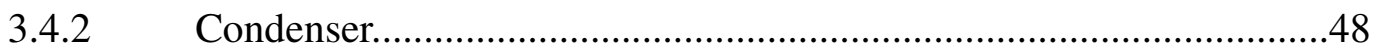

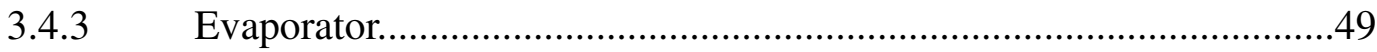

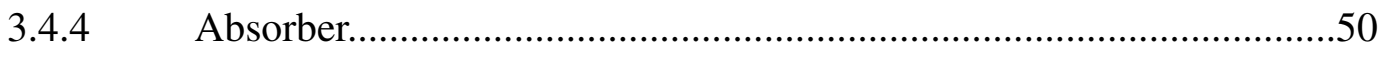

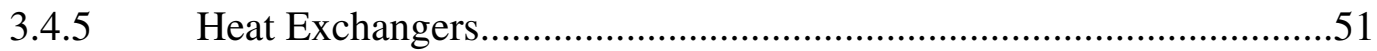

3.5 Validation / Sample Calculations.................................................................52

Chapter 4 Storage Tank Model

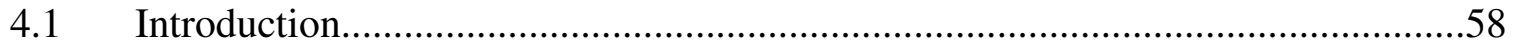

4.2 Non-Stratified Tank Model.....................................................................60

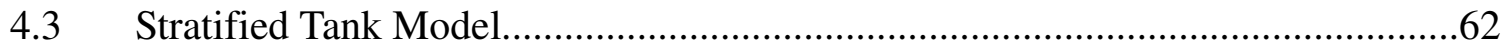


Chapter 5 Solar Collector Model

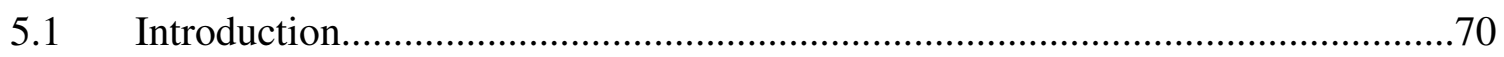

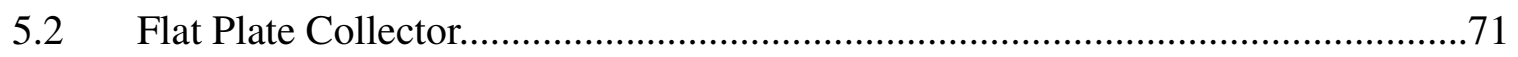

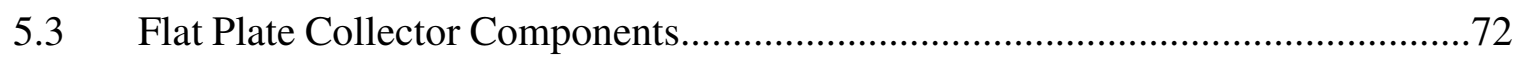

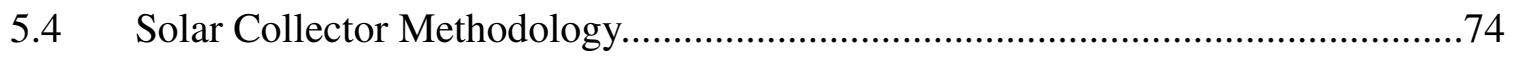

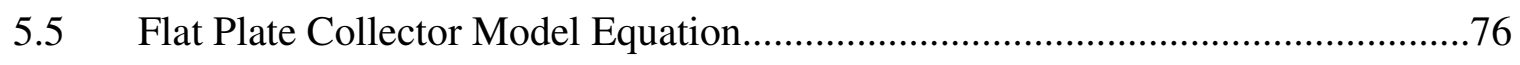

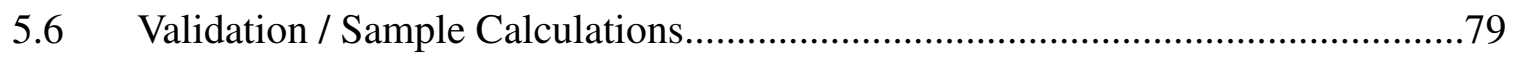

Chapter 6 Solar Load Model

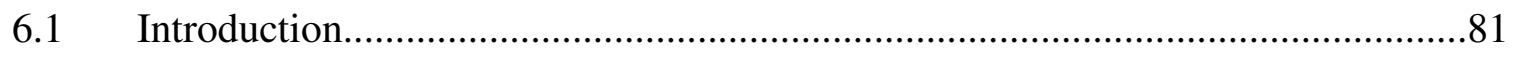

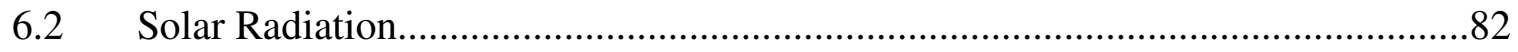

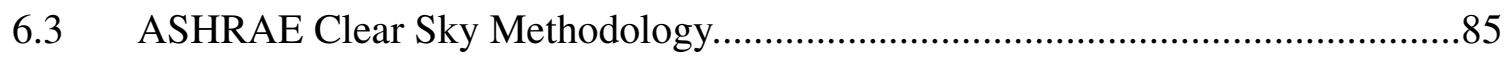

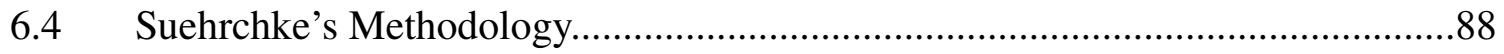

Chapter 7 Integrated Solar Absorption Cooling Building Model

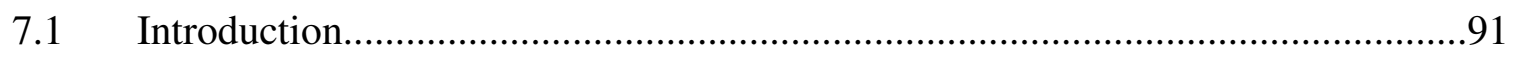

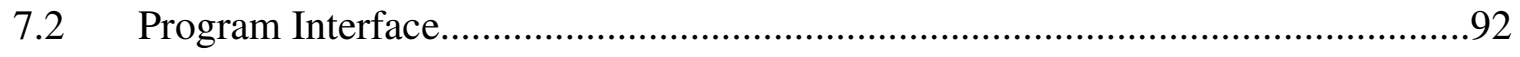

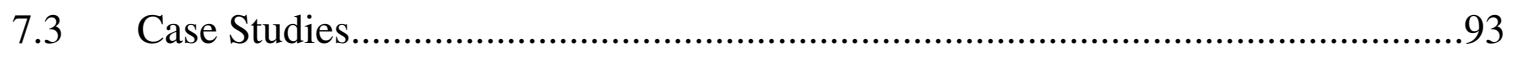

Case Study 1 - South China...........................................................93

7.3.2 Case Study 2 - Japan (HARBEMAN House)...................................95

7.3.3 Case Study 3 - United States: Albuquerque, Madison, and Miami......98 
Chapter 8 Conclusions and Recommendations

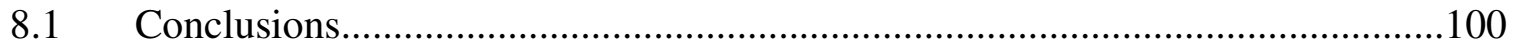

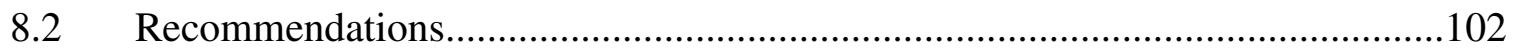

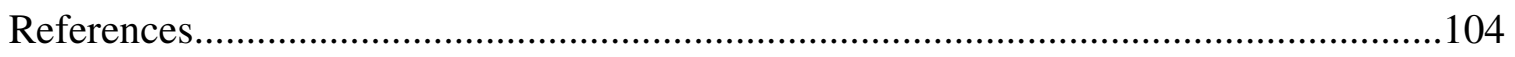

Appendices

Appendix A

A.1 Wall Conduction Time Series - PART I.......................................112

A.2 Wall Conduction Time Series - PART II........................................113

A.3 Roof Conduction Time Series - PART III....................................114

A.4 Radiant Time Series (Solar) - PART I..........................................115

A.5 Radiant Time Series (Non-Solar) - PART II................................116

A.6 Recommended Radiative and Convective Fractions.........................117

A.7 Periodic Response Factor (PRFs) Derivation.................................118

Appendix B

B.1 Double Effect Absorption Chiller............................................124

B.2 Desorber/Generator/Concentrator................................................ 125

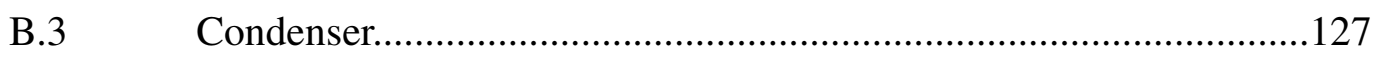

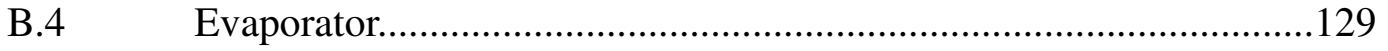

B.5 Absorber........................................................................ 130

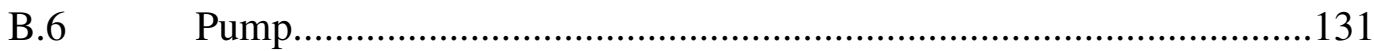


B.7

Heat Exchangers.

.132

Appendix C

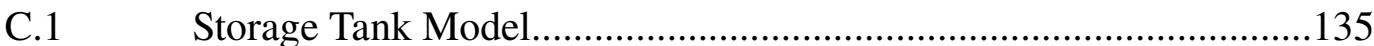




\section{LIST OF FIGURES}

Figure 1.1: $\quad$ History of US Electricity Generation and Sales......................................2

Figure 1.2: $\quad$ Proposed Integrated Design Model....................................................12

Figure 1.3: Cycle Simulation Flow Chart..............................................................12

Figure 2.1: Cooling Load and Heat Gain Relationship............................................15

Figure 2.2: Overview of Heat Balance Zone and Heat Balance Processes....................18

Figure 2.3: $\quad$ Overview of Radiant Time Series (RTS) Method....................................24

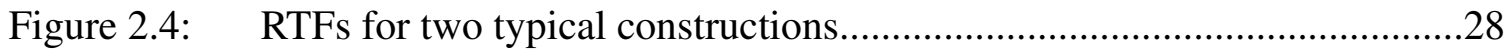

Figure 2.5: Simulation and Experimental Results for Heavy Weight and Light Weight

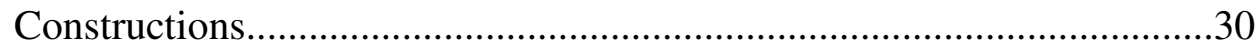

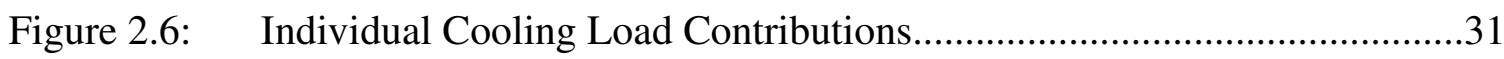

Figure 2.7: Individual Cooling Load Contributions (cont.)....................................32

Figure 2.8: Individual Cooling Load Contributions (cont.).....................................33

Figure 3.1: Absorption Machines and Schematic Diagram of Absorption Process.......37

Figure 3.2: $\quad \mathrm{COP}$ as a Function of Heat Input for LiBr-Water Absorption Chillers......39

Figure 3.3: $\quad$ Carnot Cycle for Power Generation.....................................................41

Figure 3.4: Carnot Cycle for Refrigeration.......................................................42

Figure 3.5: $\quad$ Carnot Cycle for Absorption Refrigeration............................................43

Figure 3.6: Schematic Diagram of Four Basic Components in a Single Effect Absorption Machine................................................................................44

Figure 3.7: Schematic Representation of Condensate Flow...................................45

Figure 3.8: Circuit Diagram of the Double Effect Absorption Cycle..........................46 
Figure 3.9: Circuit diagram of the Desorber/Generator/Concentrator..

Figure 3.10: Circuit Diagram of the Condenser...................................................49

Figure 3.11: Circuit Diagram of the Evaporator.........................................................50

Figure 3.12: Circuit Diagram of the Absorber.........................................................

Figure 3.13: Circuit Diagram of the Heat Exchangers.................................................52

Figure 3.14: Calculated COP for Single, Double, and Triple Effect Lithium Bromide-

Water Absorption Chillers...................................................................53

Figure 3.15: Performance Comparison for Double Effect Chiller.................................55

Figure 3.16: Effect of the Heat Input on COP and Heat Transfer Rate..........................56

Figure 4.1: Water Tank Storage: Water Circulation Through Collector and Through

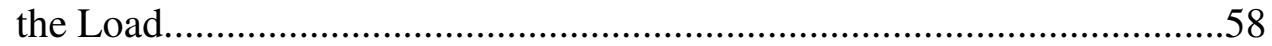

Figure 4.2: $\quad$ Alternative System with More Than One Storage Tank..........................59

Figure 4.3: Unstratified Storage of Mass m Operating at Time-Dependent Temperature

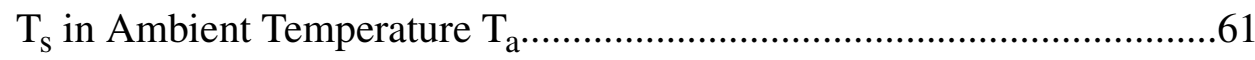

Figure 4.4: $\quad$ Stratified Liquid Storage Tank and the Internal Flows Associated with

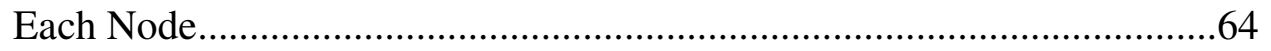

Figure 4.5: Comparison Between Simulation and Experimental Data.......................68

Figure 5.1: $\quad$ Flat Plate Collector........................................................................... 71

Figure 5.2: Cross Section of a Flat Plate Collector..................................................72

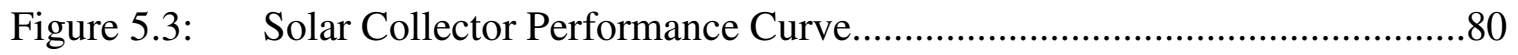

Figure 6.1: $\quad$ Solar Angles with Respect to a Tilted Surface......................................83

Figure 6.2: Clearness Numbers for the United States............................................86

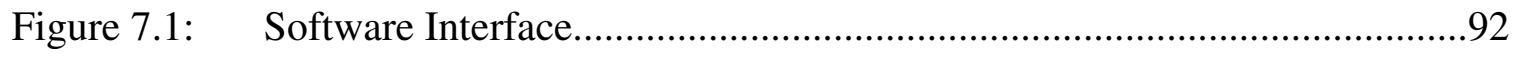


Figure 7.2: Cooling capacity of the double effect absorption chiller.

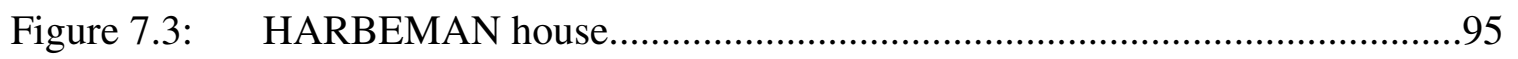

Figure 7.4: Solar radiation and solar collector outlet temperature comparisons...........96

Figure 7.5: Comparison of a cooling load in an average selected room.....................97

Figure 7.6: 1-Day Cooling Load Simulation vs. 1-Year Cooling Load Simulatio hour

Cooling Load Simulation...........................................................99

Figure B.1: Double Effect Absorption Chiller...................................................123

Figure B.2: $\quad$ Desorber/Generator/Concentrator....................................................... 124

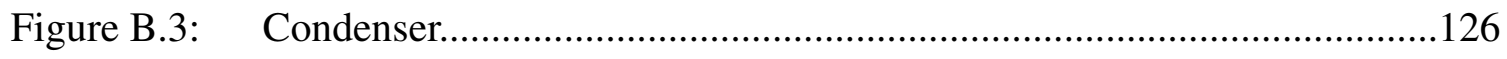

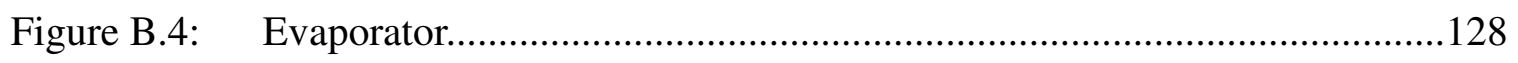

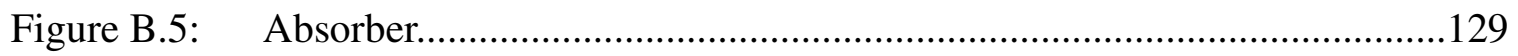

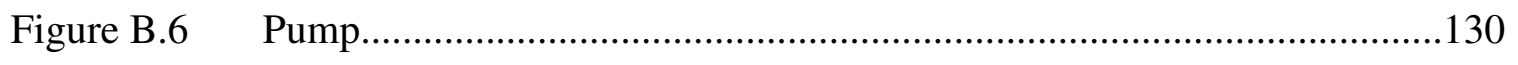

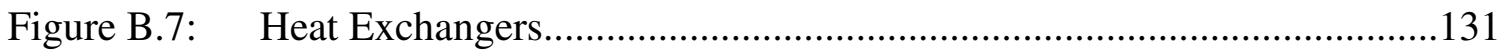




\section{LIST OF TABLES}

Table 1.1: Comparisons of Models from the Literature.............................................8

Table 5.1: Comparisons of Theoretical Aspects of Models.....................................75

Table 5.2: $\quad$ Collector Characteristic Parameters..........................................................79

Table 7.1: HARBERMAN House Specifications..................................................95

Table 7.2: $\quad$ Simulation Rsults Predicted Using Program Developed............................98

Table A.1: $\quad$ Wall Conduction Time Series - PART I................................................111

Table A.2: $\quad$ Wall Conduction Time Series - PART II.............................................112

Table A.3: $\quad$ Roof Conduction Time Series - PART III............................................113

Table A.4: $\quad$ Radiant Time Series (Solar) - PART I..............................................114

Table A.5: $\quad$ Radiant Time Series (Non-Solar) - PART II.......................................115

Table A.6: $\quad$ Recommended Radiative and Convective Fractions...............................116 


\section{NOMENCLATURE}

\begin{tabular}{|c|c|}
\hline$A$ & apparent solar radiation at air mass equal to zero, $\mathrm{W} / \mathrm{m}^{2}$ or $\mathrm{Btu} /\left(\mathrm{hr}-\mathrm{ft}^{2}\right)$ \\
\hline A & superficial area of each tank segment \\
\hline$a_{i}$ & ratio of the overall loss coefficient to the loss coefficient from the cover \\
\hline$B$ & atmospheric extinction coefficient \\
\hline$\alpha$ & tilt angle \\
\hline$\beta$ & solar altitude \\
\hline$\gamma$ & wall azimuth measured east or west from south \\
\hline$\rho_{g}$ & ground reflectance \\
\hline$\Sigma$ & tilt angle of the surface from horizontal \\
\hline$\theta$ & time \\
\hline$C_{N}$ & the percentage as given in the Figure 4-3 below. This value will be the input \\
\hline & to the program at any desired locations for the simulations. \\
\hline$C$ & ratio of diffuse irradiation on a horizontal surface to direct normal irradiation \\
\hline $\mathrm{COP}$ & coefficient of performance (dimensionless) \\
\hline$c_{0}, c_{1}$, etc & conduction time factors \\
\hline$F_{i}^{c}, F_{i}^{L}$ & collector control function \\
\hline$F^{\prime}$ & collector efficiency factor $(-)$ \\
\hline$F_{R}$ & collector heat removal factor (-) \\
\hline$G_{T}$ & incident solar energy $\left(\mathrm{W} / \mathrm{m}^{2}\right)$ \\
\hline $\mathrm{HB}$ & heat balance \\
\hline$I_{D N}$ & normal irradiation, $\mathrm{W} / \mathrm{m}^{2}$ or $\mathrm{Btu} /\left(\mathrm{hr}-\mathrm{ft}^{2}\right)$ \\
\hline $\mathrm{L}$ & energy removal from the storage tank to the load \\
\hline LW & long wave \\
\hline $\mathrm{m}$ & mass of water in the storage tank \\
\hline$\dot{m}$ & mass flow rate crossing the segment/node \\
\hline$(m c)_{e}$ & effective heat capacity of the collector per unit area $\left(\mathrm{Jm}^{-2} \mathrm{~K}^{-1}\right)$ \\
\hline $\mathrm{N}$ & node (number of node) \\
\hline$\Delta T$ & temperature variation in the tank \\
\hline$T_{a}$ & ambient temperature \\
\hline$T_{s i}$ & inside face temperature \\
\hline$T_{s i, \theta}$ & inside face temperature at $\theta$ time \\
\hline$T_{s o}$ & outside face temperature \\
\hline$T_{s o, \theta}$ & outside face temperature at $\theta$ time \\
\hline Q & energy addition from the collector and to the load \\
\hline
\end{tabular}




$\begin{array}{ll}Q_{r, \theta} & \text { radiant cooling load }\left(Q_{r}\right) \text { for the current hour }(\theta) \text {, Watts } \\ q_{r, \theta} & \text { radiant heat gain for the current hour, Watts } \\ q_{\theta} & \text { hourly conductive heat gain for the surface, Watts } \\ \text { RTS } & \text { radiant time series } \\ \text { RTSM } & \text { radiant time series method } \\ r_{0}, r_{1}, \text { etc } & \text { radiant time factors (RTF) } \\ \text { SW } & \text { short wave } \\ U_{p-c} & \text { loss coefficient from the plate to the cover } \\ U_{c-a} & \text { loss coefficient from the cover to the ambient air } \\ \mathrm{U} & \text { overall heat transfer coefficient }\end{array}$




\section{Chapter 1 Introduction}

\subsection{Motivation and Objectives}

The demands of power generation and its production through conventional means are increasing at an alarming rate. It is highly desirable to forecast energy needs on both a short and a long term basis to define sound energy generation strategies. Unfortunately, forecasts of energy needs have proved to be unreliable. Figure 1.1 shows one such forecast made in the 70's based on the trends observed from the mid 40's to early 70's. The rate was growing exponentially at $7.67 \%$ annually. Based on this projection, many new nuclear power plants were built to handle the energy deficit. In early 70's, however, the trend changed with a slower increase in the rate than anticipated. About 74 power plants were closed or decommissioned progressively between the 80's through mid 90 's. By the year 2000 the energy shortage again resurfaced. The energy shortage, coupled with complex world events and high oil prices, suggest that there will be some serious adjustments in energy production and usage for years to come. There is no simple model that can predict the energy consumption in a relatively reliable manner with all the complicated variables that effect such usage. The use of alternative energy sources, and solar energy in particular, is a potential method to soften the impact of energy deficit correction. 
US Electricity Generation \& Sales

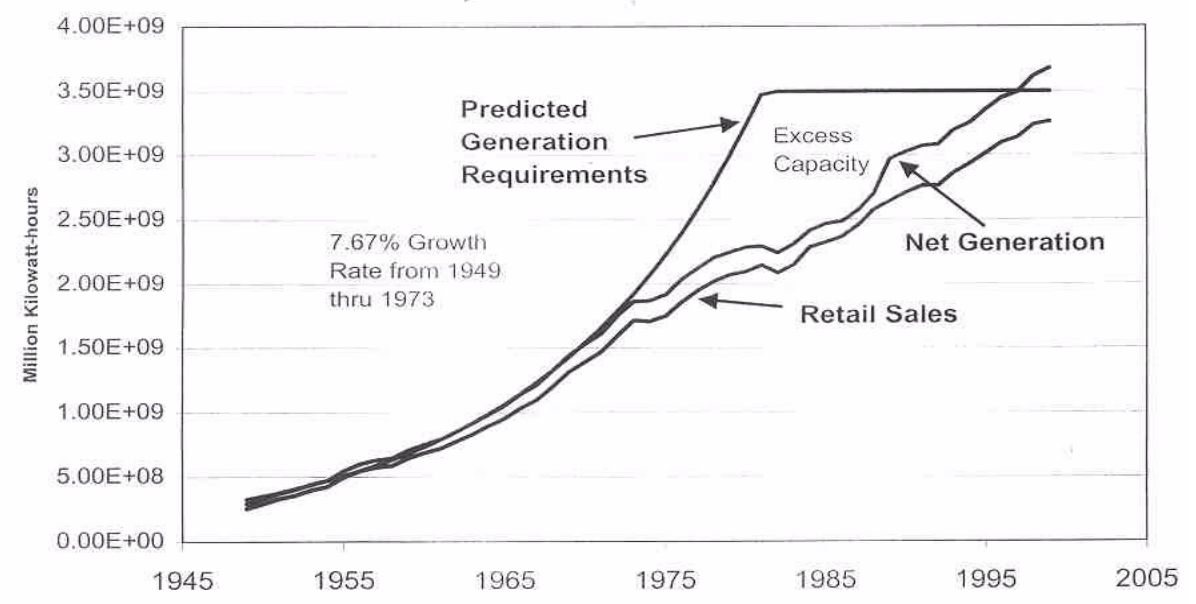

Figure 1.1 History of US Electricity Generation and Sales (Generated using DOE data http://www.doe.gov)

The wide spread use of conventional air-conditioning units is one of the main contributors to the high seasonal demand for energy in the summer season. Self-sufficient substitutes such as solar-based air-conditioning systems in sun-plentiful regions, where the need is the greatest, may help close the gap in the energy deficit. Integrated solar-absorption cooling systems are possible solution to powering the air-conditioning process for domestic use. Solar energy can be collected and stored for specific zones, whether a single home or an assembly of buildings, and also be used to power the absorption chiller system. The use of solar energy-assisted cooling system for HVAC, is one way to minimize the seasonal demand for energy during the summer season. 
Solar energy-assisted HVAC equipment can be installed in most homes for both cooling and heating purposes with minimum demands on conventional power sources. These installations will represent convenient satellite self-powered units. The integrated absorption system will be an ideal application, particularly if and when the technology is widely available and cost effective. Currently, absorption chillers are used in power plants built by manufacturers such as Trane, Carrier, and York, at unit loads starting from 500 tons. Yazaki, another manufacturer, has built lower capacity units of less than 10 tons cooling, which is more desirable for the typical household. These units all use conventional power to drive the cooling cycles. The use of solar energy as a prime mover has not been introduced until recently.

Solar collectors are devices designed to collect energy from the sun. The most common are flat-plate collectors. The energy collected is enough to run a small absorption system with approximately a 3-ton cooling capacity where the hot water collection range is limited to approximately $80{ }^{\circ} \mathrm{C}$. When the desired hot source temperature requirement is greater than $100{ }^{\circ} \mathrm{C}$, concentric collectors are recommended. Commercial or power plant applications at cooling capacities approximately 1000-tons or more are best suited with this type of application.

An absorption chiller system commonly has single, double, and triple effects depending on application needs. The higher the effects, the more cooling capacity can be provided. 
Single effect absorption chillers are usually sufficient for small applications in a typical home. The basic components for the absorption chiller are the generator (also called desorber), condenser, evaporator, absorber, multiple heat exchangers, and pumps. The operation of absorption chiller systems and the components listed will be described in subsequent chapters.

The storage tank is another important component of an absorption chiller system. This tank enables climate control operation to be continuous during periods when solar energy is not available (evenings) or when it is not sufficient to drive the cycle. The size of the storage tank will depend on the safety factor adopted to extend the operation into these periods.

The research and software presented herein is intended for advanced users for the purpose of designing, optimizing and controlling an HVAC system using the absorption cooling principle with solar energy as a prime mover. The program is capable of simulating the cooling load on any periodic basis, using the RTS method, the most current and widely used for modeling cooling load performances. For residential configurations, the user can choose or build a zone by specifying parameters such as the location, direction and dimensions of surfaces, walls and/or roof structure, window specifications, internal load profiles, etc. The cooling loads will then be used to compute the cooling capacity that needs to be matched by an appropriate absorption unit. It is hoped that the research and software 
developed will be able to optimize absorption cooling systems, which can be applied to widespread usage in HVAC application.

\subsection{Background}

Space climate control and air-conditioning has become a major power drain in the overall energy balance of developed nations. The desire to perform the same objectives in a costeffective manner offers a beneficial and practical area of research. Reasonable cost means that new technologies can be developed at the same cost per unit capital as the existing conventional systems but also at reduced operational cost. Improvements in the new technologies are summarized as follows:

1. Comparable initial investment to conventional systems.

2. Low operating cost.

3. Pollution free and environmentally friendly.

4. Capable of operating with renewable energy sources.

5. Higher life expectancy.

Cost is a very important issue. New technologies will be unattractive unless the initial investment and operational costs are comparable to the existing technologies. Moreover, the market conditions should be competitive and free from government subsidies. Solar 
energy utilization for electricity generation in California, for example, has been achieved with huge subsidies from the government. Subsidies do not simulate true market conditions and they are not reflective of initial investments and operational costs. Most power generation companies tend to focus on fossil fuel because this type of electricity generation can still produce power at equilibrium market costs and conditions.

Absorption cooling technology with solar energy as its main driver is a viable option that enables the iniial investment and operational costs to be comparable with current technologies. It can be installed together with appropriately-sized solar collectors and storage tanks to form a complete self-sufficient device that provides cooling in a specific zone. The use of electricity is very small compared to conventional cooling devices since the energy used to run the absorption chillers is taken from the hot water received through the collector. Hot water can also be held in a storage tank for later use when solar energy is not available. This type of application will be attractive and the cost of production, installation and operating will be reasonable when they are produced on a larger scale. Today, most research is focused on the feasibility of such systems for commercial purposes. 


\subsection{Literature Review}

Most studies in solar absorption technologies have been limited to solar heating applications. The absorption cycle, however, has been known and used since the early 1900s for cooling purposes such as food refrigeration and building cooling. These absorption chillers are for larger applications and require large amounts of steam usage for energy input into the system.

Absorption cooling may be an alternative to a continuous systems such an absorption chillers. Most work to date on absorption cycles has been directed at food preservation rather than comfort cooling. However, these cycles may be of interest in the comfort cooling area as they offer potential solutions to the energy storage problem (Duffie and Beckman, 1991). The authors listed in Table 1.1 have performed studies related to the absorption system and concluded that the units are feasible for comfort cooling. The interest of this research has been focused on extending the absorption cooling research to yield the integrated solar absorption cooling model in selected buildings for a self-sufficient unit. 
Table 1.1: Comparisons of a few models from the literature

\begin{tabular}{|c|c|c|}
\hline Author & Date & Topic \\
\hline $\begin{array}{l}\text { G.C. Vliet } \\
\text { M.B. Lawson } \\
\text { R.A. Lithgow }\end{array}$ & $\begin{array}{l}1982 \\
\text { (ASHRAE } \\
\text { Transactions) }\end{array}$ & $\begin{array}{l}\text { Water-Lithium Bromide Double-Effect Absorp- } \\
\text { tion Cooling Cycle Analysis }\end{array}$ \\
\hline $\begin{array}{l}\text { K. Gommed } \\
\text { G. Grossman }\end{array}$ & $\begin{array}{l}1990 \\
\text { (ASHRAE } \\
\text { Transactions) }\end{array}$ & $\begin{array}{l}\text { Performance Analysis of Staged Absorption } \\
\text { Heat Pumps: Water-Lithium Bromide Systems }\end{array}$ \\
\hline $\begin{array}{l}\text { N.E. Wijeysun- } \\
\text { dera }\end{array}$ & $\begin{array}{l}1997 \text { (Solar } \\
\text { Energy } \\
\text { Journal) }\end{array}$ & $\begin{array}{l}\text { Thermodynamic Performance of Solar-Powered } \\
\text { Ideal Absorption Cycles }\end{array}$ \\
\hline E. A. Groll & $\begin{array}{l}1997 \\
\text { (ASHRAE } \\
\text { Transaction) }\end{array}$ & $\begin{array}{l}\text { Current Status of Absorption/Compression Cycle } \\
\text { Technology }\end{array}$ \\
\hline $\begin{array}{l}\text { M Hammad } \\
\text { Y. Zurigat }\end{array}$ & $\begin{array}{l}1998 \text { (Solar } \\
\text { Energy } \\
\text { Journal) }\end{array}$ & $\begin{array}{l}\text { Performance of a Second Generation Solar } \\
\text { Cooling Unit }\end{array}$ \\
\hline C. M. Lee & $\begin{array}{l}2001 \text { (Master } \\
\text { Thesis) }\end{array}$ & $\begin{array}{l}\text { Investigation of } \mathrm{LiBr} / \text { water based double effect } \\
\text { absorption cooling cycle with a computer algo- } \\
\text { rithm. }\end{array}$ \\
\hline G. Grossman & $\begin{array}{l}2001 \text { (Solar } \\
\text { Energy } \\
\text { Journal) }\end{array}$ & $\begin{array}{l}\text { Solar-Powered Systems for Cooling, Dehumidi- } \\
\text { fication, and Air-Conditioning }\end{array}$ \\
\hline
\end{tabular}

Vliet et al. (1982) developed a dynamic computer code to investigate and further improve double-effect absorption cooling machines. The computer model includes mass species, energy balances, fluid flow, heat transfer, and mass transfer correlations for each of the components. The equilibrium vapor pressure/temperature algorithms used were from the 1977 ASHRAE Fundamentals Handbook. The model predicted a coefficient of perfor- 
mance of approximately 1.12 compared to a quoted value of 1.01 , and a capacity approximately 30 percent higher than the quoted value. The current research focused on remodeling the absorption cycles with the most updated correlations used in the 2001 ASHRAE Fundamentals Handbook to extend to integrated solar systems.

Wijeysundera (1997) discussed the use of ideal absorption cycles with external heat transfer irreversibilities to obtain the performance limits of solar-operated absorption systems. The author formulated the conductances and temperature ranges used for the ideal cycles and the results were found to be in good agreement with those given by Gommed and Grossman (1990). Furthermore, Groll (1997) performed a detailed overview of the research activities during the last 15 years on the absorption/compression cycles. The author concluded that the work presented so far indicates that absorption cycles achieve much better performance than conventional vapor-compression cycles and the absorption technology will continue in the near future for real life applications. Therefore, the current research additionally focussed towards integrating the absorption chiller with building models by taking into account the actual configuration of the building.

Hammad and Zurigat (1998) conducted experimental research on the performance of the Lithium Bromide-Water absorption cycle in Jordan. The authors obtained higher COP values than those found in the literature from the experimental setup for an actual 1.5 ton 
absorption chiller. The results indicated that this absorption chiller may be used to set the standard for future commercial units.

Lee (2001) performed an absorption system simulation of the double-effect absorption cycle and compared it to experimental data. The author performed parametric studies to further improve the absorption system capabilities since the capability of the unit had not yet been fully utilized. Grossman (2001) described the current trends in the absorption technology using single, double, and triple effect cycles. The author discussed the cost associated with the absorption unit and concluded that the absorption cycle technology has been identified as the basis of a promising cooling systems and is capable of efficiently exploiting low-temperature solar heat.

There are a number of approaches used to model the cooling load prediction of buildings. The most prominent are the Heat Balance (HB), the Radiant Time Series (RTS), the CLTD, and the TETD methods (2001 ASHRAE Fundamentals). The building cooling load model has been developed under the American Society of Heating, Refrigerating, and Air-Conditioning Engineers (ASHRAE) research activities for more than 10 years. The most recent method to predict the cooling load, the Radiant Time Series (RTS) Method, was introduced recently in the 2001 ASHRAE Fundamentals Handbook. The building model is presented in this dissertation as the dynamic working component for the absorption technology application with the solar load model. 
From the literature review it becomes apparent that a flexible simulation code will be a powerful research design tool. As of now, solar absorption cooling has not been widely exposed to the public as the knowledge is limited to researchers. A few test models are conducted to demonstrate that the solar absorption cooling could be widely used in the near future to reduce energy and electric consumption.

This dissertation integrates and utilizes all the literature summarized above in addition to the author's research work to correctly model a complete building absorption cooling system as cost a effective alternative means to conventional vapor compression systems.

\subsection{Research Summary}

The goal of this research is to develop an independent or self contained application to conduct computer simulations of an integrated solar energy and absorption cooling model for HVAC applicaions in buildings. The approach taken to obtain this goal is to integrate all the major components for HVAC applications such as solar collectors, storage tanks, and an absorption system using solar energy approach. The dissertation will first discuss the flow of the integrated model as shown in Figures 1.2 and 1.3. 


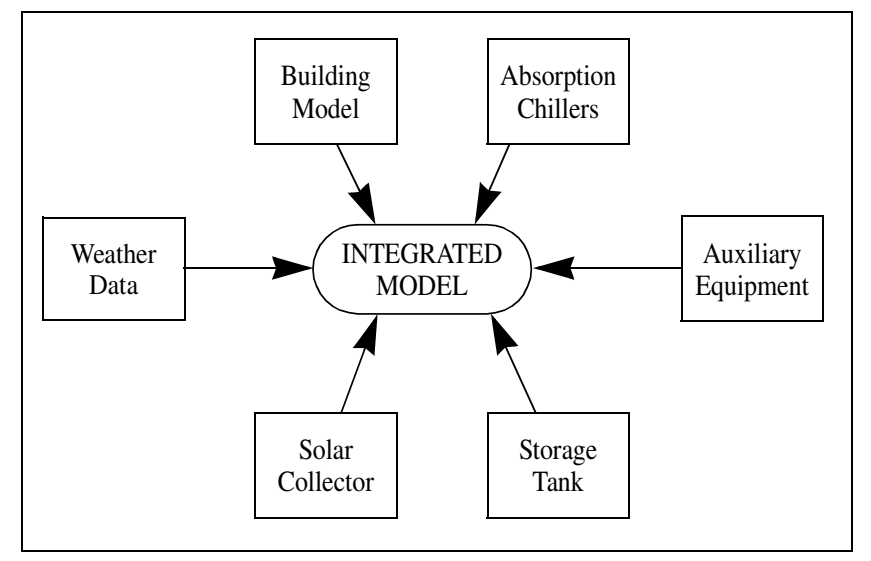

Figure 1.2 Proposed Integrated Design Model

Separate chapters will then discuss the building cooling system, absorption cooling system, storage tank, solar collector, and solar load models. A validation of each model is presented using published experimental data and simulation results. The dissertation will then conclude with the integrated solar absorption cooling model, which is presented as a whole by incorporating each model into a single unit, in Chapter 7.

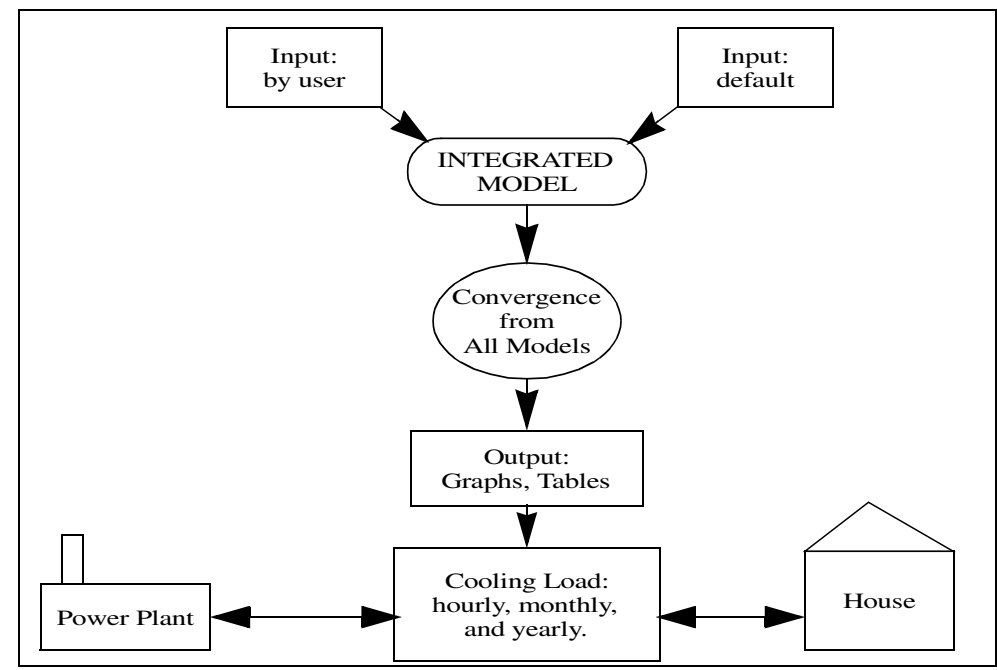

Figure 1.3 Cycle Simulation Flow Chart 


\section{Chapter 2 Building Cooling Model}

\subsection{Introduction}

A zone is a designed environment that provides heating, cooling, and appropriate ventilation to maintain a comfortable environment for the occupants. Zones also include the transient heat exchange from the accessories inside, such as furniture, equipment, and occupants. This building cooling model represents a zone, or assembly of zones, designed to accommodate occupants at a comfortable level. The zone comprises a certain number and/or type of surfaces including windows, walls, roof, skylight, ventilation, etc., which are modeled consistent with the standard construction policies and materials used today. This chapter discusses the development of the building cooling model using the Radiant Time Series (RTS) method for predicting the required cooling load.

\subsection{Cooling Load Methodology}

The Heat Balance (HB) Method is the fundamental method of heat exchange modeling for zones in building cooling models. This is sometimes called the "exact solution" for the estimation of a cooling load. "Exact solution" is the foundation of all other methods such as the Total Equivalent Temperature Difference/Time Averaging (TETD/TA) Method 
(ASHRAE, 1967), U.K.'s Admittance Method (Loudon, 1968), Transfer Function Method

(TFM) (ASHRAE, 1972), and Cooling Load Temperature Difference/Solar Cooling Load/

Cooling Load Factor (CLTD/SCL/CLF) Method (ASHRAE, 1977).

The Radiant Time Series (RTS) method is a new approach to calculate the cooling load in buildings. The RTS method is simpler than the HB method because it eliminates the complication that arise in the HB method.

Extensive research on this cooling load approach has been conducted for approximately 10 years and the RTS method was documented in ASHRAE Fundamentals 2001. Improvements and validations are being made in the cooling load analysis on a continuous basis.

\subsection{Cooling Load and Heat Gain Overview}

Cooling load is the rate at which energy must be removed from a space to maintain the temperature and humidity at the design values. The concept of cooling load is the same as that of a normal refrigerator where a certain space at a controlled temperature is maintained. In order to maintain a steady low temperature for refrigeration, heat transferred or generated in a space needs to be removed at the same rate as the transfer or generation. For a building cooling load, variables are such as solar factors, building structure materials, 
humidity, heat load from occupants, lighting, transient energy storage, and energy release by objects with non-negligible heat capacities must be considered. The appropriately designed model must be able to handle all these variables under any weather and heat load conditions at any time of the year. The early stage design estimates must be accurate to within a minimum margin of error as any errors in the early stages will propagate and could possibly be magnified throughout later stages.

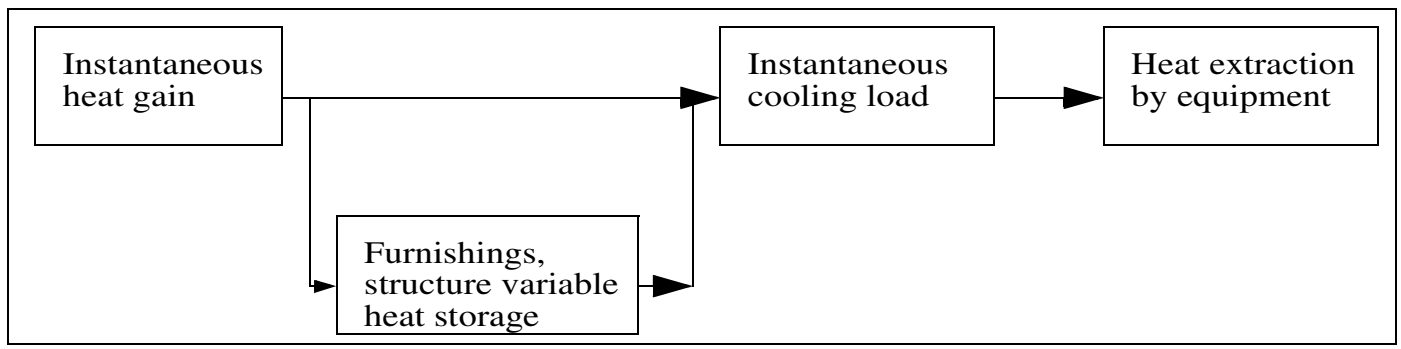

Figure 2.1 Cooling load and heat gain relationship (McQuiston et al., 2000) Note: "The heat produced, or the heat gained, in a specific zone will magnify the cooling load after a certain delay (transient-radiative component) or directly (convective component)."

Heat gain is the rate at which energy is transferred to, or generated within, a space.

The relationship between heat gain and cooling load is shown in Figure 2.1. An acceptable model should not be a simple, steady-state analysis, but should take transient effects into account. This is as the heat is being absorbed, stored, and released simultaneously into the room at various rates depending on the type of structure. The common heat gain sources are as follows (McQuiston et al., 2000):

1. Solar radiation through fenestrations, 
2. Inner surface convection and radiation resulting from heat conduction from outdoors,

3. Sensible heat (convection and radiation) from internal objects,

4. Latent heat (within the space),

5. Infiltration and ventilation.

The Heat Balance (HB) method (Pederson et al., 1997) is a transient method, which models the heat balance of the surface-by-surface conduction, convection, and radiation for each interior and exterior room surface. It also models the heat balance of the room or zone air.

The heat balance analysis must take into account all structures, internal loads (including people) and external variations such as sun, wind, and outside temperature. This heat balance model can often be very tedious due to the number of iterative steps required to ensure convergence.

The Radiant Time Series (RTS) Method (Spitler et al., 1997) is also a transient method, that, simplifies and replaces all other methods without having to solve the full heat balance equations. Furthermore, the RTS method uses two sets of predetermined coefficients, the periodic response factors (PRF) and the radiant time factors (RTF), which will be discussed in later sections. 
The Radiant Time Series method, which is derived from the iterative heat balance method, is devised to accomplish the same objectives (without iteration) with results comparable to the heat balance calculations. The RTS method is therefore simpler and suitable for implementation with a spreadsheet. The RTS method is highly recommended in the ASHRAE community to replace earlier methods. The structure of the RTS methodology is best explained on the basis of the HB method, which is described next.

\subsection{Heat Balance (HB) Method}

\subsubsection{Heat Balance (HB) - Overview}

Heat Balance is a method that takes into account many of the variables that effect and determine the cooling load. All the methods that were discussed earlier are based on the heat balance formulation with some minor manipulations to the very detailed processes involved in the original formulation. These modifications were made in order to meet certain objectives in predicting the cooling load. Documentation and/or detailed explanation of the HB method was only recently published by Pederson et al. (1997).

The Heat Balance method takes into account the heat balance on the outside and the inside faces of the structure, with heat conduction between the faces, yielding an internal air heat 
balance. The assumptions involved in deriving the HB method include uniform surface temperatures, uniform long wave (LW) and short wave (SW) irradiation, diffuse radiating surfaces, and one-dimensional heat conduction. The calculations for the outside surface heat balance, wall conduction, and inside surface heat balance are repeated for each of the surfaces enclosing the zone. The details of the processes involved in the heat balance formulation can be viewed in Figure 2.2.

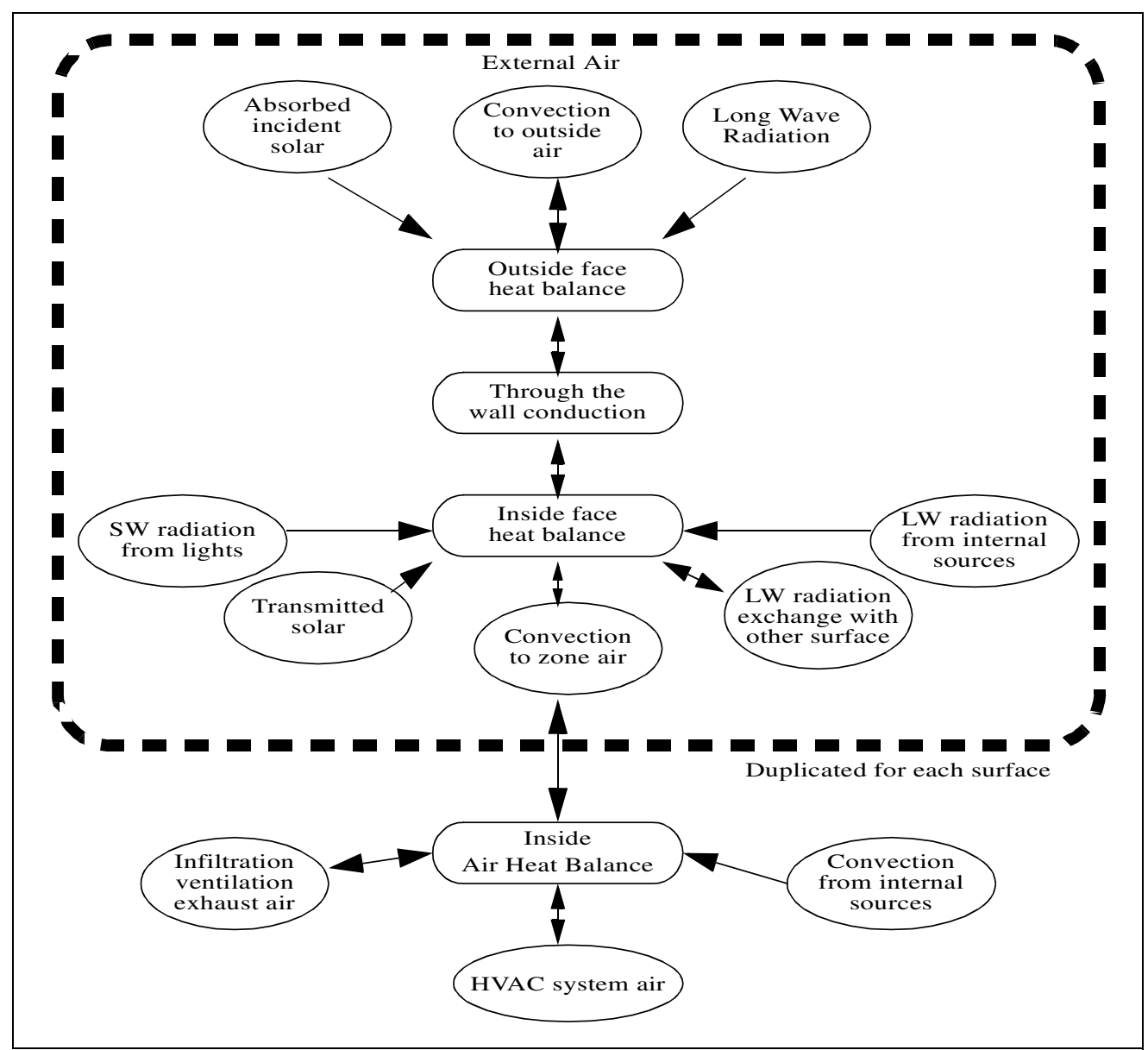

Figure 2.2 Overview of Heat Balance Zone and Heat Balance Processes (2001 ASHRAE Fundamentals handbook (SI)) 


\subsubsection{Heat Balance (HB) - Formulation}

The mathematical formulation is described in the ASHRAE toolkit. The conduction heat transfer is modeled as a one-dimensional, transient process with constant material properties for the cooling load and energy calculations (McQuiston et al. 2000). The simplified heat diffusion equation in Cartesian coordinate is shown below (Incropera et al., 1996).

$$
\frac{\partial^{2} T(x, t)}{\partial x^{2}}=\frac{1}{\alpha} \cdot \frac{\partial T(x, t)}{\partial \theta}
$$

As can be seen from the heat diffusion equation the conduction transfer functions (CTFs); $\mathrm{T}(\mathrm{x}, \mathrm{t})$, controls the response of the equation. CTFs are dependent only on material properties and reflect the transient response of a given construction for any set of environmental boundary conditions. Since material properties are typically assumed to be constant (in HVAC thermal load calculations), it is possible to pre-calculate these coefficients.

The conduction time factors reflect the percentage of an earlier heat gain at the exterior of a wall or roof that becomes heat gain on the inside during the current hour. For most common design applications, contributions depend primarily on the overall massiveness of the construction and the thermal responsiveness of the surfaces that the radiant heat gain strikes. The details of conduction time factor formulations are shown in Appendix A.7.

The behavior of the transfer function is largely influenced by the heat flux. The statement of Fourier's law shown below specifies the conduction heat flux in terms of the thermal conductivity of the material and the temperature gradient across a differential thickness. 


$$
q^{\prime \prime}=-k \cdot \frac{\partial T(x, t)}{\partial x}
$$

Equation (2-2), which is usually solved numerically, results in a simple linear equation that expresses the current heat flux in terms of the current temperature, and the temperature and heat flux histories.

For a one-dimensional case, the transient conduction problem can be solved analytically. However, complications arise when dealing with multi-layered construction. Thus, numerical methods, such as the Finite Difference Method (FDM) or Finite Element Method (FEM), the Frequency Response method, the Z-transform method, and the Lumped Parameter method are used to solve the problem.

The linear form of Equations (2-3) and (2-4) greatly reduces the required computational effort compared to other numerical techniques. The CTF formulation of the surface heat fluxes involves four sets of coefficients, $\mathrm{X}, \mathrm{Y}, \mathrm{Z}$, and $\Phi_{j}$. These two equations present the general form for the heat fluxes inside and outside, respectively, for the time dependent conduction problem through multi-layer walls (ASHRAE 2001).

$$
\begin{gathered}
q_{k i}^{\prime \prime}(t)=-Z_{o} T_{s i, \theta}-\sum_{j=1}^{n z} Z_{j} T_{s i, \theta-j \delta}+Y_{o} T_{s o, \theta}+\sum_{j=1}^{n z} Y_{j} T_{s o, \theta-j \delta}+\sum_{j=1}^{n q} \Phi_{j} q_{k i, \theta-j \delta}^{\prime \prime} \text { (2-3) } \\
q_{k o}^{\prime \prime}(t)=-Y_{o} T_{s i, \theta}-\sum_{j=1}^{n z} Y_{j} T_{s i, \theta-j \delta}+X_{o} T_{s o, \theta}+\sum_{j=1}^{n z} X_{j} T_{s o, \theta-j \delta}+\sum_{j=1}^{n q} \Phi_{j} q_{k o, \theta-j \delta}^{\prime \prime}(2-4)
\end{gathered}
$$

In these equations, the index " $\mathrm{j}$ ” on the right hand side is used to indicate the hour.

$$
X_{j} \quad=\text { outside conduction transfer function }(\mathrm{CTF}), \mathrm{j}=0,1, \ldots \mathrm{nz}
$$


$Y_{j} \quad=$ cross conduction transfer function $(\mathrm{CTF}), \mathrm{j}=0,1, \ldots \mathrm{nz}$

$Z_{j} \quad=$ inside conduction transfer function $(\mathrm{CTF}), \mathrm{j}=0,1, \ldots \mathrm{nz}$

$\Phi_{j} \quad$ = flux conduction transfer function (CTF),j= $1,2, \ldots \mathrm{nq}$

$\theta \quad=$ time

$\delta \quad=$ time step

$T_{s i} \quad=$ inside face temperature, ${ }^{\circ} \mathrm{C}$

$T_{\text {so }} \quad=$ outside face temperature, ${ }^{\circ} \mathrm{C}$

$q^{\prime \prime}{ }_{k i} \quad=$ conductive heat flux on inside face, $\mathrm{W} / \mathrm{m}^{2}$

$q^{\prime \prime}{ }_{k o} \quad=$ conductive heat flux on outside face, $\mathrm{W} / \mathrm{m}^{2}$

$\mathrm{nz}, \mathrm{nq}=$ number of terms needed to reach desired accuracy in the solution (highly dependent on the wall structure).

The complication, however, in applying Equations (2-3) and (2-4), is that the past values of the surface temperatures and heat fluxes are not known. Therefore, it is necessary to assume values for the initial calculation and then iterate the calculation in 24-hour intervals until a steady periodic solution is reached. The steady periodic solution is reached by the convergence on both the inside and outside heat fluxes.

The primary variables in the linearized heat balance equations for a general zone are the 12 inside face temperatures, $T_{s i}$, and the 12 outside face temperatures, $T_{s o}$, (index - i) at each of the 24-hour periods (index - j). The cooling loads, $\mathrm{q}_{\mathrm{sys}}$, are calculated for 
$\mathrm{j}=1,2, \ldots 24$. Both Equations (2-3) and (2-4) are combined and solved for $T_{\text {so }}$ to produce 12 equations applicable at each time step. $T_{s i}$ is then solved in the same manner using the next 12 equations. The two equations need to be solved simultaneously. Depending on the order of updating (iterating), the HB method can become more time-consuming and also has inherent instability problems.

Although these equations represent solutions to the transient one-dimensional conduction problem, it is useful to consider the steady state limit of these equations. Under steadystate conditions, the exterior and interior heat fluxes are equal and the following identities can be obtained;

$$
\sum_{n=0}^{n z} X_{n}=\sum_{n=0}^{n y} Y_{n}=\sum_{n=0}^{n z} Z_{n}
$$

In combination with the standard formulation for the steady-state heat transfer through a wall, $q^{\prime \prime}=U \Delta T$, an expression for $\mathrm{U}$, the overall heat transfer coefficient, in terms of conduction transfer functions, can be derived as shown below:

$$
U=\frac{\sum_{n=0}^{n y} Y_{n}}{1-\sum_{n=1}^{n \Phi} \Phi_{n}}
$$

CTFs for typical constructions are available in the ASHRAE Fundamentals Handbook (1997). However, the ASHRAE Loads Toolkit (Pedersen, 2001) have made it possible to quickly and accurately construct a stand alone computer program that will calculate CTFs for any arbitrary wall configuration. This dissertation does not focus on producing these 
coefficients, instead all the values were tabulated for the typical construction in evaluating a specific application. A separate program is also available for configurations other than those included in the software presented. This program has been developed by Spitler and Fischer (2000) and is available through the internet.

\subsection{Radiant Time Series (RTS) Method}

\subsubsection{RTS -Overview}

The Radiant Time Series (RTS) method produces solutions with the same overall efficiency as the Heat Balance method, and does not require any iteration. This method is suitable for peak design load calculations but is not recommended for annual energy simulations due to its inherent limiting assumptions (McQuiston et al., 2000). The usage of the RTS method within the context of the present research should therefore be limited to peak load analysis. To extend the analysis to conduct yearly simulations, which is not the intent of this research, additional assumptions would be required to obtain the results. The procedure used to determine the cooling load under the RTS formulation is shown in Figure 2.3. 


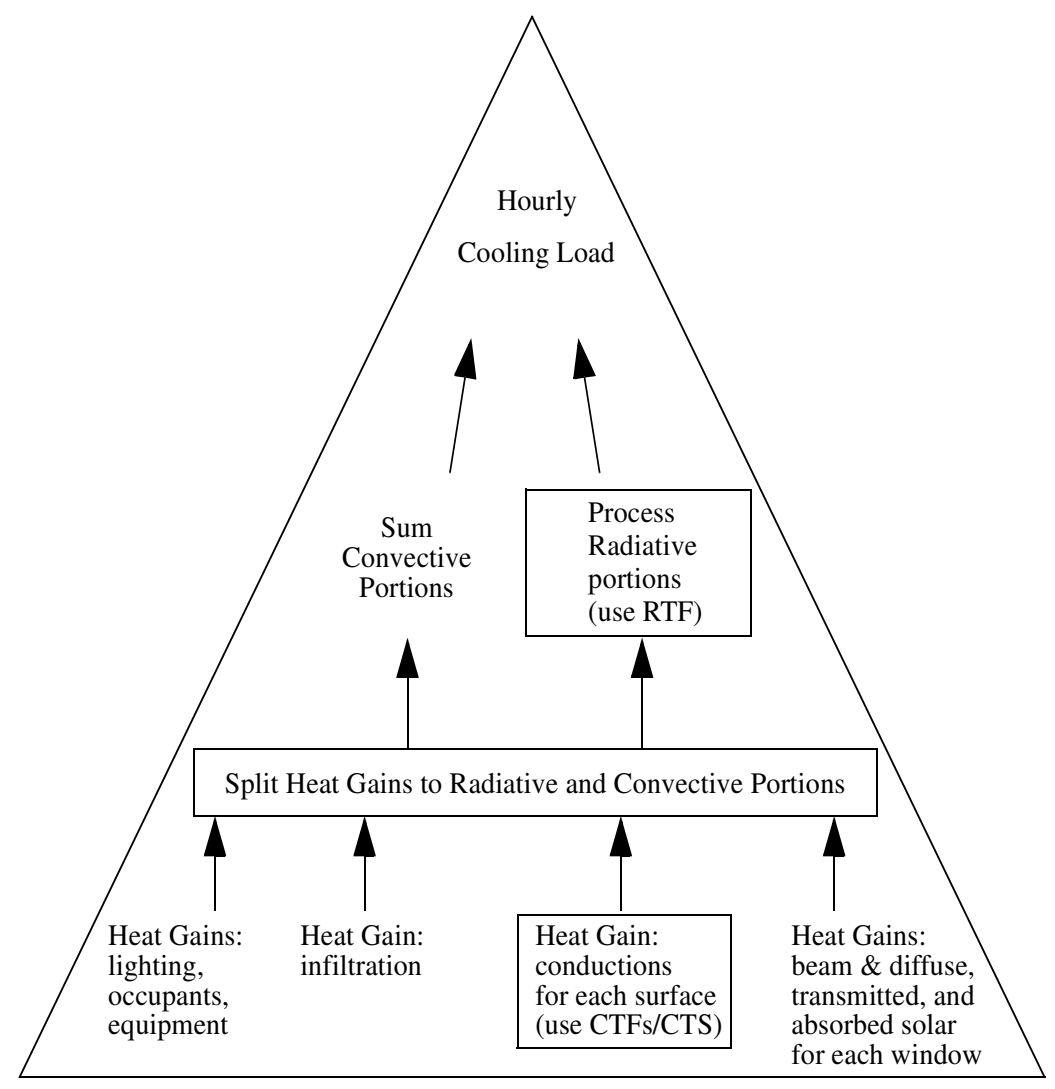

Figure 2.3 Overview of Radiant Time Series (RTS) Method

The major difference in the RTS methodology as compared to the heat balance method is that the wall temperatures and the surface heat fluxes are no longer required. The steps are:

1. Calculate heat gains from each category; calculate conduction heat gain using Conduction Time Factors (CTFs).

2. Split all heat gains to radiative and convective portions.

3. (a) Sum all convective heat gains. (b) Process the radiative portions using Radiant Time Factors (RTF) to reflect time delay from earlier time periods. 
4. Sum the convective and radiative portions for each hour to yield "hourly cooling load".

It needs to be stressed that all the heat gains from each category are divided into two parts: radiative and convective, where the radiative part is processed differently than the convective part.

\subsubsection{Calculating Heat Gains}

Heat gains involve elements like wall, roof, window, lighting, occupants, and equipment. Heat gain contributions to the load in the form of convective (instantaneous) or timedelayed (radiative) must be taken into account differently for each component of the heat gain.

The instantaneous conduction heat transfer through the exterior walls/roofs is defined by

$q_{i, \theta-n}=U A\left(t_{\text {sol air }, \theta-n}-t_{\text {room }}\right)$

The conductive heat gain through the walls/roofs can be calculated using conductive heat inputs for the current hour using time delayed contributions from the previous 23 hours,

$q_{\theta}=c_{0} q_{i, \theta}+c_{1} q_{i, \theta-1}+c_{2} q_{i, \theta-2}+c_{3} q_{i, \theta-3}+\ldots+c_{23} q_{i, \theta-23}$

where

$q_{\theta}=$ hourly conductive heat gain for the surface, Watts

$q_{i, \theta}=$ heat input for the current hour, Watts 
$q_{i, \theta-n}=\quad$ heat input $\mathrm{n}$ hours ago, Watts

$c_{0}, c_{1}$, etc $=$ conduction time series $(\mathrm{CTS})$

In order to effectively use the ASHRAE cooling load procedures, it is necessary to understand and correctly apply conduction transfer functions (CTFs) or periodic response factors (PRFs) to the conductive heat transfer calculation. CTFs are required in the Heat Balance Method, whereas PRFs are used in the RTS method.

The periodic response factors are further simplified by dividing the 24 periodic response factors by the respective overall surface U-factor to form the conduction time series (CTS), $c_{0}, c_{1}$, etc of Equation (2-8). See Appendix A.5.

The assumption of steady, periodic heat input conditions for design load calculations can allow the conduction transfer functions to be formulated into periodic response factors (PRF). The assumption allows Equation (2-8) to be reduced into a simpler more manageable form (Spitler and Fischer, 1999). ASHRAE, however, have made PRF data available through ASHRAE toolkit 2001. The data is required if layers need to be added to the walls, which is not readily available in the Library program. In this project the author has utilized data from the ASHRAE toolkit.

Equation (2-8) can be simplified so it can be expressed in terms of temperature gradients, by combining with Equations (2-7) to yield a new format;

$$
q^{\prime \prime}{ }_{\theta}=\sum_{j=0}^{23} Y_{P j}\left(t_{e, \theta-j \delta}-t_{r c}\right)
$$


Equation (2-9) is based on the steady, periodic nature of the sol-air temperature over a 24hour period (Spitler et al. 1997). Although the number of periodic response factors (PRF), $Y_{P j}$, may vary, the 24 PRFs shown in Equation (2-9) correspond to 24 hourly changes in the sol-air temperature for a single term. It is clear that the overall heat balance transfer coefficient, $\mathrm{U}$, is represented by the sum of the periodic response factors as shown below:

$$
U=\sum_{j=0}^{23} Y_{P j}
$$

The PRF series provides a visual representation of the thermal response of the wall. It does this by scaling the contribution of previous fluxes (in the form of temperature gradients) to the current conduction heat flux.

\subsubsection{Calculating Hourly Cooling Load}

The RTS method uses the Radiant Time Factors (RTFs) to predict the hourly contribution of the radiant heat gains to the cooling load. This heat gain must be eventually converted to cooling loads without any form of heat loss through the building configuration. This method yields a set of time series that represent the time dependent thermal response of an adiabatic zone to a single steady periodic pulse of radiant energy incident on the portion of the radiant pulse convected from the zone surfaces to the zone air at each hour.

The RTFs are different for each unique zone geometry and construction type. For a zone with different construction on each surface a different set of RTFs is required. Figure 2.4 below illustrates RTFs for a light and a heavy weight zone subject to an identical unit radi- 
ant pulse. As long as the input radiant pulse is unity, or the calculated hourly cooling loads are normalized with the input radiant pulse, the resulting 24-hour coefficients are the RTFs. The relatively flat profile shown in Figure 2.4 represents the slow thermal response of the heavy weight zone. The shape of the curve indicates a low heat extraction rate due to the strong thermal storage effect of the heavy weight materials.

Modifications can be made to all these data by specifying alternative configurations with other software such as the PRF/RTF Generator produced by ASHRAE. For that particular run, south wall, east wall, north wall, west wall, roof, and all the respective windows give different cooling loads, which results in the total cooling load for that zone. Each effect can be observed, plotted, and visually be studied. Further studies can be conducted to optimize the cooling load.

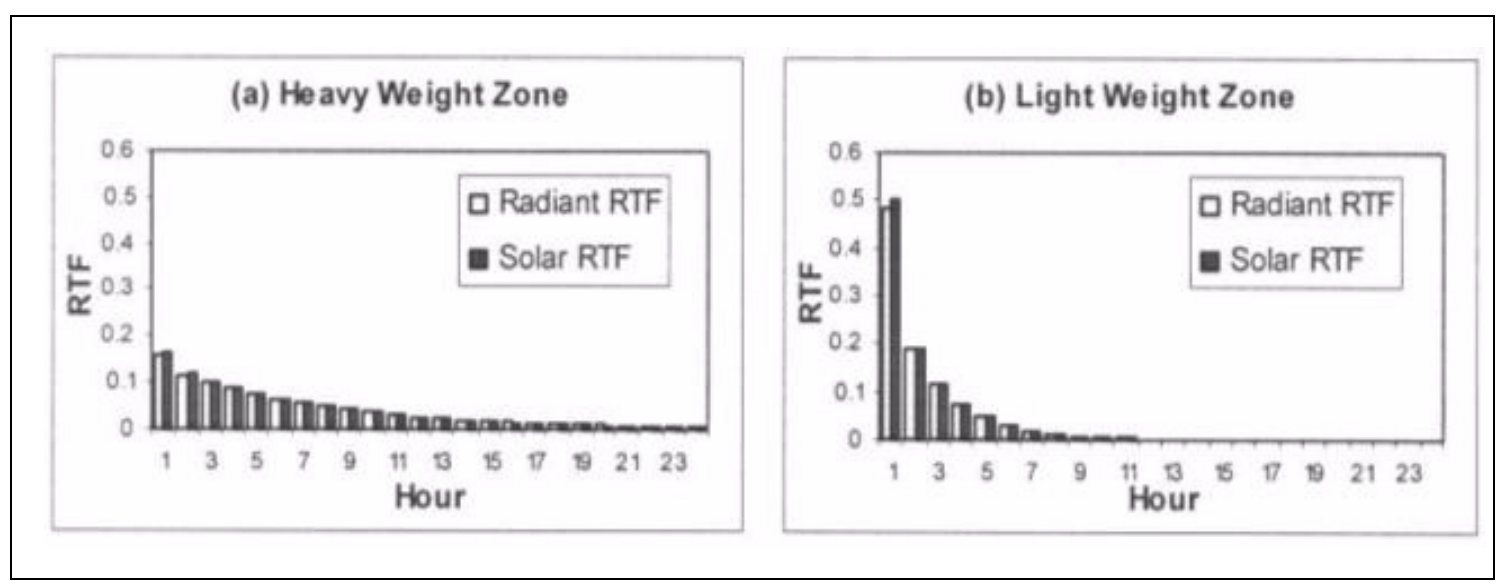

Figure 2.4 RTFs for two typical constructions (a) heavy weight (b) light weight

The radiative component of the heat gains, which is processed with the RTFs, reflects the amount of energy stored in the structure to be released at a later time. In cases whereby 
materials differ from those used in the program development, a procedure is available in Appendix A.7 to allow such studies to be conducted with the program presented.

RTS data are to be tabulated separately in every zone configuration for solar and non-solar components. The construction materials used in the zone description are divided into three major categories: light weight (LW), medium weight (MW), and heavy weight (HW). The typical choice in the United States is LW construction.

The contributions to the cooling load due to the radiative components can be calculated as follows:

$Q_{r, \theta}=r_{0} q_{r, \theta}+r_{1} q_{r, \theta-1}+r_{2} q_{r, \theta-2}+r_{3} q_{r, \theta-3}+\ldots+r_{23} q_{r, \theta-23}$

where

$Q_{r, \theta}=\quad$ radiant cooling load $\left(Q_{r}\right)$ for the current hour $(\theta)$, Watts

$q_{r, \theta}=$ radiant heat gain for the current hour, Watts

$q_{r, \theta-n}=\quad$ radiant heat gain $\mathrm{n}$ hours ago, Watts

$r_{0}, r_{1}, e t c=$ radiant time factors $(\mathrm{RTFs})$

The time series multiplication, in effect, distributes heat gains over time. Radiant time factors reflect the percentage of radiant heat gains from the previous time period, which now becomes the cooling load during the current hour. By definition, each radiant or conduction time series must total 100\% (McQuiston et al., 2000). 


\subsubsection{Validation / Sample Calculations}

Validation of the heavy weight and light weight building construction models was performed using sample cooling load specifications obtained from Iu et al. (2003). Two similar buildings were constructed in Stillwater, Oklahoma, representing the heavy weight and light weight structure, to analyze the impact of structure type on cooling load. The parameters used in the simulation are the temperatures inside and outside the model, the walls structure and material, the location and weather conditions. The cooling load results for 24-hours were plotted to compare the actual case with the simulation that was performed.

Using the RTS, method a simulation was conducted to predict the cooling load profile for these structures. The results are shown in Figure 2.5 alongside the experimental data. The numerical simulation predicted the cooling load based on parameters such as latitude, longitude, and hourly outside temperature, which is acceptable given that the objective of the program is to predict the maximum cooling load on a given day.
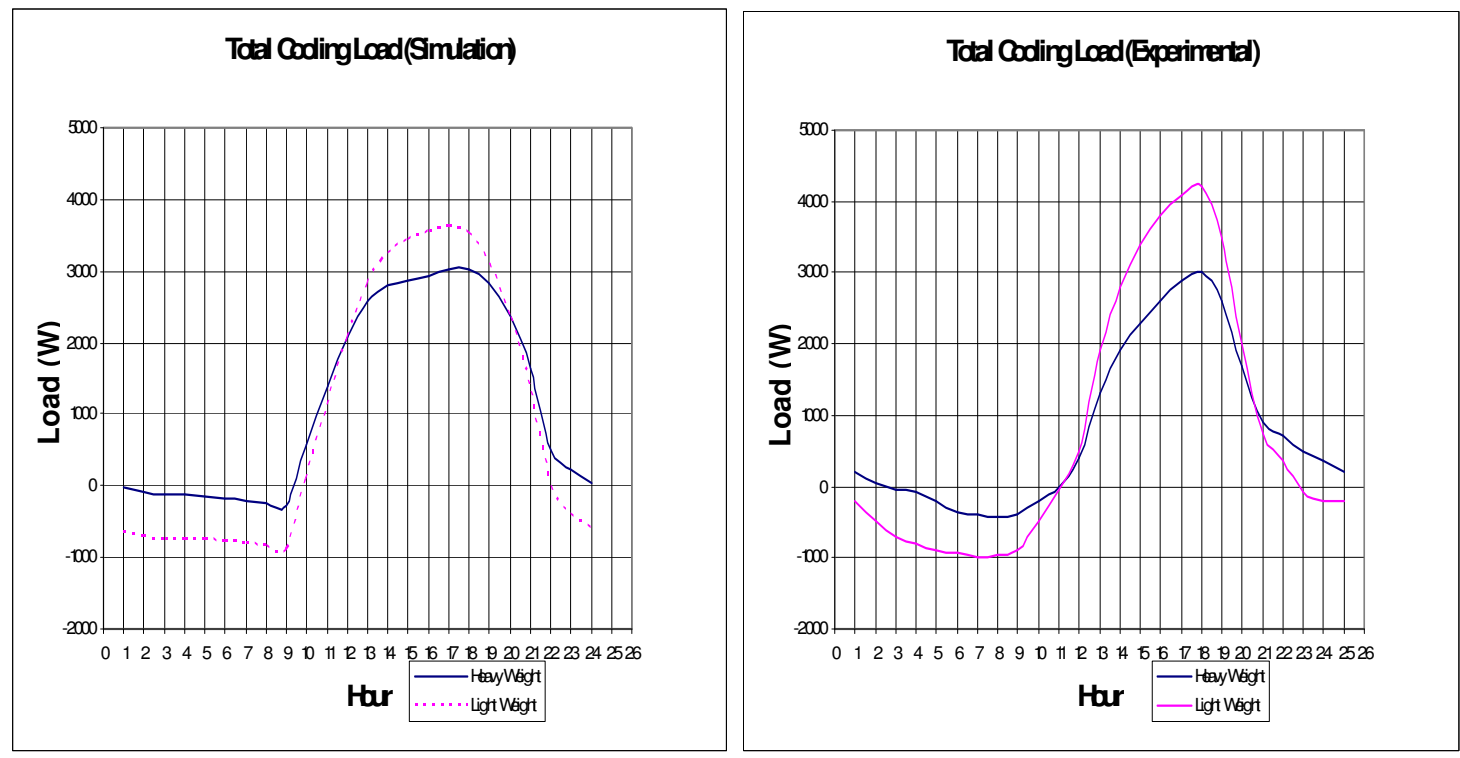

Figure 2.5 Simulation and Experimental Results for Heavy Weight and Light Weight 
Based on these results, the numerical simulations can be used as the basis for designing a cooling device for the purpose of removing heat from a specific loaction in any part of the world. The simulation results agree, with some tolerable error, with the experimental data. Thus, the RTS method can be used to quickly calculate the cooling load given a reasonable input configuration.

Calculation of the total cooling load was performed using the load determined for each component of the structure. A thorough study was required for the given structure to establish the effect of walls, windows on each wall, a roof, and a floor for a specific zone. Since the total cooling load predictions was considered acceptable, it is reasonable to assume that the individual loads through surfaces used in the calculations are also acceptable. Figures 2.6, 2.7, and 2.8 show individual wall and window contributions to the total cooling load depicted in Figure 2.5.

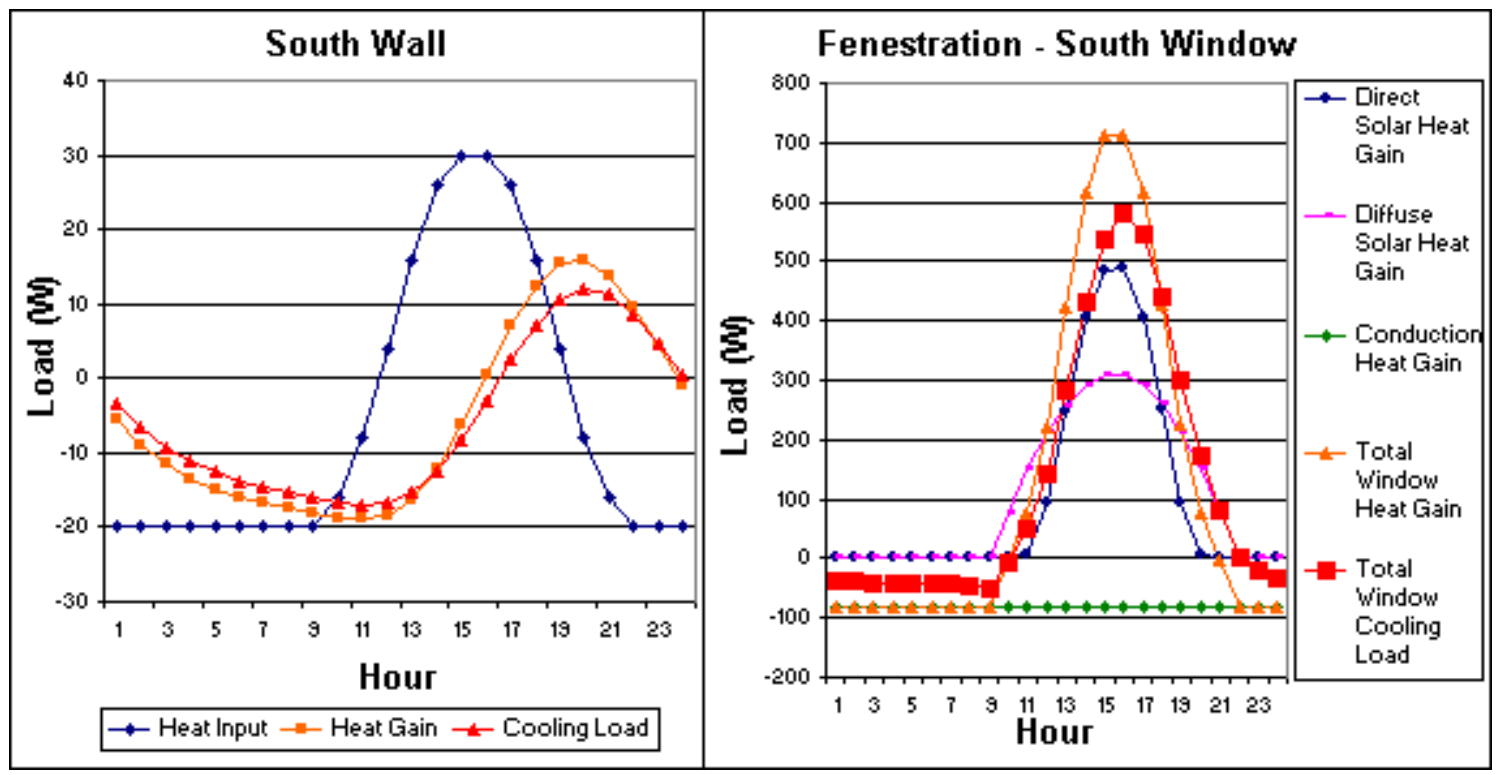

Figure 2.6 Individual cooling load contributions 

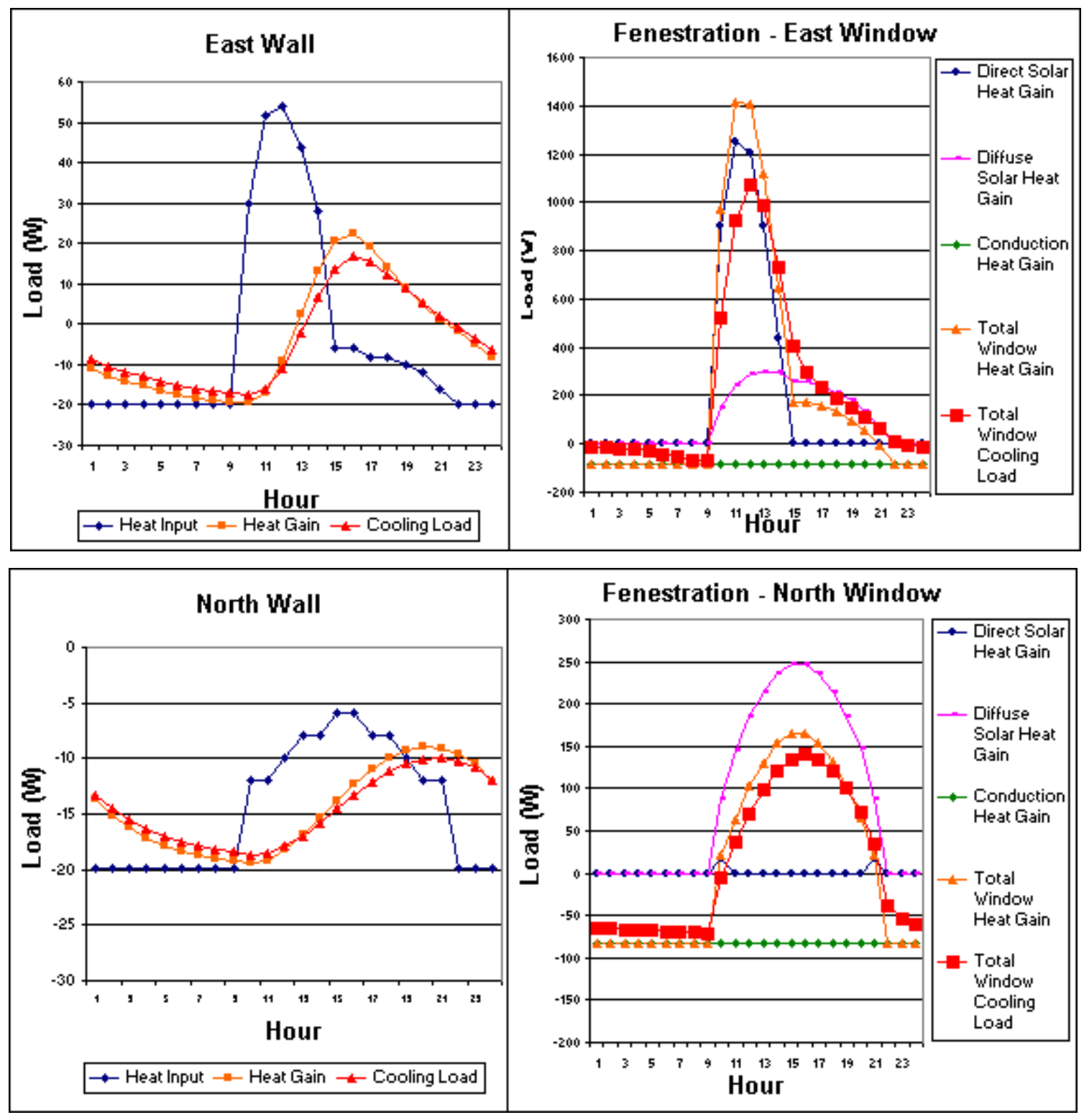

Figure 2.7 Individual cooling load contributions (cont.) 

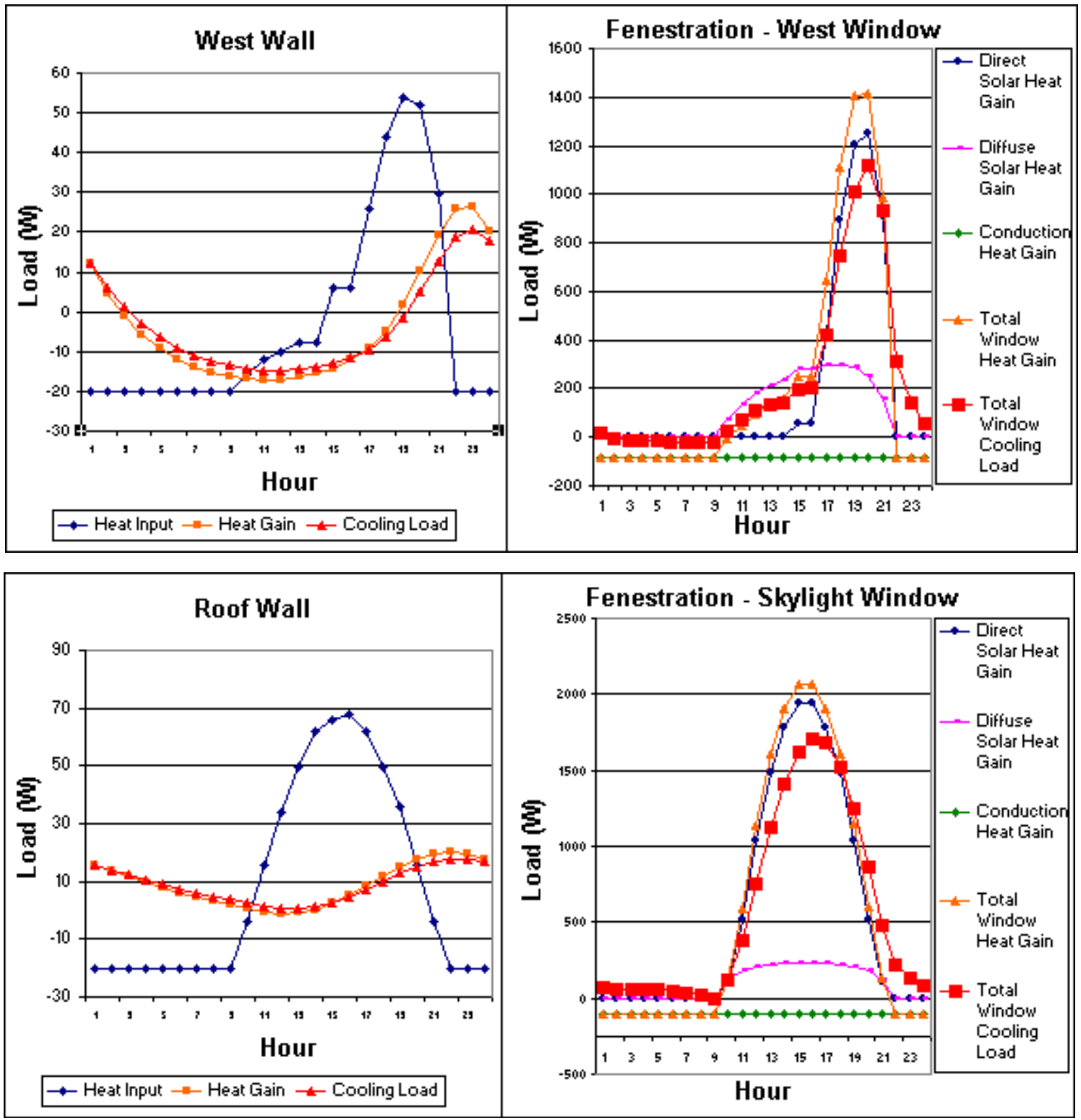

Figure 2.8 Individual cooling load contributions (cont.)

Heat input to the structure was calculated using the information on the overall heat transfer coefficient for that particular design, the surface area, and the difference between the outside air temperature and the inside air temperature. However, as previously discussed, the outside air temperature was not the actual or current ambient temperature since the RTS 
Method uses the sol-air temperature instead. The actual air temperature would yield more favorable results using the heat balance method until convergence is achieved with the inside and outside heat flux. For the RTS method, the sol-air represents the outside air, or ambient temperature, as a sinusoidal temperature profile by taking into account the current outside air temperature, exterior surface absorptivity and emissivity, heat transfer correlation for the outside air, the difference between long-wave radiation incident, and the total surface irradiance. The total surface irradiance is explained in detail in the Solar Load Model discussion (Chapter 6) as the amount of solar energy accumulated on the outside surface.

Heat Gain is calculated based on the RTS approach where the transient analysis is taken into account for a 24-hour lag time. This is because materials absorbed and release energy at different rates, and thus can be categorized as heavy, medium, or light structures. The factor that is being used at each hour duration is called the periodic response factor, which is multiplied by the approximated heat input using the solar load analogy and finally summed for each separate 24-hour factor. The 24-hour factors are called the periodic response factors (PRF) and form a complete series for one composite structure.

The cooling load calculation is now based on the convective and radiative portions that were split. The convective portion is simply the fraction that is being absorbed and released instantaneously. The radiative portion is the complicated part where each one of the hourly heat inputs that is processed with the PRF to yield the heat gain that is again taken to the next step for further approximation once all structure components are formed together to generate a complete zone of interest. The heat gain from each separate wall and roof will contribute a different impact on the total cooling load in the specified zone. 
Another series is used to approximate the amount of heat gain that is distributed from each wall or roof structure to the confined zone comprised of all the structures. This series is called Radiant Time Series (RTS) which has 24 factors which are known as Radiant Time factors (RTF). This series can be generated with a heat balance approach or program, and all the data structure for the typical zone configurations are tabulated in the ASHRAE Fundamentals 2001. The radiative portion of the heat gain is multiplied by the respective RTF and summed for each hour to yield hourly cooling loads. The maximum cooling load is typically the main interest of the designer so that the appropriate sizing for the cooling devices can be conducted.

The building model is one of the components of the overall integrated absorption cooling model that was developed using the RTS method. This model requires other components such as the absorption chiller, which will be discussed in the next chapter. 


\section{Chapter 3 Absorption System Model}

\subsection{Introduction}

Power plant boilers produce steam at a higher temperature, or better known as a higher heat grade to drive a cycle. Electricity generation and gas turbines are applications that utilize higher heat grade. The absorption technology lends itself to producing the cooling needs using the lower heat grade collected from the solar energy as opposed to high temperature energy sources obtained from conventional methods. The operation of an absorption system is similar to a vapor compression machine. In the absorption cycle, a lower heat grade is sufficient to drive the cycle. A lower heat grade is considered the available heat from the sun captured by the solar collector, whereby, the temperature involved is generally lower. Thus, it is capable of being a stand alone machine and a perfect match for renewable energy usage.

Absorption machines are most commonly used for cooling applications. The absorption cycle is based on a modified heat pump cycle. Different solutions are used for different systems and applications. As in air conditioning systems using absorption machines the typical working solution is a lithium bromide water solution. A Lithium Bromide/Water solution (LiBr-water) is commonly used because water can be easily desorbed (separated) or absorbed from the lithium bromide. This type of solution is normally used for cooling buildings, as it is able to chill the water to temperature between $40^{\circ} \mathrm{F}$ and $100{ }^{\circ} \mathrm{F}\left(4^{\circ} \mathrm{C}\right.$ and $38^{\circ} \mathrm{C}$ ). Whereas absorption machines for food refrigeration applications (or for below 
the freezing point) would typically use aqueous ammonia as it able to provide ideal temperatures between $-60^{\circ} \mathrm{F}$ and $40^{\circ} \mathrm{F}\left(-51^{\circ} \mathrm{C}\right.$ and $\left.4^{\circ} \mathrm{C}\right)$ which are appropriate fit for this purpose (Dorgan et al., 1995).
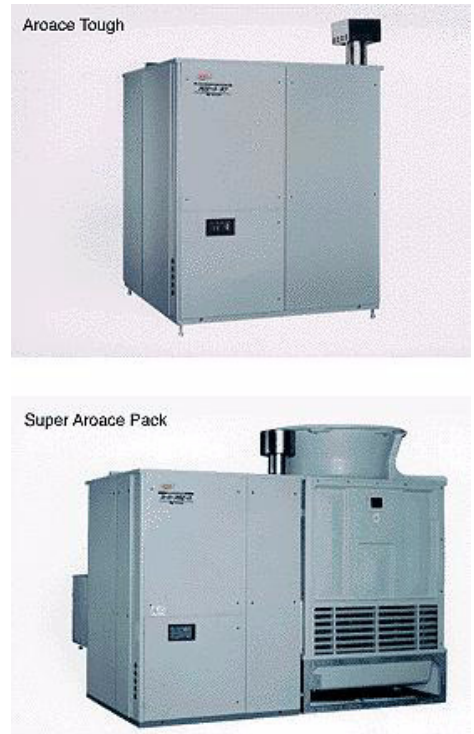

2 - 10 ton Absorption Machine
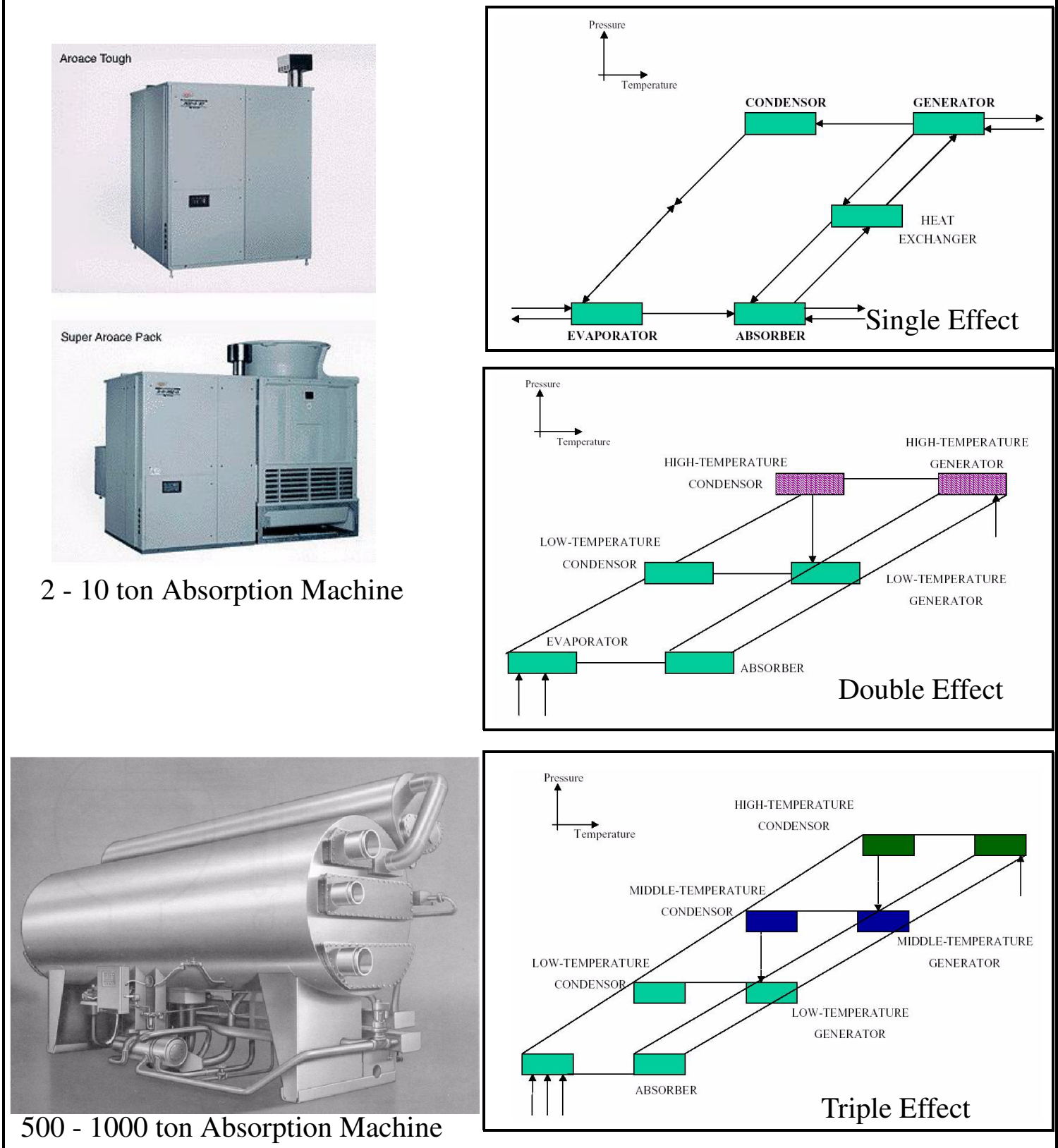

Figure 3.1 Absorption Machines and Schematic Diagram of Absorption Process 
The 500 - 1000 ton lithium bromide absorption machines are typically used in power plants to deliver chilled water in a large quantities for use in the cooling system of a building or heat extraction applications in a factory. The smaller capacity such as 2-10 ton units are applicable and suitable for a single home or small office cooling applications. This small size absorption unit is the main focus in this dissertation and which is linked in subsequent chapters with a renewable energy source to produce an integrated solar energy absorption machine.

The typical coefficient of performance (COP) for a given heat source is shown in Figure 3.2 for solar-powered air conditioning systems (Grossmann, 2002). The COP is calculated based on the heat input to the system and the cooling capacity produced by the unit. The COP describes how well the absorption machine operates under different conditions, such as when the heat input varies. Therefore, the sizing of the absorption machine can be made based on the cooling load or cooling needs at one desired location. The absorption system coefficient of performance (COP) is defined as shown in Equation (3-1).

$$
C O P=\frac{\text { Cooling Output }}{\text { Heat Input }}
$$




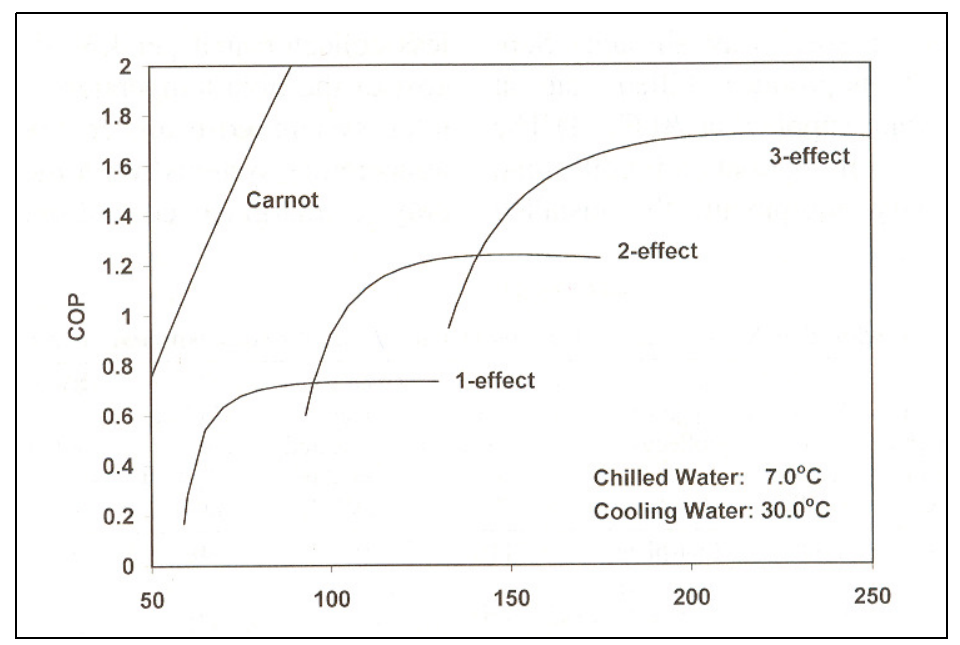

Figure 3.2 COP as a Function of Heat Input for LiBr-Water Absorption Chillers

The COP for absorption machines will increase as more heat is supplied to the desorber. However, it will remain unchanged for a range of heat input, depending on the capacity (tonnage) of the unit. In the model presented by Grossman (2002), and also produced by the simulation results in Section 3.5, the COP stays at a constant level or may slightly decrease, no matter how much heat is added. This can clearly be seen in the single effect, double effect, and triple effect curves in Figure 3.2. In this range, the COP can only be increased by improving the effect of the absorption, namely, moving from a single to a double effect cycle or from a double effect to a triple effect.

Vapor-compression machines have a higher COP than the absorption machines. A vaporcompression COP is in the range of 2 to 6.75 . Even though vapor-compression has a higher COP, the power input required is from a high grade energy source. Therefore, the cost of the energy needed to obtain the same cooling output from absorption and vaporcompression machines has to be taken into account. 
The absorption model developed in this dissertation is linked with the building model discussed in the previous chapter and provides the cooling effect to the building envelope.

\subsection{Basics of Absorption Systems}

Carnot cycles for both power generation and refrigeration cycles are presented to describe the overall absorption cycle in terms of an idealized energy conversion cycle. The temperature-specific entropy (T-s) diagram for the work producing cycle and refrigeration cycle are described in Figures 3.3 and 3.4.

For a power generation cycle, the clockwise processes can be described as follows:
$\mathrm{AB}$ : isothermal heat $\left(\mathrm{Q}_{2}\right)$ addition at $\mathrm{T}_{2}$
$\mathrm{BC}$ : isentropic work $\left(\mathrm{W}_{\text {out }}\right)$ production
CD: isothermal heat $\left(Q_{1 a}\right)$ rejection at $T_{1}$
DA: isentropic work $\left(\mathrm{W}_{\text {in }}\right)$ input 


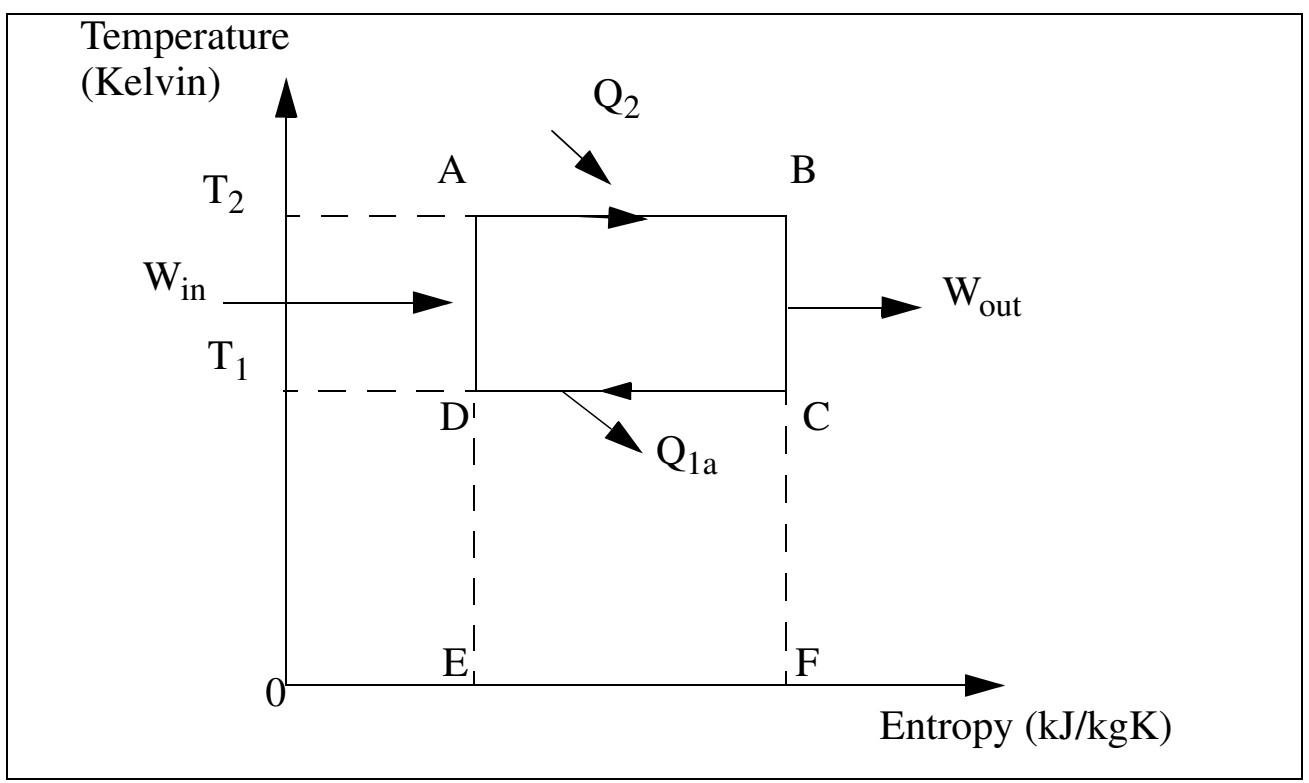

Figure 3.3 Carnot Cycle for Power Generation

Since all processes are reversible:

Area ABCD represents the net amount of work produced, $\mathrm{W}$

Area CDEF represents the heat rejection, $\mathrm{Q}_{1 \mathrm{a}}$

Area ABFE represents the heat addition, $Q_{2}$

Thus, the governing equation formulated from the reversible carnot cycle is

$Q_{2}=Q_{1 a}+W$

For a refrigeration cycle the direction of all processes are reversed, as compared to the power generation cycle, which yields:

$\mathrm{AB}$ : isothermal heat $\left(\mathrm{Q}_{0}\right)$ addition at $\mathrm{T}_{0}$

$\mathrm{BC}$ : isentropic compression work $\left(\mathrm{W}_{\mathrm{in}}\right)$ input 
$\mathrm{CD}$ : isothermal heat $\left(\mathrm{Q}_{1 \mathrm{~b}}\right)$ rejection at $\mathrm{T}_{1}$

DA: isentropic expansion work $\left(\mathrm{W}_{\text {out }}\right)$ output

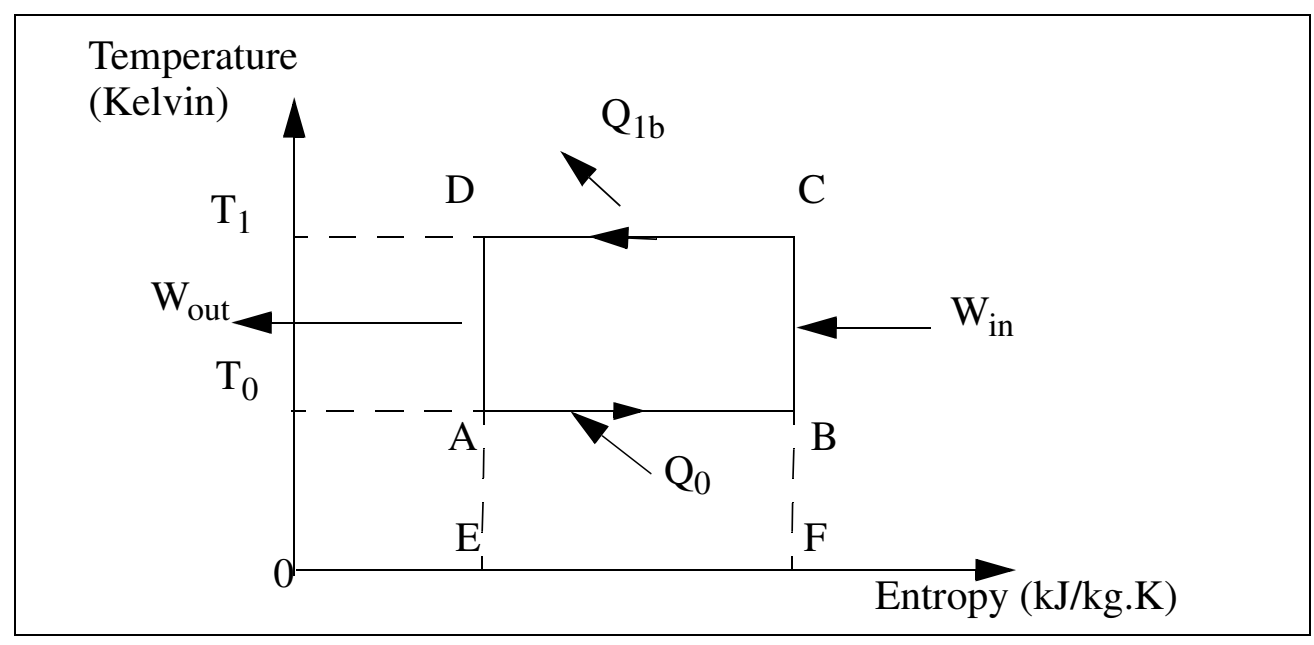

Figure 3.4Carnot Cycle for Refrigeration

and,

Area $A B C D$ represents the net work input required, $\mathrm{W}$

Area CDEF heat rejected, $\mathrm{Q}_{1 \mathrm{~b}}$

Area ABFE heat absorbed, $\mathrm{Q}_{0}$

In the absorption cycle, the power generation and the refrigeration components of the previous two cycles are combined to form one unit as shown in Figure 3.5. 


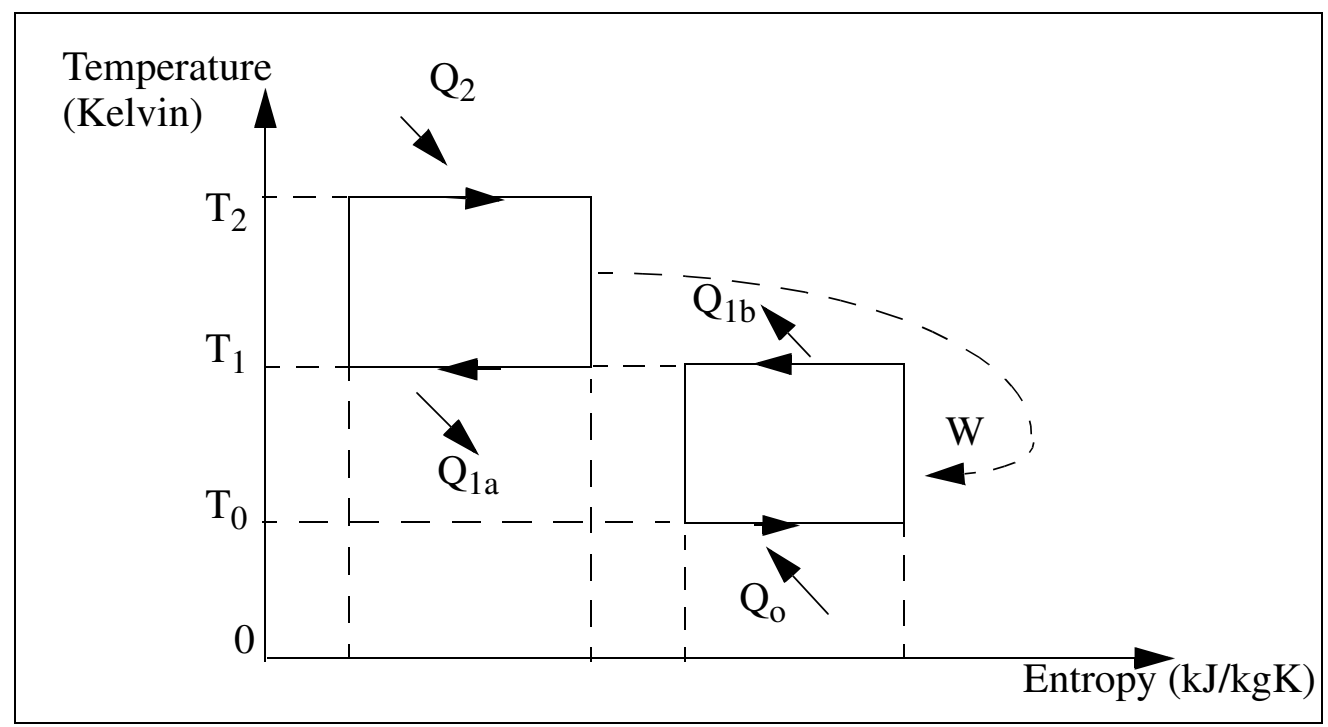

Figure 3.5 Carnot cycle for absorption refrigeration

The major assumption here is that the amount of work needed by the refrigeration cycle is the same as the amount of work produced by the power generation cycle.

\subsection{Absorption Cycle Description}

The cross-sectional representation of a single effect absorption chiller using a lithium bromide and water solution (LiBr-water) absorption is shown in Figure 3.6 and the detailed circuit diagram of a double effect absorption cycle is shown in Figure 3.8.

The four basic components in a single effect cycle are the desorber, condenser, evaporator, and absorber. The unit can be divided into a high pressure region and a low pressure region. The desorber and condenser are in the high pressure region, while the evaporator and the absorber are in the low pressure region. Both of these regions are below atmo- 
spheric pressure. The pressure on the high side is typically ten times greater than that on the low side.

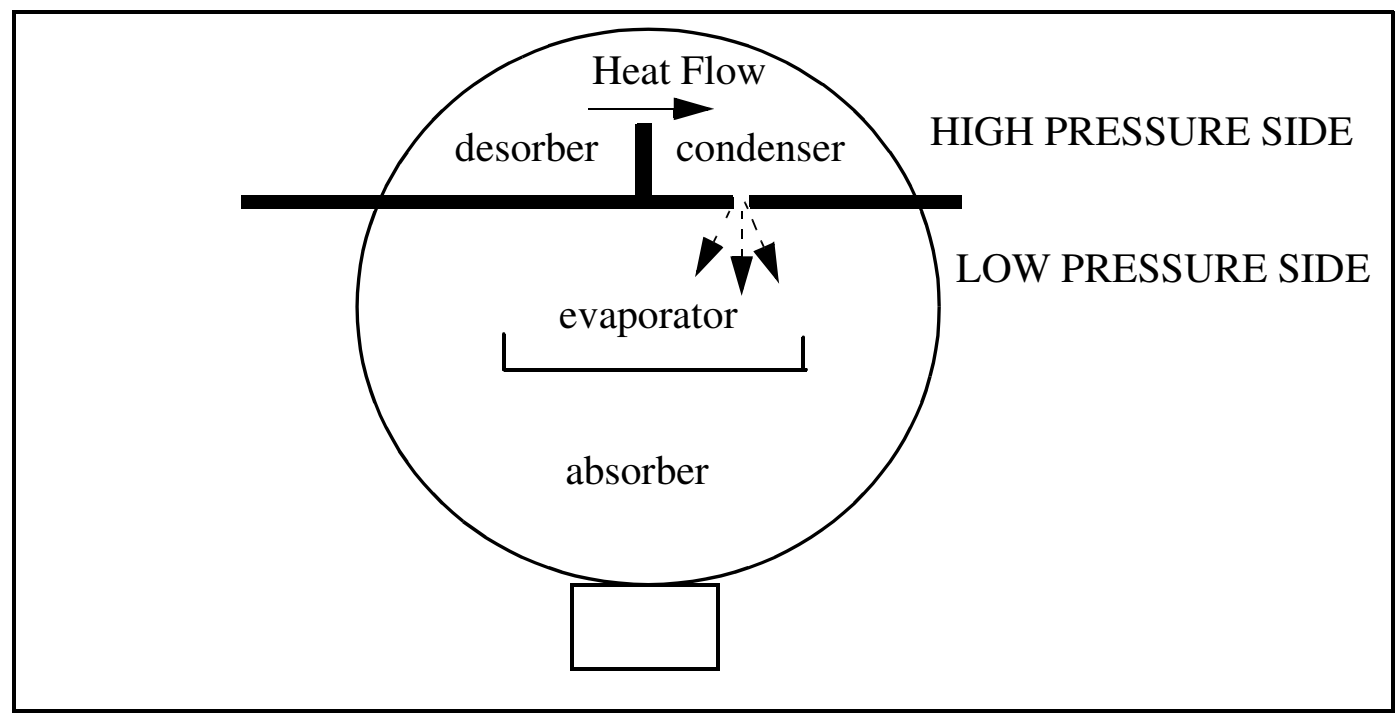

Figure 3.6 Schematic Diagram of Four Basic Components in a Single Effect Absorption Machine

In a single effect absorption chiller, dilute or weak lithium bromide water solution is constantly raised by a pump from the absorber to the desorber. At the desorber, the solutions are boiled off and only the water vapor will flow over the barrier to the condenser, leaving the concentrated solution that is mixed again with the dilute solution and pumped back again to the desorber. In the condenser, water vapor is condensed by the cooling water that flows in a bundle of tubes. Condensed water will flow down to the low pressure side of the evaporator through the small orifices and flashes to a low pressure vapor. Chilled water is then produced at the evaporator. The refrigerant vapor from this evaporative cooling process moves downward to the absorber side. The absorption process occurs at the absorber section, where the lithium bromide solution absorbs the refrigerant vapor. The double 
effect model is based on a similar cycle except that two generators/desorbers are used. The mathematical formulations used in the code development to describe the process above are explained in Section 3.4.

The developed program is capable of simulating single, double, and triple effect cycles. The proper heat and mass transfer analyses and correlations are used to approximate the actual behavior of the components in the absorption chiller. For example, the vapor that is separated from the lithium bromide solution at the desorber is assumed to flow into the condenser. At the condenser, cooling water flows in a bundle of tubes to condense the vapor as shown in Figure 3.7. The vapor will change phase from vapor to liquid and the appropriate correlations were used to model the heat transfer process.
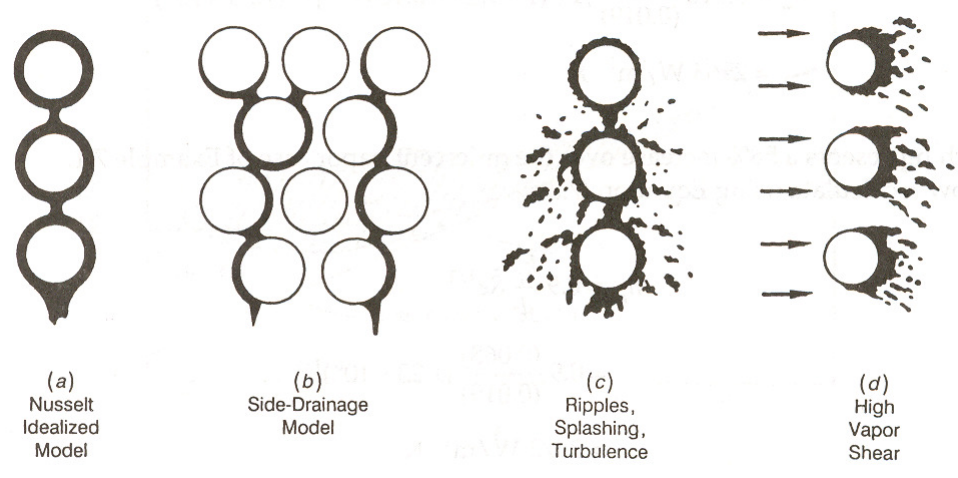

$$
\begin{gathered}
(d) \\
\text { High } \\
\text { Vapor } \\
\text { Shear }
\end{gathered}
$$

Figure 3.7 Schematic Representation of Condensate Flow

The different flow behaviors Nusselt idealized model; side-drainage model; ripples, splashing, turbulence model; and high vapor shear model, that can be used in the program are shown in Figure 3.7. The most appropriate selection of the flow model is based on matching the simulation results with experimental data. Obviously this appears to be the practical resolution since we have no access to observe the actual flow patterns in the unit. 


\subsection{Mathematical Formulation}

This section discusses the mathematical formulation for the absorption system components based on the double effect cycle shown in Figure 3.8. Each component is explained separately and the detailed mathematical formulations for each are further discussed in the Appendix B.

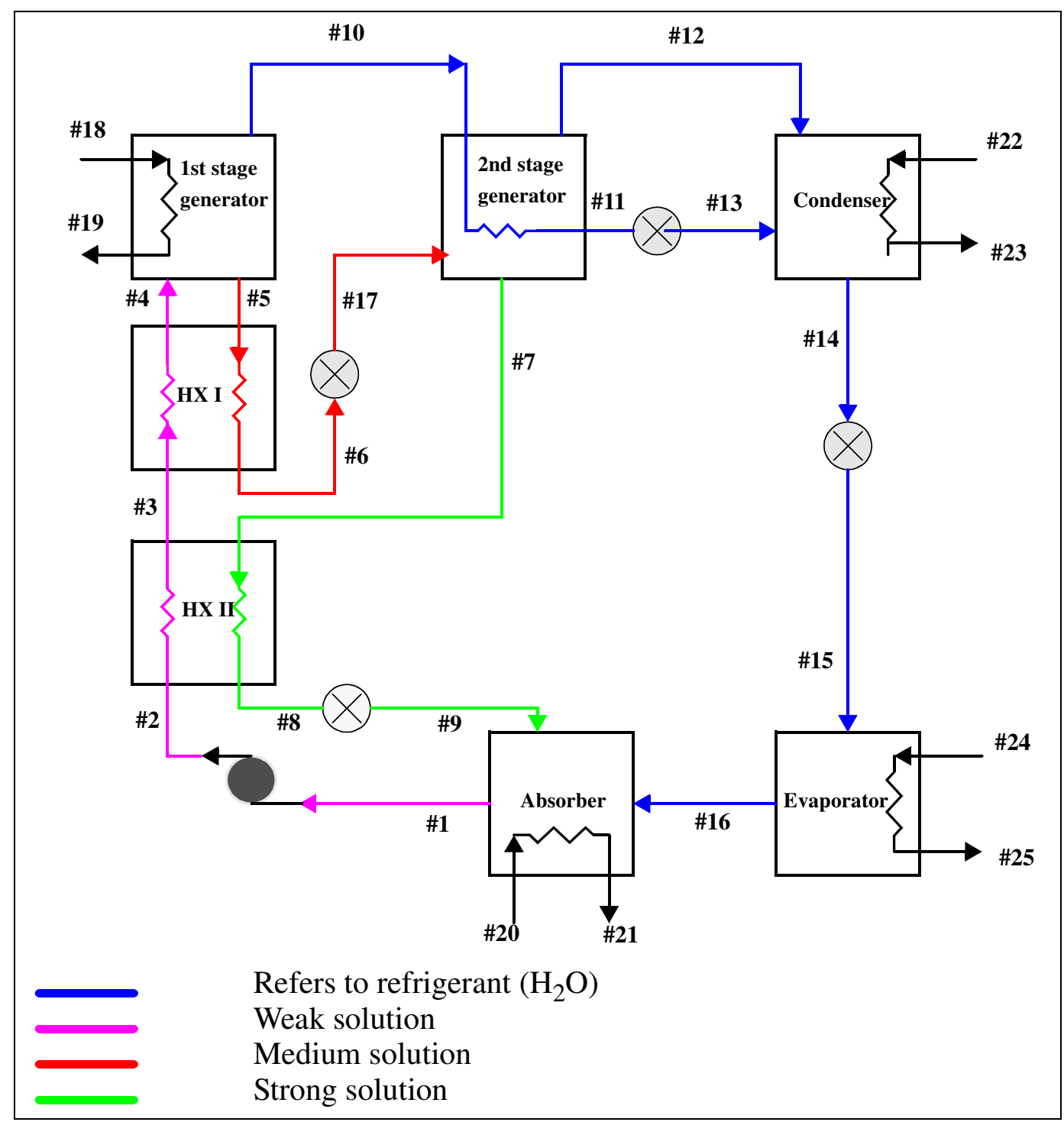

Figure 3.8 Circuit Diagram of the Double Effect Absorption Cycle. 


\subsubsection{Desorber}

The desorber also known as the generator or concentrator, acts as a boiler. The lithium bromide water solution will be boiled off using a hot water supply from the solar collector or storage tank. In other applications, steam or hot water can be taken from other available sources.

State \#18, as shown in Figure 3.9, represents the hot water supply from the source model. Once the weak lithium bromide water solution is brought to the boiling point, which is designed to take place at a certain operating temperature and pressure, the mixture will release the water in vapor form at state \#10. Vapor will then flow to the second desorber as the secondary heat input to boil the incoming medium strong lithium bromide water solution shown at state \#17. Vapor at state \#10 will be condensed and exit as liquid water at state \#11. The medium strong solution then becomes more concentrated (state \#7) and is mixed with the dilute solution to be recycled to the first desorber. For the single effect case, vapor from the desorber will directly flow towards the colder region in the condenser. The governing equations for the energy balance and heat transfer processes that occur in the absorption chiller are listed in Appendix B.2. 


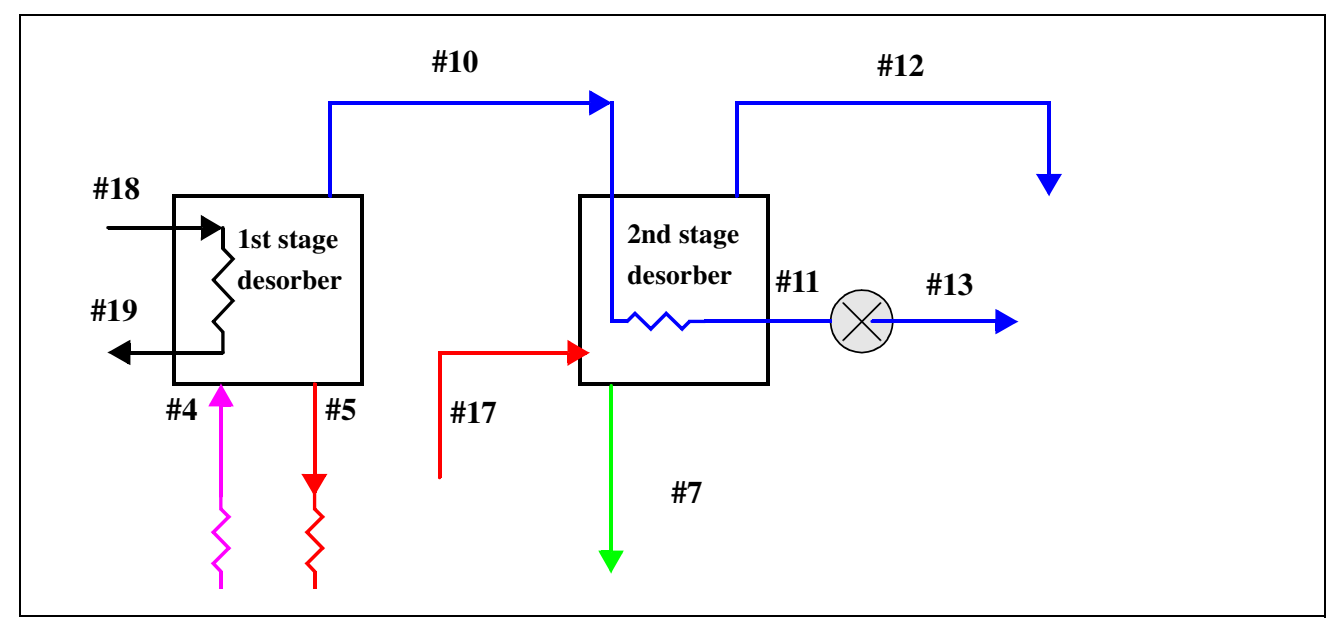

Figure 3.9 Circuit Diagram of the Desorber/Generator/Concentrator

\subsubsection{Condenser}

In the condenser, as shown in Figure 3.10, incoming vapor from the concentrator (state \#12 and/or state \#13) is cooled to a liquid form (state \#14) in the high pressure region. This is a natural process since heat is transferred from the hot to cold region. This causes the vapor to flow from the desorber region to the condenser region. The condenser consists of a bundle of tubes through which cold water flows (state \#22 to state \#23). Condensation occurs on the outside of the tubes in the condenser region where the cooling water supply absorbs the heat of vaporization from the water vapor. The governing equations for the condenser are listed in Appendix B.3. 


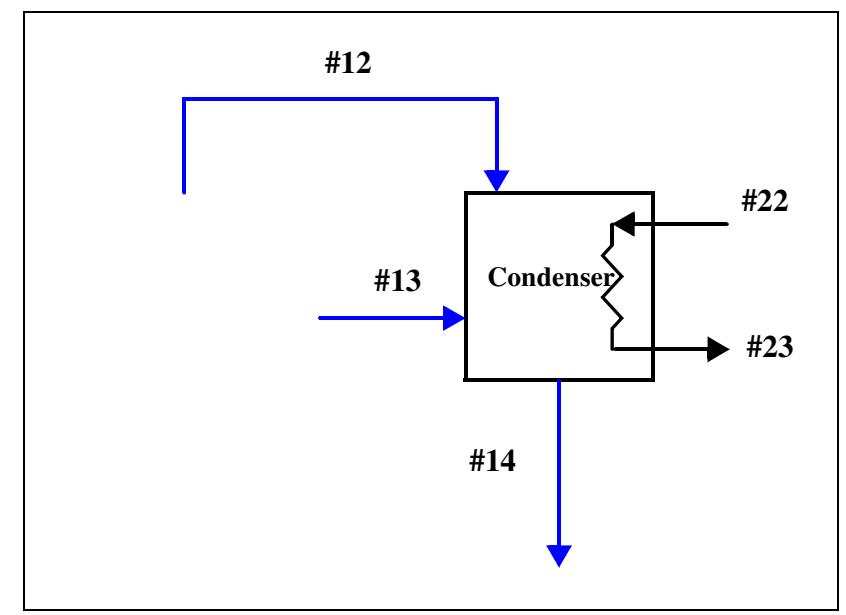

Figure 3.10 Circuit Diagram of the Condenser

\subsubsection{Evaporator}

The evaporator forms the low pressure side of the absorption chiller and its function is to produce the chilled water. The low temperature two phase (liquid-vapor) water exiting the condenser (state \#15) will evaporate to a low temperature water vapor due to the heat transfer from the water supply tubes (state \#24). This heat transfer process occurs due to the heat of vaporization from the water supply. The resulting is the chilled water produced in the water supply tubes (state \#25) since the two phase water (state \#15) is colder than the water supplied. The pressure in the evaporator is approximately 10 times smaller than the pressure in the condenser and the desorber.

Between the condenser and the evaporator, the refrigerant, or liquid water is forced down through the orifice due to the pressure difference from the high pressure side of the con- 
denser (state \#14) to the low pressure region (state \#15) of the evaporator. This causes the liquid refrigerant on the condenser side to flash through the orifice and also causes the temperature to decrease. The process will continue until the refrigerant reaches the saturation temperature of the evaporator pressure. The governing equations for the evaporator are listed in Appendix B.4.

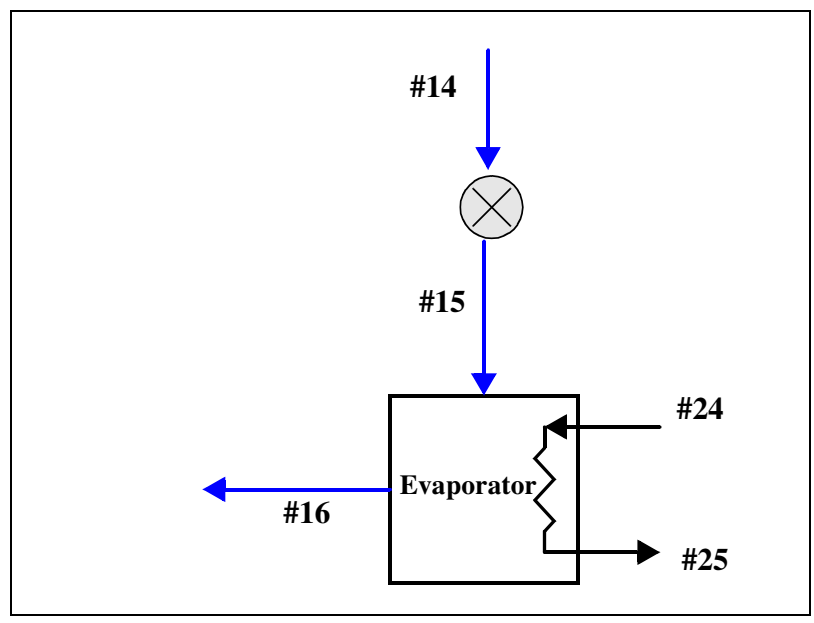

Figure 3.11 Circuit Diagram of the Evaporator

\subsubsection{Absorber}

The absorber forms the lowest pressure side of the absorption chiller. Its function is to absorb the water (state \#16) from the evaporator to be circulated back to the desorber. The evaporation process from the evaporator causes the refrigerant to flow to the absorber (state \#16). The refrigerant will be absorbed by the low concentration of the salt solution (state \#9). Once the Lithium Bromide water solution becomes diluted (state \#1) it will be 
returned to the concentrator. The solution is also interrelated between the absorber and desorber through the heat exchanger, see Section 3.4.5, for better performance of the absorption system.

The refrigerant vapor also gains energy from the heat of vaporization provided by the cooling water as it passes through the tubes (state \#21) at the absorber and causes the incoming vapor (state \#16) from the evaporator to absorb the heat. The governing equations for the absorber are listed in Appendix B.5.

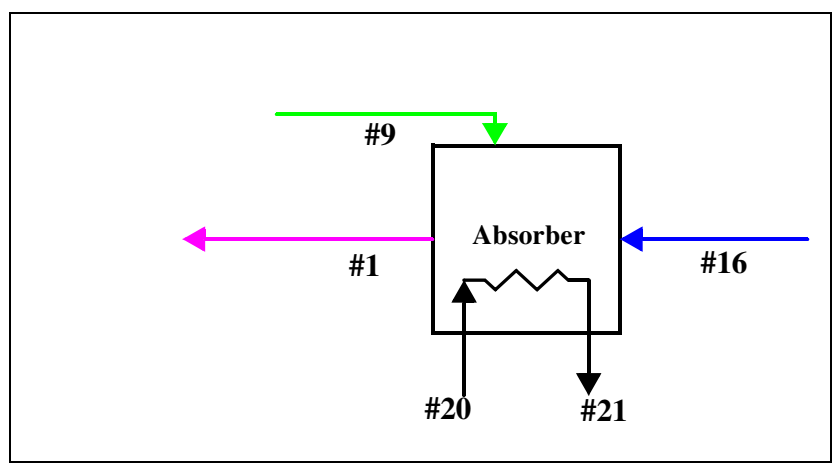

Figure 3.12 Circuit Diagram of the Absorber

\subsubsection{Heat Exchangers}

Heat Exchangers are used to exchange heat between the hot concentrated solution returning to the absorber and the cool dilute solution being pump to the desorber as shown in Figure 3.13. Two or three heat exchangers are needed for double effect absorption machines depending on the manufacturer. The heat exchangers reduce the heat energy required in the concentrator to raise the temperature of the dilute solution (state \#1/state 
$\# 3 /$ state \#4) to the boiling point. The additional heat is gained from the medium strong solution (state \#5) and the strong solution (state \#7) exiting from the desorbers. Without heat exchangers, more heat needs to be supplied (state \#18) to the desorber in order to boil the lithium bromide-water solution (state \#4). Heat exchangers also reduce the cooling load in the absorber section. The governing equations for the heat exchanger are listed in Appendix B.7.

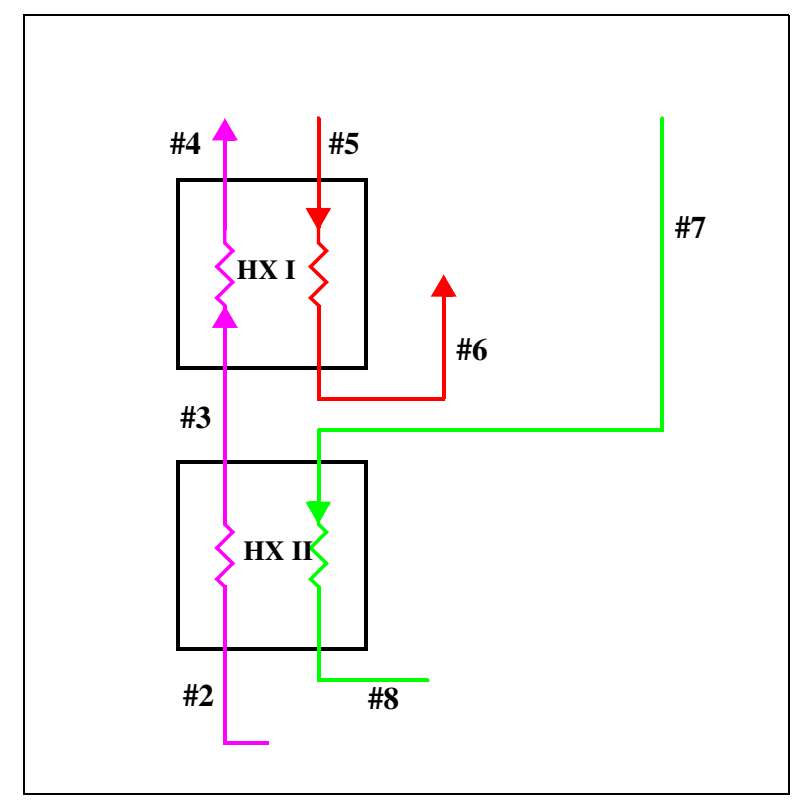

Figure 3.13 Circuit Diagram of the Heat Exchangers

\subsection{Validation / Sample Calculations}

Validation of the single-, double-, and triple-effects models was performed using the absorption chillers specification obtained from Grossman (2002). The coefficient of per- 
formance (COP) as a function of solar heat supply temperature for single-, double- and triple-effect LiBr-Water absorption chillers is shown in Figure 3.14. The three cases were simulated under the same operating conditions for a cooling water inlet temperature of $30^{\circ} \mathrm{C}$ and chilled water outlet temperature of $7^{\circ} \mathrm{C}$. The published results by Grossman (2002), as shown in Figure 3.2, indicates that the developed program is capable of simulating the same results as shown in Figure 3.14.

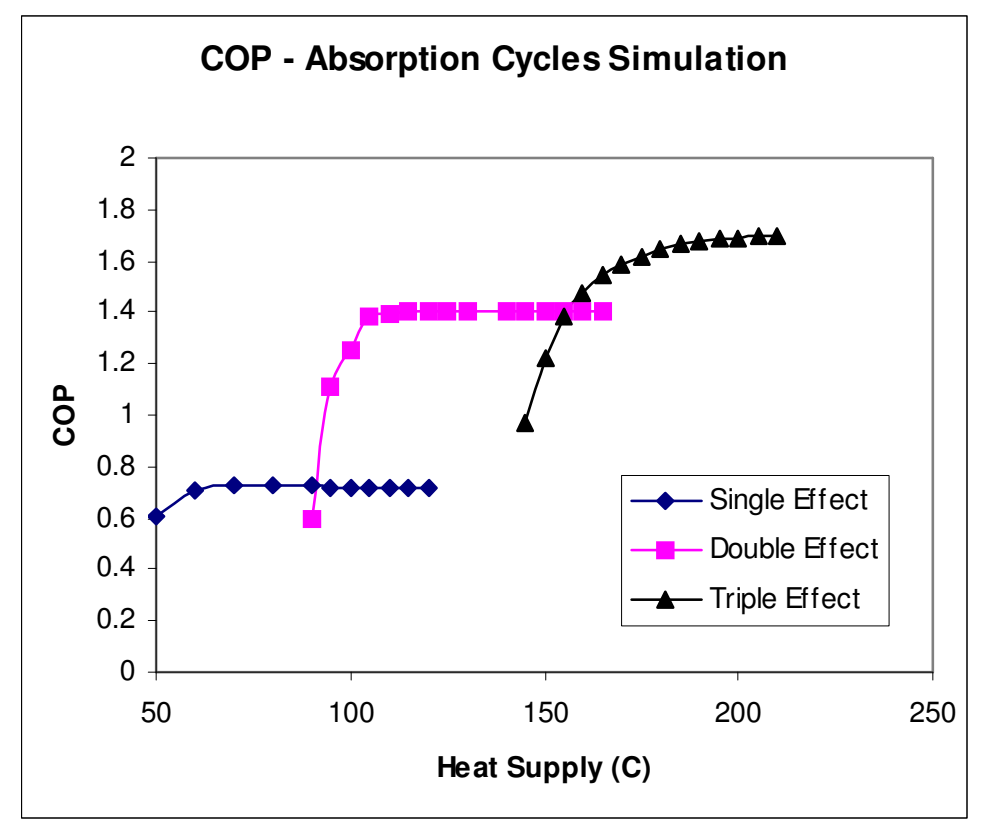

Figure 3.14 Calculated COP for Single, Double, and Triple Effect Lithium BromideWater Absorption Chillers

The trend for all three configurations shows good agreement of the simulations and the published results. There is, however, a slight increase in the predicted COP values for the double effect chiller. The reason for the slight increase is that some of the parameters that were used in the references were not published. The COP values are in the acceptable range for that particular absorption machine. This is acceptable by industry standards of 
two different absorption machine manufacturers. For example, the Trane 1000 ton unit and York 1000 ton unit machines, have a slight variation in their product performance for the same unit capacity.

The COP values were calculated for each single, double, and triple effect based on the input hot water temperatures ranging from $60^{\circ} \mathrm{C}$ to $120^{\circ} \mathrm{C}, 90^{\circ} \mathrm{C}$ to $170^{\circ} \mathrm{C}$, and $140^{\circ} \mathrm{C}$ to $220^{\circ} \mathrm{C}$ respectively for each effect. The input temperatures to the program were chosen to be approximately the same as those used in the published results. The code can be extended to lower or higher ranges of temperature for additional case studies.

The COP graphs show that it is not practical to use the selected absorption machines when the input temperature is low. This will yield to a low performance chilled water production by this system. Additional heat must be added, such as an auxiliary heater, to boost the heat supply in case the supplied hot water is not sufficient. This lower temperature of the hot water supply is an issue when the source of hot water is from solar energy. In power plant application, this is not a major problem as the hot water temperature can be easily controlled from the fossil fuel source such as the natural gas, oil, or coal.

Figure 3.15 shows two simulations that compare the simulated double effect absorption performance with the published data. The good agreement of the predictions for both COP and capacity to the published experimental results show that the developed program is capable of analyzing the performance of various absorption chillers. When the source hot water temperature is increased from $110^{\circ} \mathrm{C}$ to $160^{\circ} \mathrm{C}$, the COP values slightly increase to approximately 1.1 for the simulation and 1.3 for the experimental results. This small error between the experimental and the simulated value is acceptable due to the need to predict some of the parameters used in the program as they were not available in the literature. 

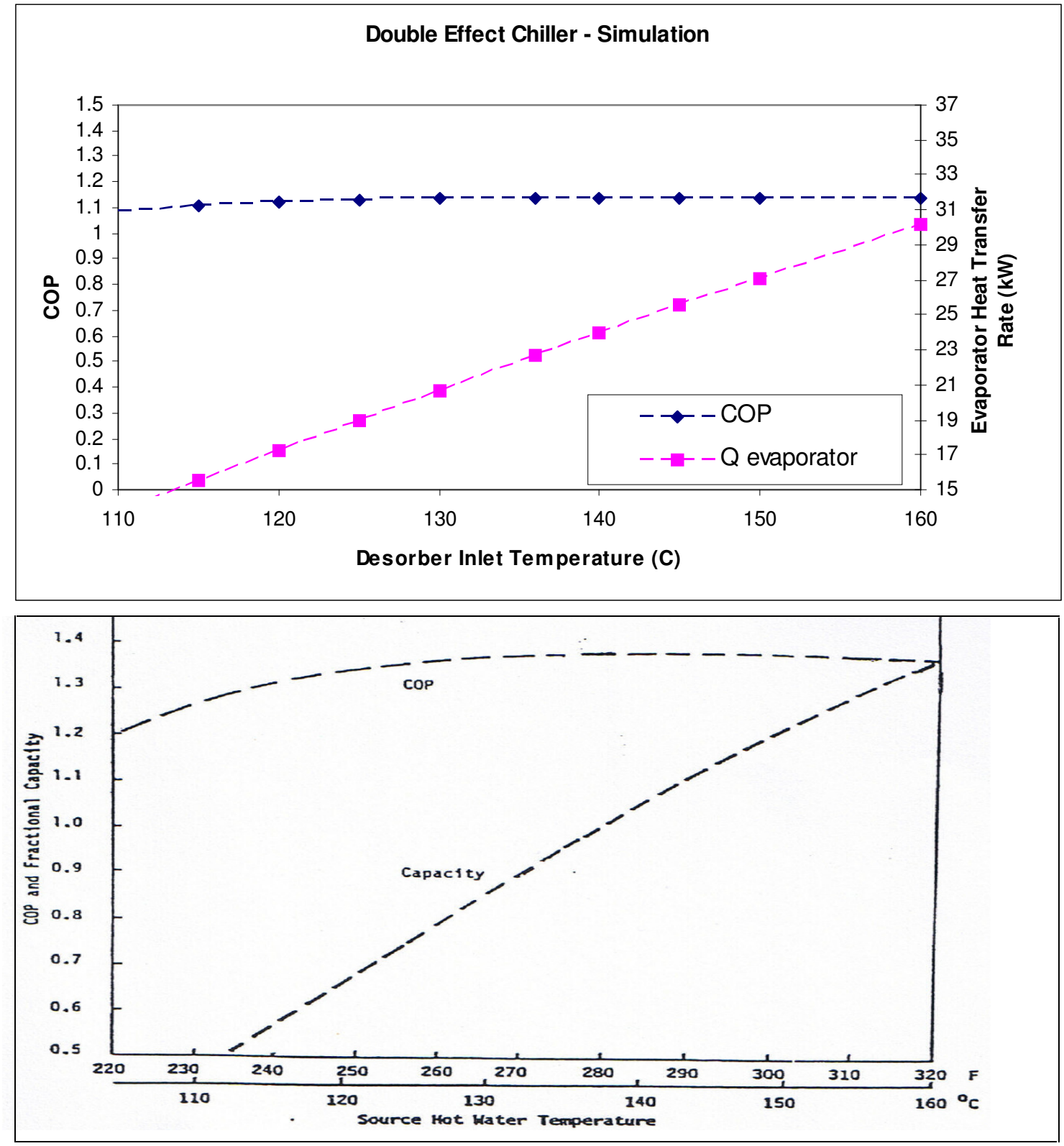

Figure 3.15 Performance Comparison for Double Effect Chiller: Simulation Results (top graph) Published Results [Vliet et al., 1982] (bottom graph)

The cooling capacity curve shows very good agreement as the capacity, or the heat transfer in the evaporator, for the simulation increases at the same rate as the experimental values. The capacity increases due to a higher input temperature that yields a greater amount 
of separation in the lithium bromide and water solutions at the desorber. The separation causes more water vapor, or steam formation, that moves to the condenser and is later fed to the evaporator where the two phase water vapor exists at a lower temperature and pressure to produce more chilled water or higher power capacity

Simulations were also conducted of a single effect absorption chiller. These studies were performed to determine the effect of changes in the heat input and the flow rates on the COP. Figure 3.16 shows the results of the same parametric studies as those performed to obtain the results shown in the Figure 3.15. The single effect behaves in the same manner but with lower COP and capacity. The source hot water temperature is also limited from $70^{\circ} \mathrm{C}$ to approximately $100^{\circ} \mathrm{C}$ since the single effect has some limitation as previously described. However the single effect system operates well at a much lower temperature range as opposed to the double and triple effect chillers. .

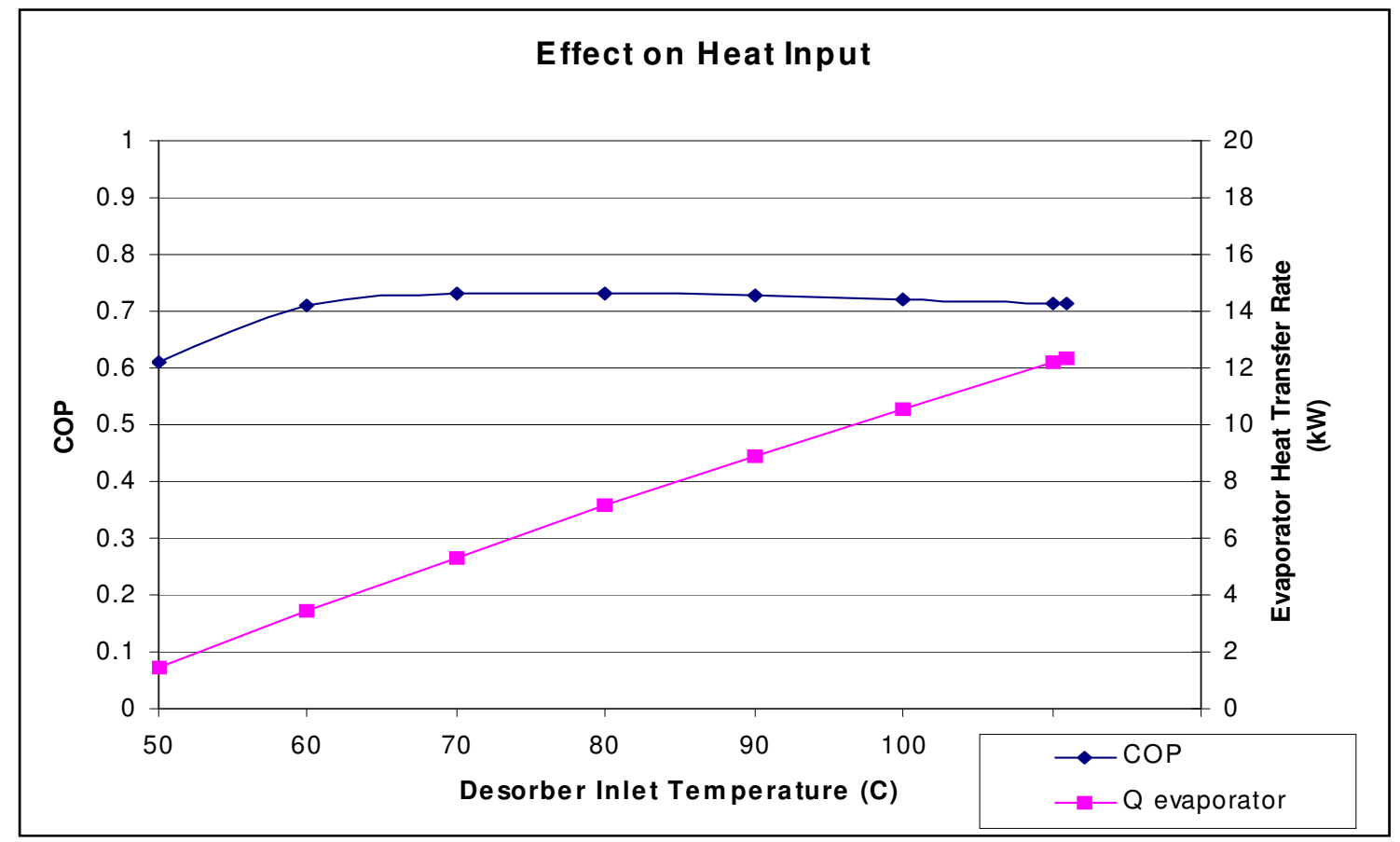

Figure 3.16 Effect of the Heat Input on COP and Heat Transfer Rate 
This situation demonstrates that the single effect chiller is more desirable for the small application of a single home and can be used with the aid of solar energy. This will be further explained in later chapters. The hot water used in the desorber has to be maintained and regulated in order to provide the cooling needs of the room. The next chapter discusses the storage tank model that provides the heat input for the absorption chiller 


\section{Chapter 4 Storage Tank Model}

\subsection{Introduction}

As solar energy cannot be captured at a constant rate and is not available at all times, methods are devised to capture and store the energy to be used at later times. As in the absorption chiller unit, the hot water source replaces the high temperature heat input to the unit. Thus, it is necessary to have sufficient hot water available at all times to operate the cooling system during any time of the day. The quantity chilled water produced by the absorption chiller that is greater than the demand can be stored and used at a later time. The storage of hot water, cold water, or both can be implemented with the absorption chiller system for the appropriate application. Figure 4.1 shows the storage tank inlet and outlet liquid circulation for a sample solar system.

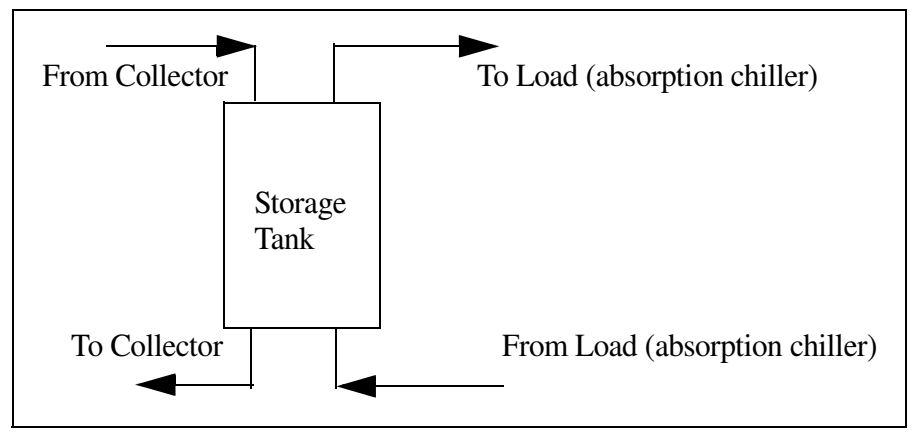

Figure 4.1 Water Tank Storage: Water Circulation Through Collector and Through the Load. 
Modeling of the liquid storage tank is needed to predict the operation of a stand alone system. The storage itself can be arranged in several ways. The combination would include methods of varying the placement of the inlet and outlet to the tank; arranging multiple tank configurations; and orienting the tank either vertically or horizontally to achieve maximum efficiency. There are also ways that an internal coil can be utilized in the storage tank if a backup system or auxiliary heat input from another heater is required. An alternative system is shown in Figure 4.2, where the arrangement of multiple tanks allows optimization of the hot water storage usage.

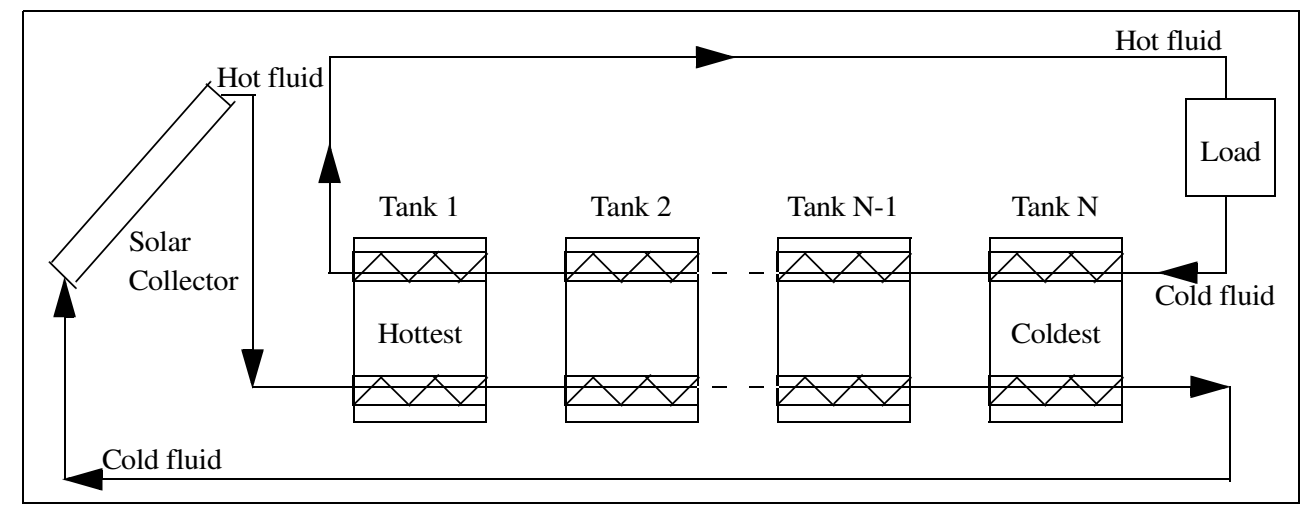

Figure 4.2 Alternative System with More Than One Storage Tank (Mather et al., 2002)

To correctly model and optimize the storage tank operation, other necessary devices such as the solar collector, piping, etc., must be taken into account so that they can be appropriately integrated into the model. This ensures that all the sub-models will work in unison. The input and output parameters such as the temperature, pressure, and flow rates are highly correlated to each other to predict the system behaviors. 
Various numerical models can be used to predict the performance of the energy storage, such as a fully mixed (non-stratified) tank, multi node or stratified tank, plug flow, and computational analysis. The next section discusses the non-stratified and stratified models, which are used as the numerical analysis for the hot water storage predictions in the developed program. The plug flow and other computational methods, such as three dimensional analysis are not incorporated in the program development as the earlier methods accurately predict the experimental results.

\subsection{Non-stratified Tank Model}

In a non-stratified tank model, a fully mixed tank model of water storage is developed using a lumped analysis. The tank is assumed to be a single unit and an energy analysis is applied to only one node representing the overall fluid temperature distribution in the whole tank as shown in Figure 4.3. The schematic diagram shows the energy from collectors, energy to load and energy losses to surrounding as described in the following mathematical formulation starting with Equation (4-1). This formulation yields the transient analysis of the non-stratified tank as shown in Equation (4-3)

The heat capacity of the fluid in the storage tank can be calculated using the mass, specific heat capacity and the temperature change that occurs in the tank as:

$Q=m \times C_{p} \times \Delta T$

where;

Q = heat capacity (J) 
$\Delta T=$ temperature variation in the $\operatorname{tank}(\mathrm{K})$

$\mathrm{m} \quad=$ liquid mass in the storage tank $(\mathrm{kg})$

$C_{p}=$ specific heat capacity of the liquid $(\mathrm{J} / \mathrm{kgK})$

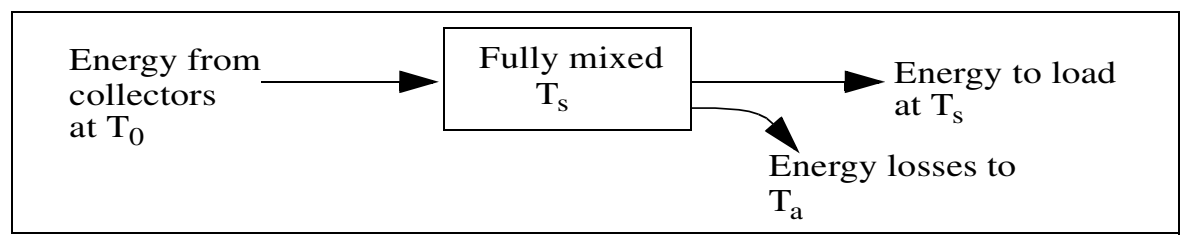

Figure 4.3 Unstratified Storage of Mass m Operating at Time-Dependent Temperature $\mathrm{T}_{\mathrm{s}}$ in Ambient Temperature $\mathrm{T}_{\mathrm{a}}$

The transient energy balance can then be formulated for the storage tank as shown below,

$m C_{p} \frac{d T_{s}}{d t}=Q-L-(U A)\left(T_{s}-T_{a}\right)$

where

$\mathrm{m}=$ mass of the liquid in the storage tank $(\mathrm{kg})$

$\mathrm{Q}$ and $\mathrm{L}=$ energy addition/removal from the collector and to the load at a specified time

$\mathrm{T}_{\mathrm{a}}=$ ambient temperature for the tank $(\mathrm{K})$

$(\mathrm{UA})=$ loss coefficient area product, $(\mathrm{W} / \mathrm{K})$

The energy balance can be solved using the Euler Method (or finite difference approach):

$T_{s}^{n}=T_{s}^{n-1}+\frac{\Delta t}{\left(m C_{p}\right)}\left[Q-L-(U A)\left(T_{s}-T_{a}\right)\right]$ 
This fully mixed tank model will not give an actual description of the temperature distribution in the entire tank. It will only give an estimate of the overall fluid temperature in the tank.

The next section discusses the temperature distribution in the tank obtained by modeling the liquid as multiple layers or multi nodes. Each layer is assumed to flow up and down depending on the density of the water. The non-stratified tank model contains only one node that is assumed to represent the temperature of the entire tank. By incorporating more than one node, a detailed study of the temperature distribution in the entire tank, especially when there is a large temperature variation from the top to the bottom of the tank, could be obtained.

\subsection{Stratified Tank Model}

In the stratified tank model (Duffie and Beckman, 1991), nodes are used to represent several layers for differentiating the temperature distribution. Hot water is normally formed on the upper levels and the temperature will decrease towards the bottom surface, as depicted in Figure 4.4.

The inlet water enters at the node in the tank that approximately matches its temperature. The temperature profile is then estimated given the initial values of the inlet water temperature, and the solution is carried out until convergence is achieved.

In the formulations below, $\mathrm{m}$ represents the water mass in the segment under consideration, $\mathrm{T}$ is the water temperature in that segment, $\dot{m}$ is the mass flow rate crossing the seg- 
ment, $T_{a}$ represents the ambient temperature, $\mathrm{U}$ is the overall heat transfer coefficient and A is the superficial area of each tank segment. $F_{c}^{i}$ and $F_{l}^{i}$ are the collector control functions to determine which node receives water from the collector and the load, respectively. The control function $F_{c}^{i}$ is used to indicate the correct placement of the liquid entering the stratified storage tank from the solar collector. This control function will model the liquid as evenly distributed in a specific layer in the storage tank. Then the energy balance can be applied to solve for the temperature profile in the tank after all layers are defined. The control function $F_{c}^{i}$ is defined as:

$$
F_{c}^{i}=\left\{\begin{array}{ccccc}
1 & \text { if } & i=1 & \text { and } & T_{c, \text { out }}>T_{s, i} \\
1 & \text { if } \quad i=1 & \text { and } & T_{s, i} \geq T_{c, \text { out }}>T_{s, 1} \\
0 & \text { if } \quad i=0 & \text { or } & i=N+1 \\
0 & \text { otherwise } & &
\end{array}\right.
$$




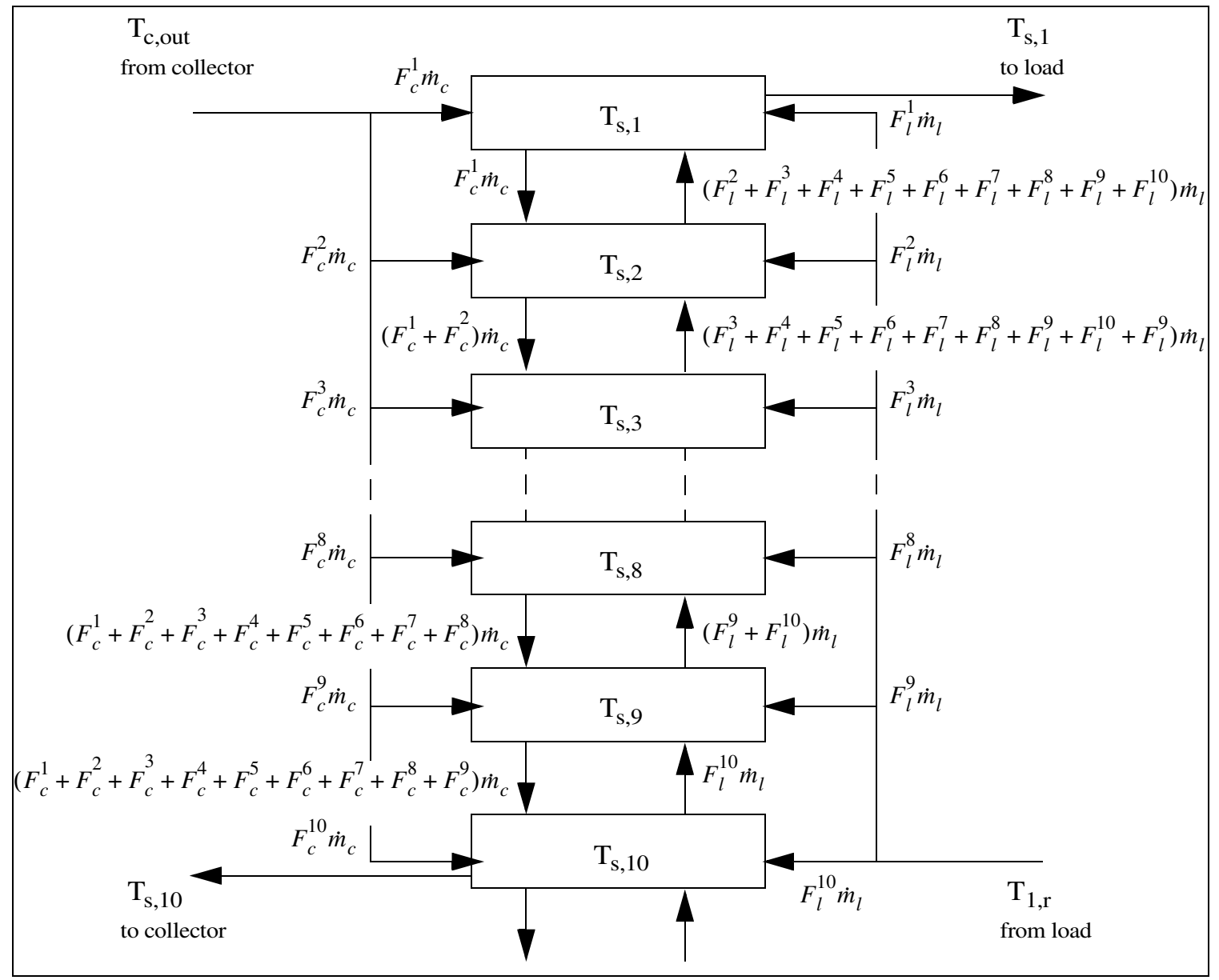

Figure 4.4 Stratified Liquid Storage Tank and the Internal Flows Associated with Each Node

Similarly, water entering the storage tank from the load will be formulated in the same manner, such that the correct node will receive the liquid based on the load control function $F_{l}^{i}$ as follows: 


$$
F_{l}^{i}=\left\{\begin{array}{ccccc}
1 & \text { if } & i=1 & \text { and } & T_{l}<T_{s, N} \\
1 & \text { if } & i=1 & \text { and } & T_{s, i-1} \geq T_{l}>T_{s, i} \\
0 & \text { if } & i=0 & \text { or } & i=N+1 \\
0 & \text { otherwise } & & &
\end{array}\right.
$$

The energy balance for section $\mathrm{i}$ of an $\mathrm{n}$-section tank is formulated as follows:

$$
\begin{aligned}
&\left(m C_{p}\right)_{s, i} \frac{d T_{s, i}}{d t}=(U A)_{s}\left(T_{a}-T_{s, i}\right)+ \\
&\left(\dot{m} C_{p}\right)_{c}\left\lfloor F_{c}^{i}\left(T_{c, o}-T_{i}\right)+\left(T_{i-1}-T_{i}\right)\right.\left.\sum_{n=1}^{l-1} F_{c}^{j}\right\rfloor+ \\
&\left(\dot{m} C_{p}\right)_{L}\left\lfloor F_{l}^{i}\left(T_{l, r}-T_{i}\right)+\left(T_{i+1}-T_{i}\right) \sum_{j=(n-i+1)} F_{l}^{j}\right\rfloor
\end{aligned}
$$

The $(U A)_{s}\left(T_{a}-T_{s, i}\right)$ term takes into account the heat losses to the environment as depicted in Figure 4.3.

The tank is modelled to have $\mathrm{N}$ fully mixed volume segments (nodes). Energy balances for each layer are solved simultaneously by taking into account all the factors involved in the tank such as the inlet and outlet conditions, losses, and auxiliary input. These fixed layers are assumed to move in a manner such that one layer will move and replace the next, consistent with their temperature values. This internal shifting of layers is controlled by the control functions, "F".

The degree of stratification is determined by the choice of $\mathrm{N}$. Higher values of $\mathrm{N}$ result in more stratification. For the case of $\mathrm{N}=1$, the tank is modelled as a fully mixed tank and no stratification effect is possible. An assumption employed in the multi-node model is that the fluid streams flowing up and down from each node are fully mixed before they enter 
each node. With this assumption, the heat source flow and the load flow are treated simultaneously.

The stratified tank model can be improved with the selection of an optimum number of nodes. The nodes can be visualized as the segments in the tank and the numerical method is applied to predict the temperature at each node. The higher the number of nodes the better the prediction. There is, however, a limitation on the node selection beyond which no computational gains can be achieved. The optimum number of nodes is typically between 10 to 15 nodes. As an example, a more than 30 nodes model is considered too large and would be an inefficient use of computing power.

\subsection{Validation / Sample Calculations}

Validation of the stratified liquid storage tank model was performed using the storage water tank configuration obtained from Olivesky et al. (2003). The storage tank volume is $0.079 \mathrm{~m}^{3}$ and the height is $0.6 \mathrm{~m}$. The ratio of the height to the tank diameter is 1.36 . The storage tank, with an initial hot water temperature of approximately $82{ }^{\circ} \mathrm{C}$, is placed in a room at ambient room air temperature. The water temperature inside the tank was monitored using the thermocouples placed in the tank at various heights. The readings were taken every hour, and the temperature profile along the height of the tank was plotted.

The simulation results were obtained using the same parameters as the experimental investigation previously described. The temperature values recorded in the experimental setup obtained by Olivesky et al. (2003) were plotted against the height of the tank to 
assess the validity of the developed program. Figure 4.5 shows the comparison of the simulation results using the stratified node model to the experimental results. As can be seen from the figure, the stratified tank model, or the multi node model, is in good agreement with the experimental data taken from the literature.

As shown in Figure 4.5, initially all thermocouples gave the same reading, which can be seen at the zero hour on the graph, as approximately $82{ }^{\circ} \mathrm{C}$. The temperature readings are then recorded at certain intervals to study the temperature change of the water in the storage tank. After one hour a constant temperature drop of approximately one degree is observed, starting from the top of the tank to a height of 0.2 meters from the bottom of the tank. The temperature values from the 0.2 meter height to the bottom of the tank gradually decrease from top to bottom, resulting in a temperature of $76{ }^{\circ} \mathrm{C}$ close to the bottom location. The same pattern can also be seen at hours 3, 5, 7, etc. as depicted on Figure 4.5. The final temperature readings were taken at hour 45 . At this hour, $2 / 3$ of the tank is at $48{ }^{\circ} \mathrm{C}$ in the experimental investigation and the prediction from the stratified tank model is approximately $48.5^{\circ} \mathrm{C}$. The value at 0.02 meter is $40.5^{\circ} \mathrm{C}$ for the experimental data and $40{ }^{\circ} \mathrm{C}$ for the simulation. 


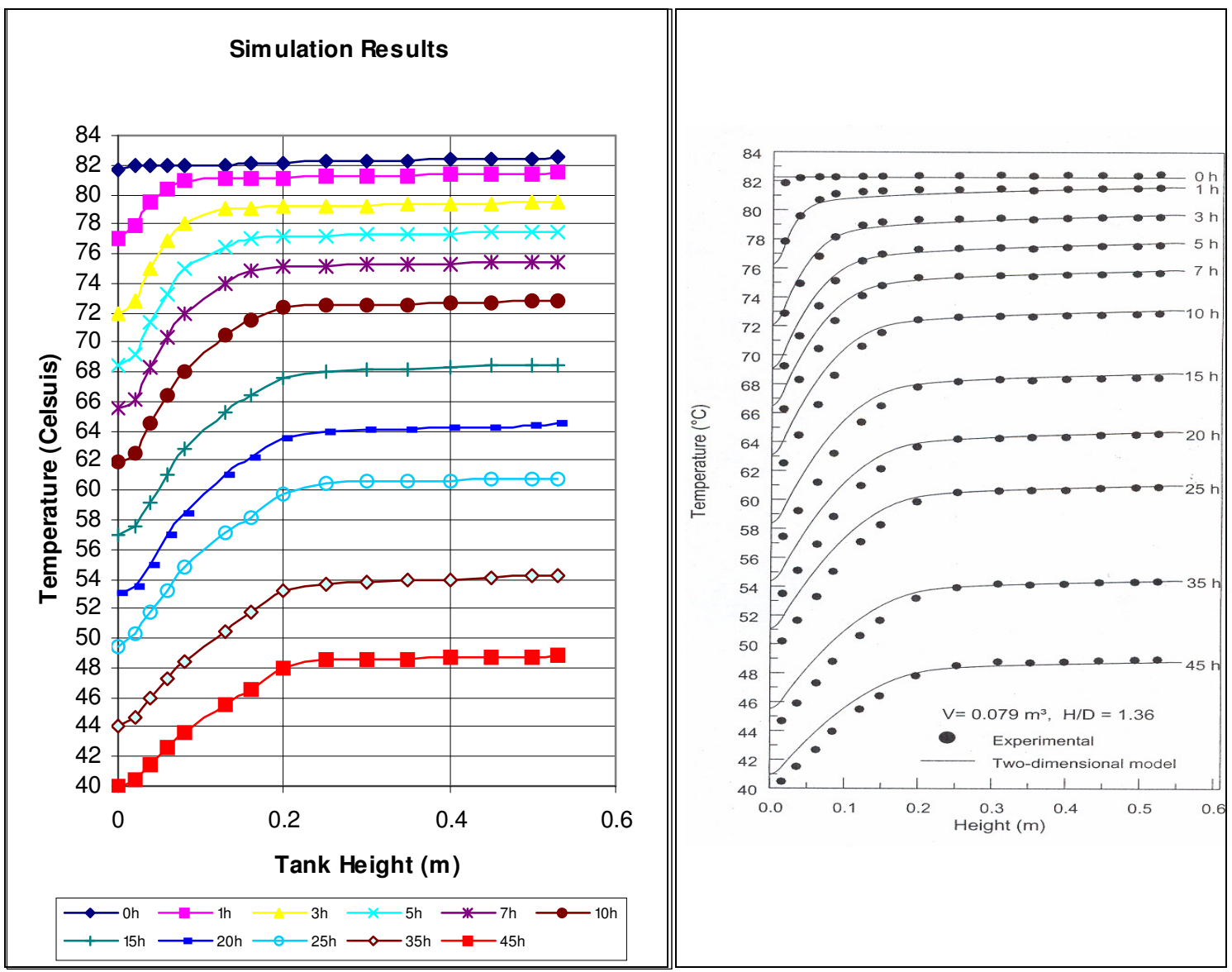

Figure 4.5 Comparison Between Simulation and Experimental Data: Simulation Data from Developed Program (left), Experimental Data [Oliveski et al., 2003] (right)

The objective of this storage tank simulation is to obtain the temperature profile in the tank, which will show the temperature layers from top to bottom. These temperature layers, as described in the multi-node section, are obtained using a one dimensional model that does not require excessive computing resources to achieve convergence, as opposed to obtaining this same temperature information using a more sophisticated computational resources. Based on the results shown in Figure 4.5, it was not necessary to construct a 
two- or three-dimensional model, as this reseaarch focuses on optimizing the entire system, and the multi-node or stratified model is deemed sufficient to achieve this objective.

It is important to note that this temperature profile would be one of the parameters to monitor for the absorption chiller input tempeature range setting. If the temperature drops below a certain limit, the auxiliary heater can be used as a backup so that the absorption chiler operation can be maintained at any desired comfort level. This would be difficult to achieve using the non-stratified model as it predicts just one temperature for the entire tank. This predicted temperature can be significantly different from the actual input temperature, resulting in inefficeint operation of the absorption chiller.

The storage tank model is the third component of the integrated cooling system model. Stored hot water is to be used at the temperature that is appropriate for the absorption system application described in the previous chapter. Up to this point, the method used to capture the heat required to raise the temperature of the water has not been modeled. The solar collector is the device used to transport the energy from the sun to the water prior to its storage in the tank. The next chapter discusses the solar collector model, which is another component in the integrated cooling system model. 


\section{Chapter 5 Solar Collector Model}

\subsection{Introduction}

A solar collector is a special kind of heat exchanger that transforms solar energy into heat. A solar collector can be used for both heating and cooling purposes depending on the type of application. In the heating mode, solar energy can be captured to be used in multitude of ways. In the case of cooling, energy can be used as the high temperature heat source to run the absorption chillers for air conditioning and refrigeration applications.

For the cooling needs of a medium sized building, a flat plate solar collector is used as a means of collecting energy. This energy will be used by the absorption chiller in the form of hot water for chilled water generation. In the absorption systems, the heat source is used to evaporate the lithium bromide water or ammonia water solution. This system replaces the conventional cooling system where compressor is needed to pressurize the refrigerant into the superheated vapor state. In the absorption cooling cycle, stored solar energy is used to vaporize the refrigerant into the vapor phase. Solar collectors have been widely used in residential and commercial buildings where the size, area, and the type of the collector varies according to the energy needs.

For power plant applications, different types of collectors, such as parabolic trough and concentric, must be used since the flat plate collector operates below $100^{\circ} \mathrm{C}$. The following section discusses the collector configurations and mathematical formulations as part of the integrated model describing the capture of heat from the sun. 


\subsection{Flat Plate Collector}

A flat plate collector, shown in Figure 5.1, is designed for application at moderate temperatures up to $100{ }^{\circ} \mathrm{C}$. They use both beam and diffuse solar radiation and do not require any tracking of the sun.

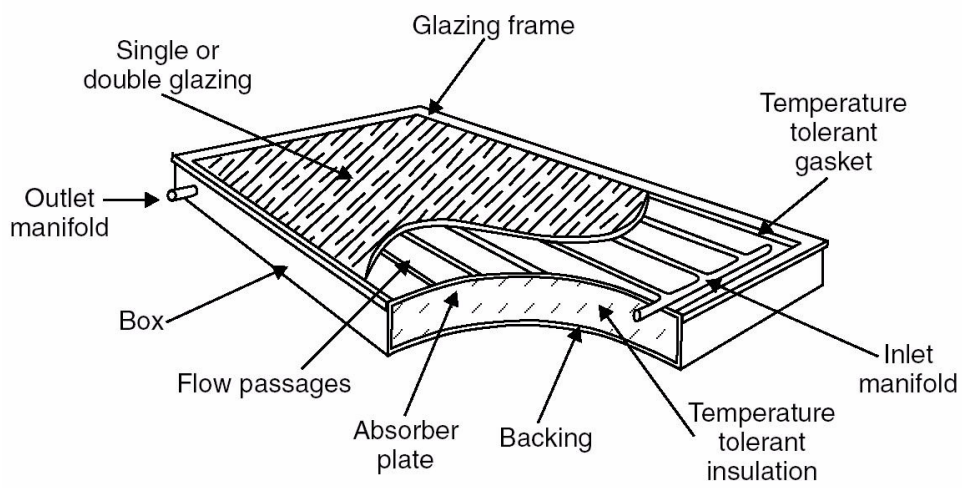

Figure 5.1 Flat Plate Collector

A flat plate collector is always mounted in a stationary position (typically on a roof) and the orientation is set to the best operating position. There is also a portable flat-plate collector that can be oriented in any position. In this situation, the collector can be mechanically adjusted to track the sun path.

A dynamic modeling of the flat plate solar collector is incorporated into the designed model as part of the integrated solar absorption cooling system. The model is then validated with a few experimental results obtained from several literatures to predict its performance under varying weather conditions. 


\subsection{Flat Plate Collector Components}

Figure 5.2 shows the cross section of a basic flat-plate solar collector. It consists of the following items:

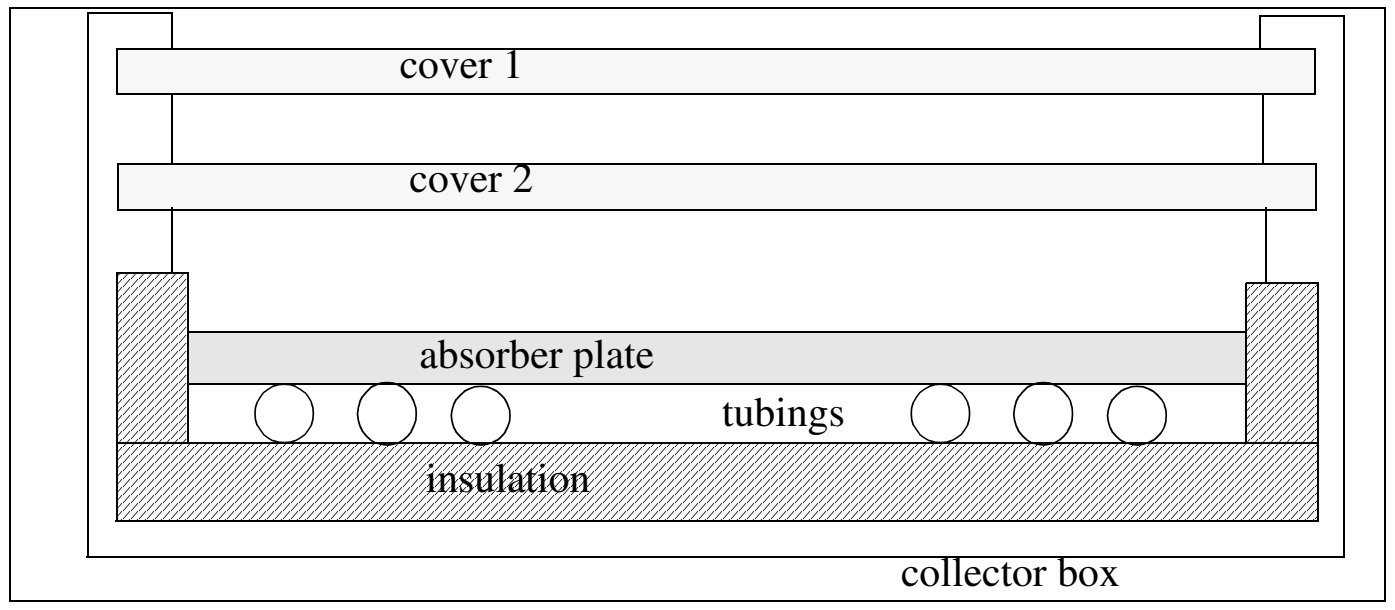

Figure 5.2 Cross Section of a Flat Plate Collector

Absorber Plate

This plate is a treated solar energy absorbing surface. It is used to absorb and transfer the absorbed energy to the fluid. It is located above the tubing through which the fluid flows. The absorber is normally made of a metal with high selective absorptivity.

\section{Tubing}

Liquid in the form of water or an anti-freeze solution is normally circulated through the tubes. The heat transfer process occurs from the hot absorber plate to the fluid circulated in the tubes. 
In certain circumstances, evaporation or condensation will take place between the absorber plate and the tubing. This will contribute to the inefficiency of the solar collector. Thus, a cover made of glass or plastic is designed to reduce that unwanted process. Cover materials also minimize convective and radiative losses back to the surroundings. While most collectors have only one cover, two or more covers may be needed to increase the solar collector efficiency. The air gap between layers helps reduce the heat losses.

\section{Insulation}

Minimizing heat loss through conduction is also important. Therefore, insulation is used on the sides and at the back of the collector assembly.

In the program, the user can modify the geometric parameters, materials, and specify the configuration of the collector for the purpose of investigating the impact of the various solar collector choices on the overall system performance. The program also allows the user to select a working fluid such as water, ethylene glycol/water solution, and propylene glycol/water solution to analyze the effect of the parameters listed on such a system. All of these variables are treated as fixed variables.

The input variables for solar energy are; the intensity of solar radiation, diffuse radiation proportion, collector slope, wind speed, and relative humidity. The program will determine other relevant data and convert them into available solar energy on the collector surface.

The collector dimensions, such as the overall frame dimensions, including the length, width, and thickness, and the absorber plate dimensions (length and width) can be altered. 
The number of covers $(0,1,2)$, cover material, refractive index and transmittance, and absorptance and transmittance, and the cover to plate spacing can also be specified.

\subsection{Solar Collector Methodology}

There are several methods that are documented on solar collector analysis and modelling, and providing means to experimentally evaluate solar collectors. Amer (1998) presented three groups of collector mathematical formulations:

\section{(A) One-Node Method}

Documentation on this method can be found in Arranovitch, 1977; Munroe, 1983; Saunier and Chungpaibulpatana, 1983; Stronskii et al., 1986; Chungpaibulpatana and Excell, 1988, 1990a, 1990b; Perers, 1993, 1997; Souproun, 1992; Muschaweck and Spirk1, 1993;

Bosanac et al., 1994; Spirkl et al., 1997; Zeroul et al., 1994; Wijeysundera et al., 1996; Amer et al., 1998b, 1999.

(B) Multi-node method

Documentations on this method can be found in Wijeysundera and Hawlader, 1984; Kamminga, 1985a, 1985b; Hawlader and Wijeysundera, 1987; Frid, 1990.

(C) Response function method

Documentation on this method can be found in Rogers, 1981; Emery and Rogers, 1984; BS 7657, 1986; Wang et al., 1987.

A comparison of the theoretical aspects of some models is shown in Table 5.1 below. The program developed and presented in this research uses ASHRAE standard procedure with 
some modification to the equations used to simulate the dynamic behavior of the collector. That will be presented in Section 5.5.

Table 5.1: Comparisons of Theoretical Aspects of Models

\begin{tabular}{l|l}
\hline \multicolumn{1}{c|}{ Method } & \multicolumn{1}{c}{ Model Equation } \\
\hline Rogers & $q_{u}(j)=\sum_{n=1}\left[F_{R}(\tau \alpha)_{e}\right] K_{n} I_{T j}(n)-F_{R} U_{L}\left(T_{f i}-T_{A}\right)$ \\
\hline Saunier & $q_{u}^{\infty}=\int_{R} F_{R}(\tau \alpha)_{e} h(t) I_{T j}(\tau-t) d t-F_{R} U_{L}\left(T_{f i}-T_{A}\right)$ \\
\hline Wijeysundera & $C_{t} \frac{d T_{s}}{d t}=F_{R} U_{L}\left[(\tau \alpha)_{e} I_{T}(t)-U_{L}\left(T_{f i}-T_{A}\right)\right]+\left(-(A U)_{t}\left(T_{s}-T_{A}\right)\right)$ \\
\hline QDT & $-(A U)_{i} \varepsilon_{i}\left(T_{s}-T_{A}\right)-(A U)_{o} \varepsilon_{o}\left(T_{f o}-T_{A}\right)$ \\
\hline ASHRAE & $q_{u}=F^{\prime}(\tau \alpha)_{e} I_{T}-F^{\prime} U_{L}\left(T_{f m}-T_{A}\right)-(m c)_{e} \frac{d T_{f m}}{d t}$ \\
& $\eta=\left\{F_{R}(\tau \alpha)_{e}-F_{R}(\tau \alpha)_{e}\left[\frac{T_{f i}-T_{A}}{I_{T}}\right]\right\} A_{p}$ \\
\hline$A_{c}$
\end{tabular}

The ASHRAE formulation uses the ratio of the useful energy gain to the incident solar energy to describe the efficiency of a solar collector. Other approaches describe the solar collector performance in terms of the energy gain. 


\subsection{Flat - Plate Collector Model Equation}

For a basic flat plate collector, the energy balance involving the distribution of incident solar energy can be represented as:

$Q_{u}=A_{c}\left[S-U_{L}\left(T_{p m}-T_{a}\right)\right]$

where;

$Q_{u} \quad=$ useful energy output of a collector

$A_{c} \quad=$ collector area

$T_{p m} \quad=$ mean absorber plate temperature

$T_{a} \quad=$ ambient temperature

$U_{L} \quad=$ heat transfer coefficient

$U_{L}\left(T_{p m}-T_{a}\right)=$ thermal loss component

$S \quad=$ absorber solar radiation

Solar collector efficiency, which is the ratio of the useful energy gain to the incident solar energy, quantifies the collector performance and is expressed as:

$\eta=\frac{\int Q_{u} d t}{A_{c} \int G_{T} d t}$

A collector heat removal factor, $F_{R}$, is introduced to define a quantity that relates the useful energy gain of a collector to the useful gain if the whole collector surface were at the fluid inlet temperature: 
$F_{R}=\frac{\dot{m} C_{p}}{A_{c} U_{L}}\left[1-\exp \left(-\frac{A_{c} U_{L} F}{\dot{m} C_{p}}\right)\right]$

Since the solar collector operates in a transient manner, the steady state formulation can be modified to include this behavior. Solar collector performance is also affected by the behavior of solar radiation and wind change during the day.

The analysis can be formulated as the following equation on the absorber plate, water, and part of the back insulation (Duffie et al., 1991):

$(m C)_{p} \frac{d T_{p}}{d t}=A_{c}\left[S-U_{p-c}\left(T_{p}-T_{c}\right)\right]$

where $U_{p-c}$ is the loss coefficient from the plate to the cover, where the subscripts c and p represent the cover and plate, respectively.

The energy balance for the cover is:

$(m C)_{p} \frac{d T_{c}}{d t}=A_{c}\left[U_{p-c}\left(T_{p}-T_{c}\right)+U_{c-a}\left(T_{a}-T_{c}\right)\right]$

where $U_{c-a}$ is the loss coefficient from the cover to the ambient air, where the subscripts $\mathrm{c}$ and a represent cover and ambient, respectively, and $T_{a}$ is the ambient temperature. For definitions of other parameters refer to the nomenclature section.

Solving these two equations using the simplification that $U_{c-a}\left(T_{c}-T_{a}\right)=U_{p-c}\left(T_{p}-T_{a}\right) \quad$ since the back and edge losses are assumed to be small, yields

$\left[(m C)_{p}+\frac{U_{L}}{U_{c-a}}(m C)_{c}\right] \frac{d T_{p}}{d t}=A_{c}\left[S+U_{L}\left(T_{p}-T_{a}\right)\right]$ 
The term in the square brackets on the left-hand side represents an effective heat capacity of the collector and is written as $(\mathrm{mC})_{\mathrm{e}}$. The effective heat capacity of a collector with $\mathrm{n}$ covers would be

$$
(m C)_{e}=(m C)_{p}+\sum_{i=1}^{n} a_{i}(m C)_{c, i}
$$

where $a_{i}$ is the ratio of the overall loss coefficient to the loss coefficient from the cover.

By assuming that $S$ and $T_{a}$ remain constant for a given time period, the solution to the differential equation above is:

$\frac{S-U_{L}\left(T_{p}-T_{a}\right)}{S-U_{L}\left(T_{p, \text { initial }}-T_{a}\right)}=\exp \left[\frac{A_{c} U_{L} t}{(m C)_{e}}\right]$

The simplification introduced above is significant in that the problem of determining the heat capacity effect has been reduced to solving one differential equation. Wijeysundera (1978) compared this "one-node" approximation against a "two-node" solution with experimental data. He found good agreement for both methods for single-cover collectors. For two- and three-cover collectors however, the predicted fractional temperature rise resulted in less than a $15 \%$ error. (Duffie et al., 1991) 


\subsection{Validation / Sample Calculations}

The performance curve for the developed solar collector model is shown in Figure 5.3 with the given solar collector characteristics described in Table 5.2. The tests results were based on inlet temperatures in the range of $40{ }^{\circ} \mathrm{C}$ to $80^{\circ} \mathrm{C}$.

Table 5.2: Collector Characteristic Parameters

\begin{tabular}{c|c|c|c|c}
\hline $\begin{array}{c}F_{R}(\tau \alpha)_{e} \\
(-)\end{array}$ & $\begin{array}{c}F_{R} U_{L} \\
(-)\end{array}$ & $\begin{array}{c}F^{\prime}(\tau \alpha)_{e} \\
(-)\end{array}$ & $\begin{array}{c}F^{\prime} U_{L} \\
\left(\mathrm{Wm}^{-2} \mathrm{~K}^{-1}\right)\end{array}$ & $\begin{array}{c}(m c)_{e} \\
\left(\mathrm{kJm}^{-2} \mathrm{~K}^{-1}\right)\end{array}$ \\
\hline 0.73 & 3.84 & 0.75 & 3.915 & 12.6 \\
\hline
\end{tabular}

The simulation was performed using the same parameters and test conditions as the experimental setup. The efficiency curve described by Equation (5-2) was plotted to show the simulation results produced by the developed program. It accurately predicts the behavior of the efficiency of the experimental solar collector setup. From these results it can be concluded that the solar collector design method used in the program is suitable to predict the overall system when it is linked with the other components. 

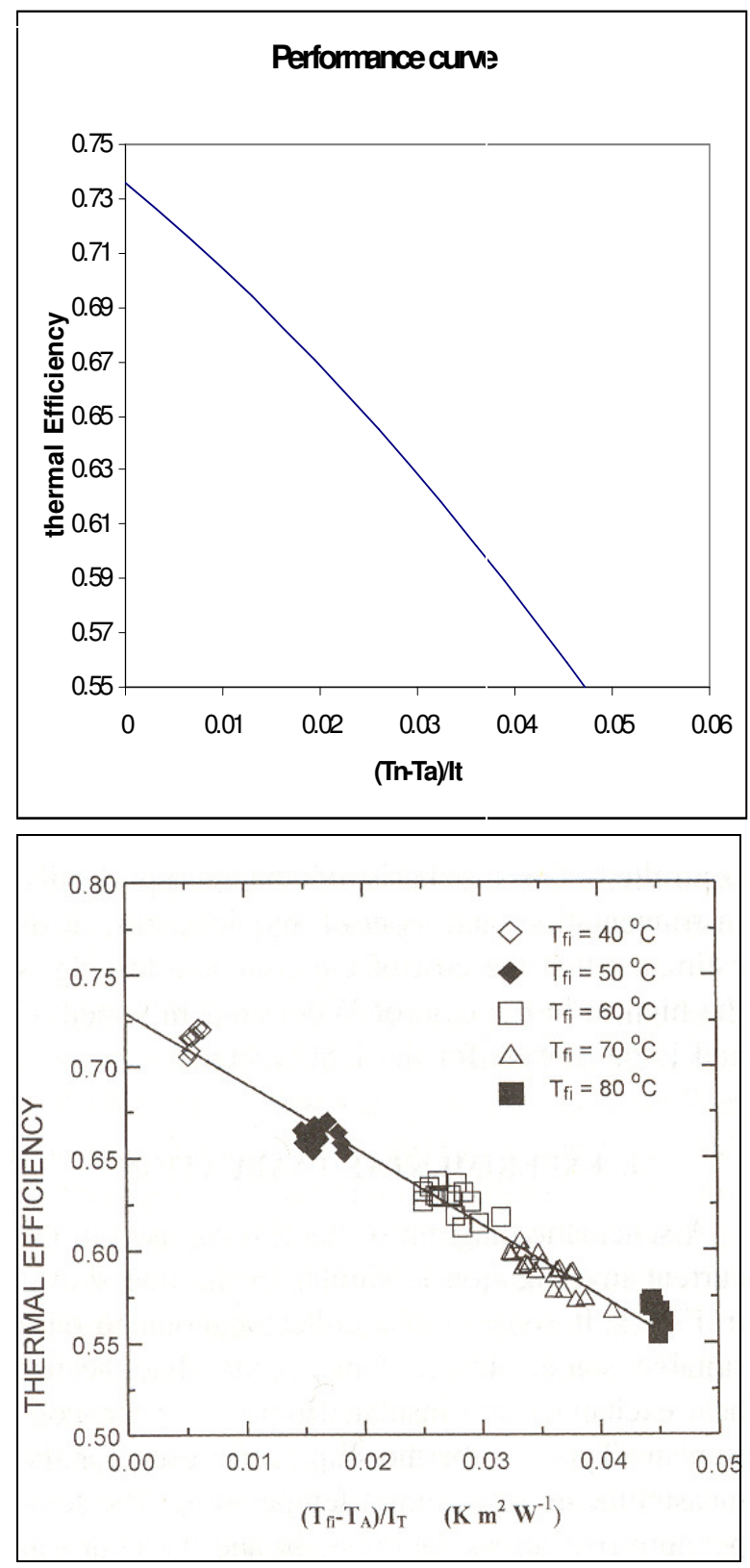

Figure 5.3 Solar Collector Performance Curve, Simulation (top), Experiment (Nayak et. al., 2000) (bottom)

The following chapter discusses the solar load model that was used to predict the climate and the solar radiation at a specific location. This information will lead the designer to correctly model and implement this solar energy application. 


\section{Chapter 6 Solar Load Model}

\subsection{Introduction}

The amount of energy that can be captured through solar means depends on many factors such as weather patterns and building location. An exact assessment of solar power availability is important because it plays a major role both in determining the heat gain of a structure or building and in providing the power necessary to run the absorption cycle. Most of the major cities in the world have solar, weather, and temperature (dry bulb, wet bulb, humidity) records for a period of time, which can be very useful for any designer.

Many devices are being used to directly measure solar radiation. In developing the software, specific methodologies are used in predicting the solar energy with higher accuracy. Simulations on a daily or monthly basis can be made and compared with the actual results obtained from existing test locations. Currently, solar radiations are in the form of an average or maximum set of values, depending on the desired application. The average solar radiation is more applicable in the solar collector or energy calculation. Meanwhile, the maximum solar radiation is best for the load calculations. It is also important to note that solar data derived from such a databank are not suitable for simulations since the data must first be incorporated into the program by the user, or a read file must be generated as part of the data input.

ASHRAE clear sky methodology is used in the program to estimate the hourly solar radiation at a specific location by providing the meteorological data and local variables. The 
method is presented in Section 6.3. The program can also make use of some of the available data such as monthly solar radiation at a specific location. Suehrcke's equation (Suehrcke 2000) and its formulation is also incorporated in the designed model and is presented in Section 6.4.

\subsection{Solar Radiation}

The relative motion of the earth with respect to sun can be readily predicted. The earth is rotating on a 24 hour cycle on its axis relative to the sun and creates several time zones. The four standard zones that are used in the contiguous United States are:

1. Eastern standard time, EST 75 deg

2. Central standard time, CST $90 \mathrm{deg}$

3. Mountain standard time, MST $105 \mathrm{deg}$

4. Pacific standard time, PST $120 \mathrm{deg}$

Some locations also use (seasonal) daylight savings time, which means the clock is advanced one hour during the seasons including late spring, summer, and early fall. This situation must be taken into consideration in the simulation process, otherwise the load calculations will be inaccurate. Typically, civil time is used in our daily life. It is based on the precise 24 hour day. Solar time is more favorable for the simulations since the time is measured by the position of the sun.

The radiation emitted by the sun and its spatial relationship to the earth results in a nearly fixed intensity of solar radiation outside of the atmosphere of the earth. The solar constant, 
$\mathrm{G}_{\mathrm{sc}}$, is the energy from the sun, per unit time, received on a unit area of surface perpendicular to the direction of propagation of the radiation at the mean earth-sun distance outside of the atmosphere (Duffie and Beckman, 1991). A value of $\mathrm{G}_{\mathrm{sc}}$ of $1367 \mathrm{~W} / \mathrm{m}^{2}$ (433 Btu/ $\mathrm{ft}^{2}-\mathrm{hr}$ ) is commonly used in most literature with an uncertainty on the order of $1 \%$ published by the World Radiation Center (WRC). Because of considerable absorption and scattering by the atmosphere, a precise value of the solar constant is not used.

The two important components of the solar radiation are beam radiation and diffuse radiation. Beam radiation is the portion of the radiation received from the sun that reaches the surface of the earth. This is also known as direct solar radiation. It is accompanied by radiation that has been scattered or re-emitted, called diffuse radiation. Diffuse radiation is the portion of the solar radiation received on the surface from all directions surrounding the surface. The sum of these two components on a surface is called total solar radiation.

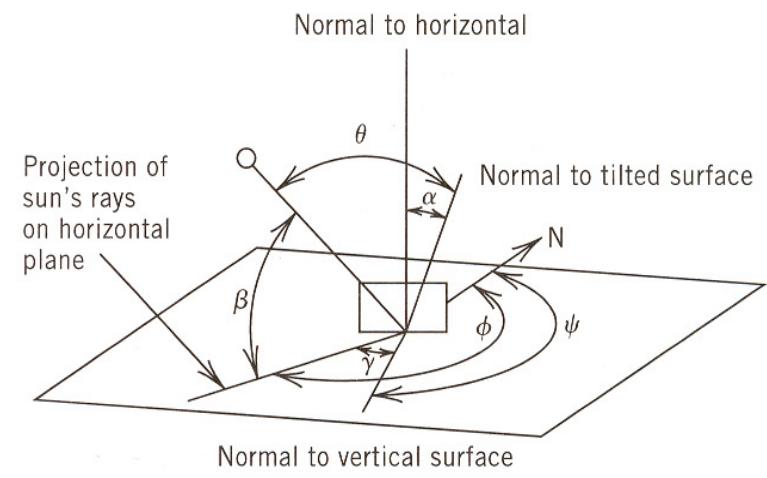

Figure 6.1 Solar Angles with Respect to a Tilted Surface (McQuiston et al., 2000) 
The geometric relationships between a plane of any particular orientation relative to the earth at any time and the in-coming beam solar radiation, that is, the position of the sun relative to that plane, can be described in terms of several angles as shown in Figure 6.1.

\section{Latitude, $l$}

angular location north or south of the equator, north positive.

\section{Declination, $\delta$}

the angular position of the sun at solar noon.

Slope, $\alpha$

the angle between the plane of the surface in question and the horizontal.

\section{Surface azimuth angle, $\gamma$}

the deviation of the projection on a horizontal plane of the normal to the surface from the local meridian, with zero due south, east negative, and west positive.

\section{Hour angle, $h$}

the angular displacement of the sun east or west of the local meridian due to rotation of the earth on its axis at 15 degrees per hour, morning negative, afternoon positive.

Angle of incidence, $\theta$

the angle between the beam radiation on a surface and the normal to that surface.

Zenith angle, $\theta_{z}$

the angle between the vertical and the line to the sun, i.e., the angle of incidence of beam radiation on a horizontal surface. 
Solar altitude angle, $\beta$

the angle between the horizontal and the line to the sun, i.e., the complement of the zenith angle.

Solar azimuth angle, $\phi$

the angular displacement from south of the projection of beam radiation on the horizontal plane. Displacements east of south are negative and west of south are positive.

\subsection{ASHRAE Clear Sky Methodology}

The value of the solar constant was defined for a surface outside the atmosphere of the earth and does not take into account the absorption and scattering of the atmosphere, which can be significant even for clear days. The value for solar irradiation or solar intensity at the surface of the earth on a clear day is given by AHSRAE Clear Sky. The software presented is designed to use the ASHRAE Clear Sky Methodology in predicting the cooling load and solar power available. It is assumed that the maximum amount of solar cooling will be during those periods when the solar insolation is the highest. Solar irradiation for a clear day at the surface is

$I_{D N}=A e^{-B / \sin \beta}$

where

$I_{D N}=$ normal irradiation, $\mathrm{W} / \mathrm{m}^{2}$ or Btu $/\left({\left.\mathrm{hr}-\mathrm{ft}^{2}\right)}^{2}\right.$

$A=$ apparent solar radiation at air mass equal to zero, $\mathrm{W} / \mathrm{m}^{2}$ or Btu/(hr- $\left.\mathrm{ft}^{2}\right)$ 


$$
\begin{aligned}
& B \quad=\text { atmospheric extinction coefficient } \\
& \beta \quad=\text { solar altitude }
\end{aligned}
$$

For direct irradiation on a surface of arbitrary orientation, the estimated atmospheric clearness numbers for that particular location are

$$
I_{D}=C_{N} I_{D N} \cos \theta
$$

where, $\cos \theta=\cos \beta \cos \gamma \sin \alpha+\sin \beta \cos \alpha$

Here

$\beta=$ solar altitude

$\gamma \quad=$ wall azimuth measured east or west from south

$\alpha \quad=$ tilt angle

$C_{N}=$ the percentage as given in Figure 6.2 below. This value will be the input to the program at any desired location for the simulations..

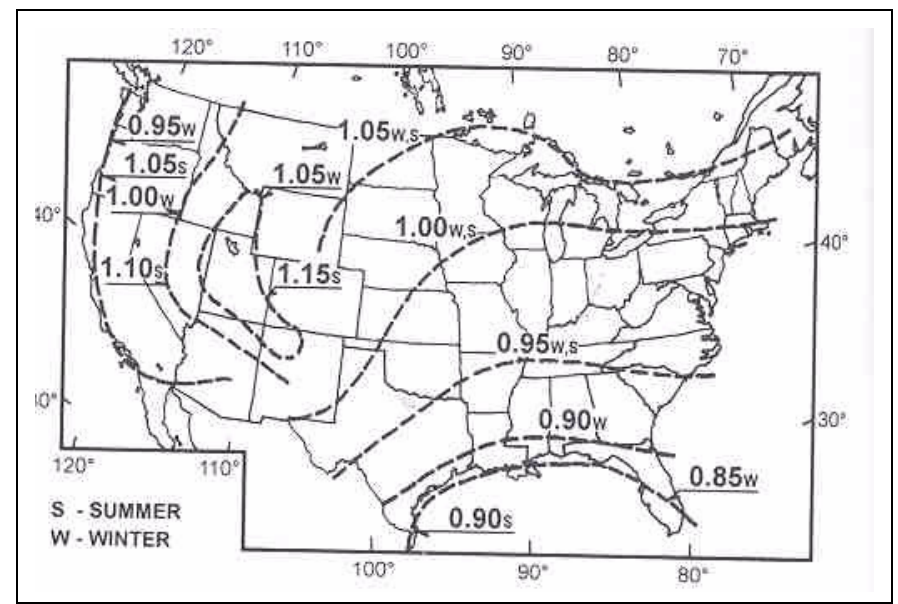

Figure 6.2 Clearness Numbers for the United States (McQuiston et al., 2000) 
For locations outside the United States, the same formulations can be used. The amount of solar radiation is based on the available climate parameters (ASHRAE Transaction, 1997), which are available in an equation format. The diffusion part is the sum of ground and sky components, where these two components can be estimated as follows:

For the ground reflected irradiance,

$$
I_{G R O U N D-d}=I_{D N}(C+\sin \beta) \rho_{g} F_{g}
$$

where

$\rho_{g} \quad=$ ground reflectance

$F_{g}=(1+\cos \Sigma) / 2$

For the sky diffusion,

$$
I_{S K Y-d}=C Y I_{D N}
$$

where

$C=$ ratio of diffuse irradiation on a horizontal surface to direct normal irradiation

$\Sigma=$ tilt angle of the surface from horizontal

Ratio Y of sky diffuse on vertical surface to sky diffuse on horizontal surface is given based on a clear day as:

$Y=0.55+0.437 \cos \theta+0.313(\cos \theta)^{2}$ 


\subsection{Suehrchke's Methodology}

The Angstrom-Prescott relationship (Black et al.,1954) is used to relate radiation to sunshine on a monthly basis as shown in Equation (6-7). This relationship led to Suehrcke's model with the addition of the sunshine fraction, which makes the equation universal and applicable to any location in the world.

$\frac{\bar{H}}{\bar{H}_{o}}=A+B \frac{n}{N}$

where

$\bar{H} \quad=$ monthly average daily radiation on a horizontal surface

$\bar{H}_{o} \quad=$ monthly mean daily horizontal extraterrestrial radiation

$n \quad=$ number of hours of bright sunshine per month

$N \quad=$ total number of daylight hours in the month

$A$ and $B=$ two constants determined empirically

Detailed formulation of Suehrcke's model can be found in Suehrcke (2000). For any given month with a number $n$ of hours of bright sunshine, the sunshine fraction is defined as:

$f_{\text {clear }}=\frac{n}{N}$

where $\mathrm{N}$ is the total number of daylight hours in the month. Suehrcke equates this approximately to: 
$\frac{\bar{H}_{b}}{\bar{H}_{b, \text { clear }}}$

Here $\bar{H}_{b}$ is the monthly average of daily horizontal surface beam radiation and $\bar{H}_{b \text {, clear }}$ is the monthly average of daily clear sky horizontal surface beam radiation.

To relate $\bar{H}_{b}$ to the monthly mean daily horizontal surface radiation $\bar{H}$, Suehrcke uses Page's diffuse fraction relationship (Page, 1961):

$\frac{\bar{H}_{d}}{\bar{H}}=1-c \bar{K}$

where $\bar{H}_{d}$ is the monthly mean daily horizontal surface diffuse radiation, c is a constant, and $\bar{K}$ is the monthly mean daily clearness index, defined as:

$\bar{K}=\frac{\bar{H}}{\bar{H}_{o}}$

with $\bar{H}_{o}$ the monthly mean daily horizontal extraterrestrial radiation. Given that by definition:

$\bar{H}=\bar{H}_{b}+\bar{H}_{d}$

Equations (6-8) to (6-12) lead to:

$\bar{H}_{b}=c \bar{H}_{o} \bar{K}^{2}$

The same relationship holds for $\bar{H}_{b, \text { clear }}$

$\bar{H}_{b, \text { clear }}=c \bar{H}_{o} \bar{K}_{\text {clear }}^{2}$ 
where $\bar{K}_{\text {clear }}$ is the monthly average clear sky clearness index, defined as:

$\bar{K}_{\text {clear }}=\frac{\bar{H}_{\text {clear }}}{\bar{H}_{o}}$

Here $\bar{H}_{\text {clear }}$ is the monthly mean daily horizontal surface clear sky radiation. Combining Equations (6-13) and (6-14) leads to the elimination of the constant $c$ and to Suehrcke's relationship:

$f_{\text {clear }}=\left(\frac{\bar{K}}{\bar{K}_{\text {clear }}}\right)^{2}$

Suehrcke's model is adequate at representing the relationship between monthly clearness index and monthly sunshine fraction. This method uses the monthly average data to calculate solar radiation. The estimation of hourly radiation from daily data can also be made using some transformation. Statistical studies of the time distribution of total radiation on horizontal surfaces through the day, using monthly average data for a number of stations, have led to generalized charts or $r_{t}$, the ratio of hourly total to daily radiation, as a function of day length and the hour in question (Duffie and Beckman, 1991). 


\section{Chapter 7 Integrated Solar Absorption Cooling Building Model}

\subsection{Introduction}

The integrated solar absorption cooling building model is composed of a complete set of components that were discussed in the previous chapters. This integrated model consists of the following designed models

1. Building Structure - walls, roof, windows, doors, internal equipment, furniture, occupants, ventilation

2. Absorption Chiller - single and double effects

3. Storage tank - non-stratified tank, stratified tank

4. Solar Collector - Flat plate collector

5. Solar Load Model

The models were solved simultaneously after each input were specified. A number of simulated models were tested at a specific location as shown by the results displayed in each section. The simulations were conducted using meteorological data or simulation depending on the case study. 


\subsection{Program Interface}

A representation of the program interface is shown in Figure 7.1 below. The software input and output can easily be accessed by clicking and entering at the specific icon. By selecting the "RUN the Program" button, the program will start the simulation and the results will be automatically displayed. Sample results are shown with the case studies discussed in the following section.
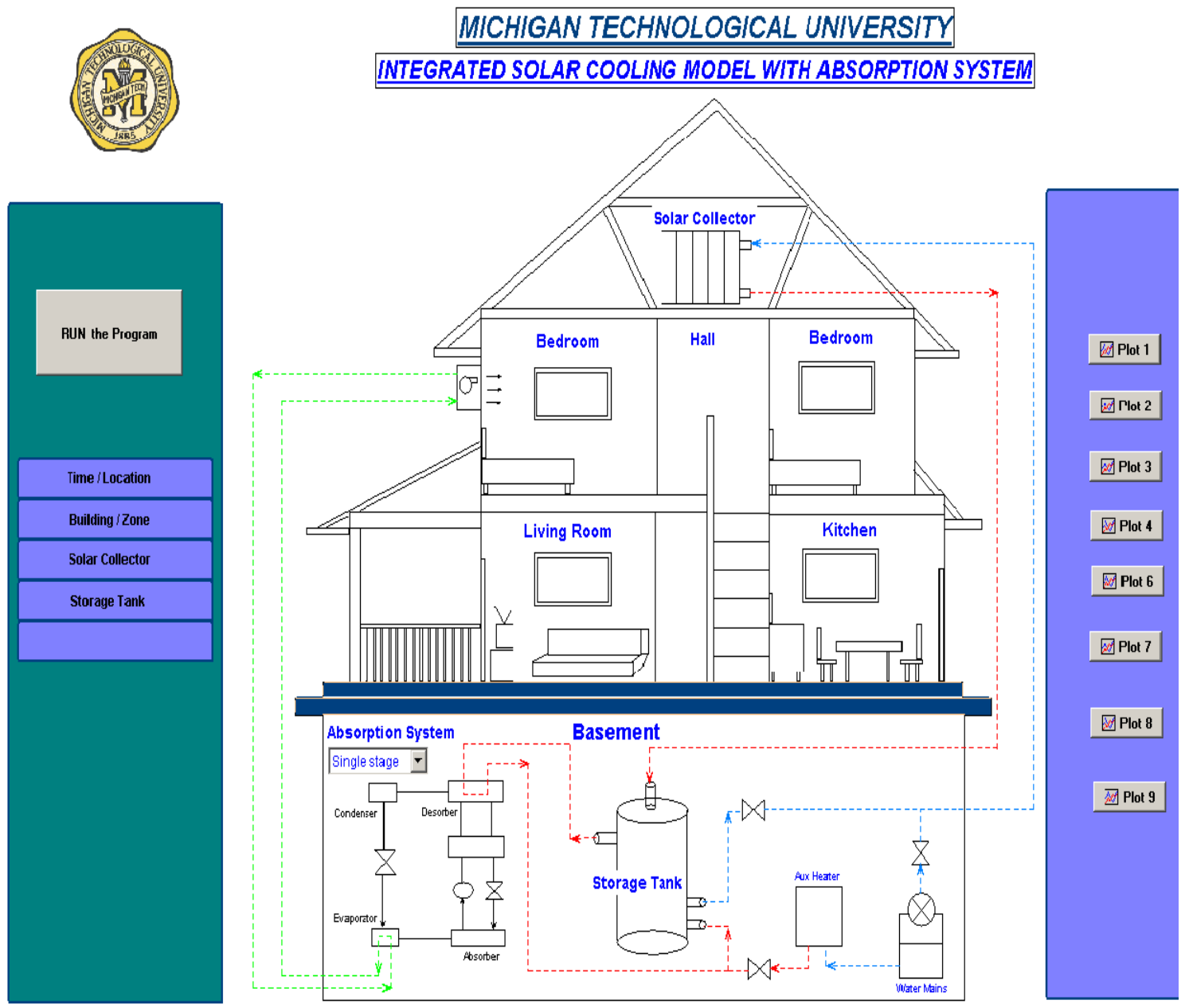

Figure 7.1 Software Interface 


\subsection{Case Studies}

\subsubsection{Case Study 1 - South China}

A comparison was made with experimental data obtained from a building located in South China (Shenzhen), which is at $113.17^{\circ} \mathrm{E}$ longitude and $22.23^{\circ} \mathrm{N}$ latitude. The building has a total room area of $80 \mathrm{~m}^{2}$. The system consisted of the following components:

(A) Flat -Plate collector, $41 \mathrm{~m}^{2}$ area.

(B) One single effect lithium bromide absorption chiller with a cooling capacity of $7 \mathrm{~kW}$.

(C) One double effect lithium bromide absorption chiller with a cooling capacity of $7 \mathrm{~kW}$.

(D) Hot water storage tank of $5 \mathrm{~m}^{3}$.

A simulation was conducted using the integrated program to predict the actual performance of the system in South China. The following graphs were plotted to compare the findings of the above configuration. Figure 7.2 shows the cooling output of the absorption chiller based on the temperature of the hot water supplied to the machine. The absorption cooling capacity graph shows the temperature of the chilled water produced on the horizontal axis based on the supplied hot water temperature for this setup. If the hot water source temperature decreases due to the fluctuating solar energy, the absorption chiller operates at a lower capacity. For example, if the load requirement is $80 \mathrm{~kW}$ and the hot water supplied to the system decreased from $80{ }^{\circ} \mathrm{C}$ to $75^{\circ} \mathrm{C}$, the cooling capacity will then decrease to approximately $75 \mathrm{~kW}$. This will in fact increase the room temperature setting 
if the load requirement is higher than the chiller can supply. Therefore, the auxiliary heater has to be used to raise the heat input to the absorption chiller. This is needed to maintain the desired comfort level, if solar energy alone cannot be used to provide enough hot water to the system.
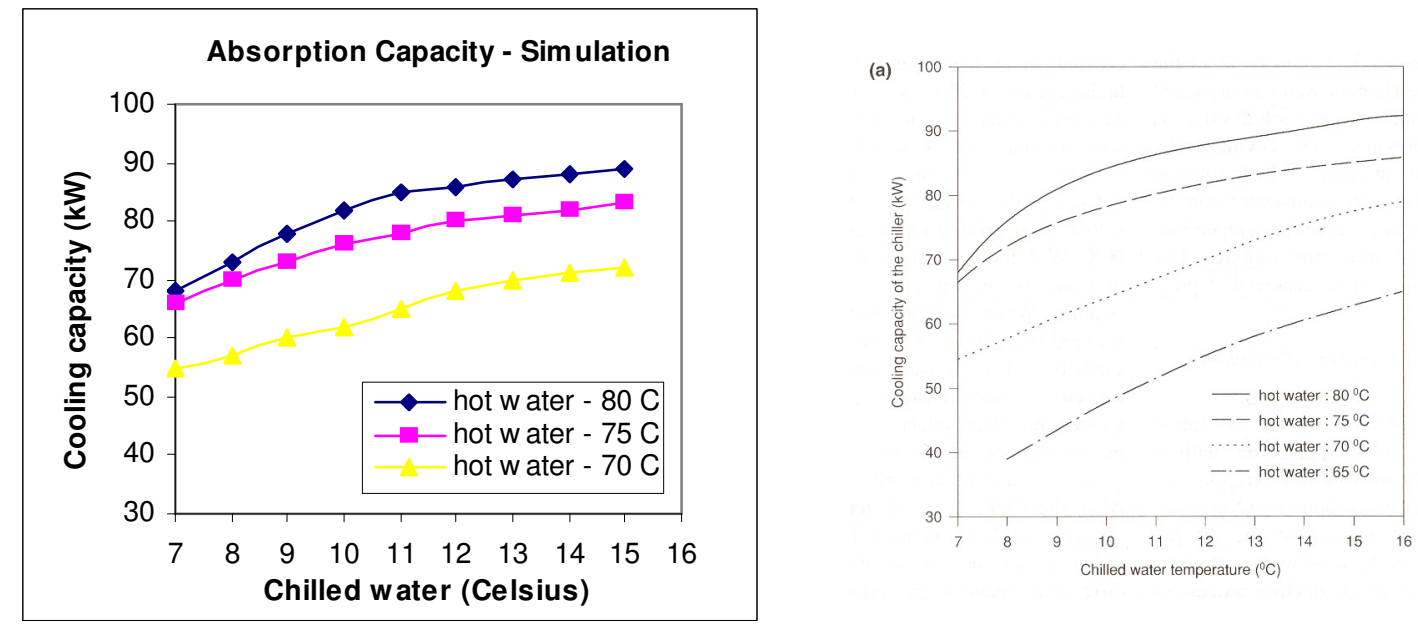

Figure 7.2 Cooling Capacity of the Double Effect Absorption Chiller. Simulation (left), Actual Performance (He, J. et. al., 2001) (right) 


\subsubsection{Case Study 2- Japan (HARBEMAN House)}

The HARBEMAN house simulation was conducted to predict the cooling load behavior in a selected room for a particular month. Figure 7.3 shows a diagram of the house, which is of moderate size, that was used for this case study. The house specifications describing the solar collector, storage tank, and room configurations are given in Table 7.1 .

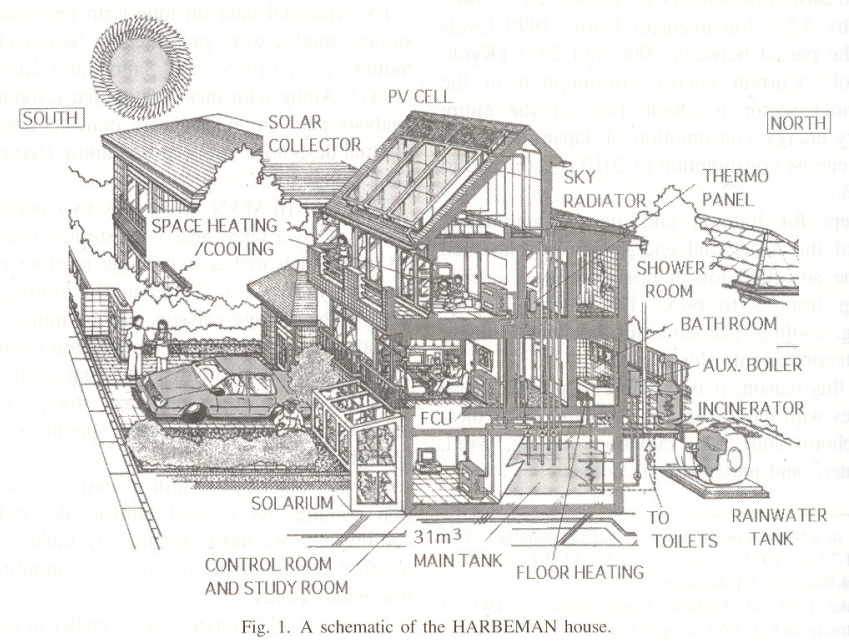

Figure 7.3 HARBEMAN House

Table 7.1: HARBEMAN House Specifications

\begin{tabular}{l|l|l}
\hline Location & Latitude & $38^{\circ} 17^{\prime} 00 \mathrm{~N}$ \\
\hline & Longitude & $140^{\circ} 50^{\prime} 14^{\prime \prime} \mathrm{E}$ \\
\hline Solar Collector & Area & $30.4 \mathrm{~m}^{2}$ \\
\hline & Tilt angle & $45^{\circ}$ (due south) \\
\hline & Azimuth angle & $20^{\circ} \mathrm{E}$ \\
\hline Storage tank & Type & Liquid \\
\hline Total floor area & Capacity & $31 \mathrm{~m}^{3}(7 \mathrm{~m}$ X 2.1 m X 2.1 m) \\
\hline Windows & Dimension & $260 \mathrm{~m}^{2}$ \\
\hline & Glazing & Pair-pane glass \\
\hline & $\begin{array}{l}\text { Overall heat transfer } \\
\text { coefficient (U-value) }\end{array}$ & $0.78 \mathrm{~W} / \mathrm{m}^{2} \mathrm{~K}$ \\
\hline
\end{tabular}


Figure 7.4 shows the comparison between the simulation and the actual data using hourly data in August. The parameters involved are the solar radiation, the inlet temperature to the solar collector and the outlet temperature from solar collector during that month. The parameters predicted by the developed program are in good agreement with the experimental data. Solar radiation is calculated to be a maximum of $900 \mathrm{~W} / \mathrm{m}^{2}$ at hour 11 , which is close to the actual data of $910 \mathrm{~W} / \mathrm{m}^{2}$ at hour 1

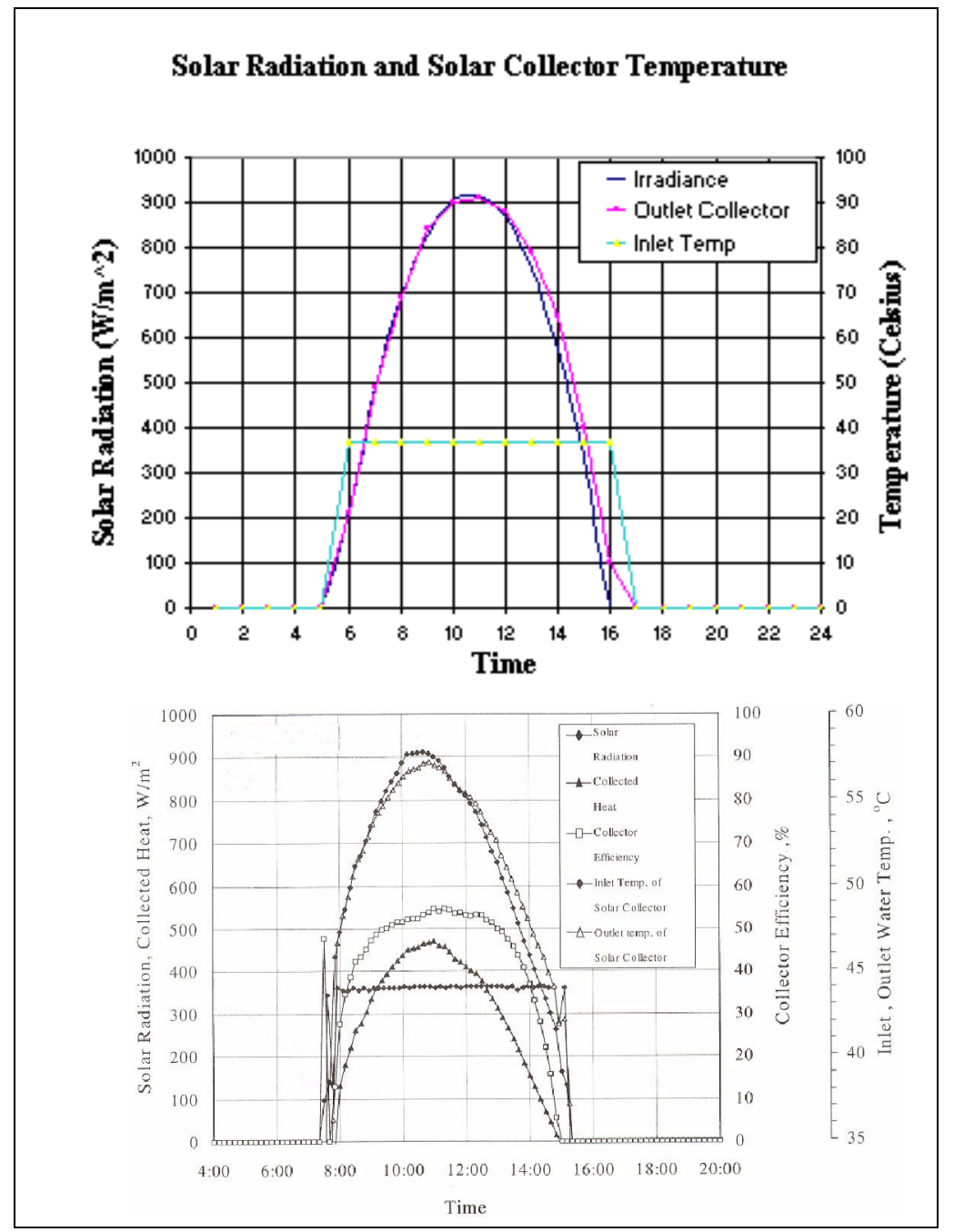

Figure 7.4 Solar Radiation and Solar Collector Outlet Temperature Comparisons; Simulation (top), HABERMAN house data (Saitoh et. al., 2001) (bottom) 

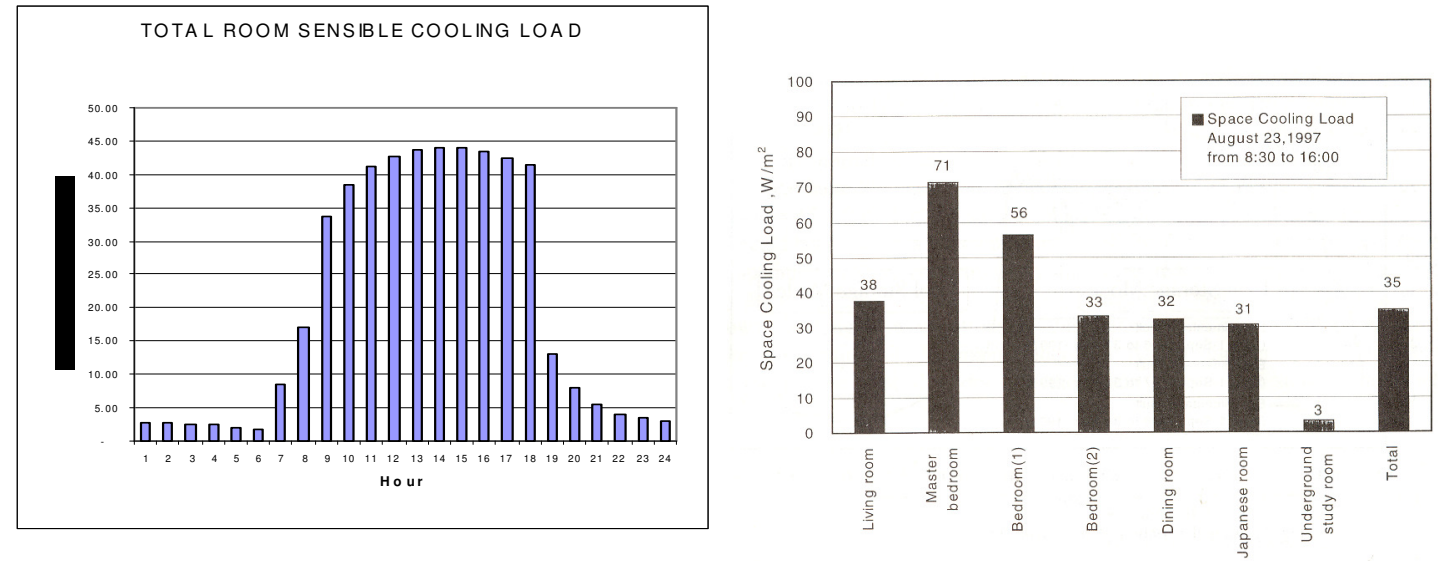

Figure 7.5 Comparison of a cooling load in an average selected room (left) simulation (right) HARBEMAN house.

The structure of an average room was constructed using the developed program, and a prediction of the cooling load was obtained. These results were compared to a selected room from the HARBEMAN house specifications, and the comparison is shown in Figure 7.5. A 24-hour cooling load profile was constructed to compare the predicted cooling load with the space cooling obtained experimentally in that room, which is given on the basis of the space cooling load per square meter per hour for each room. This is shown on the right side of Figure 7.5. The program simulation predicts that the hourly cooling load peaks at approximately $40 \mathrm{~W} / \mathrm{m}^{2}$, which is consistent with the solar radiation obtained values shown in Figure 7.4. The cooling load was modest in the morning since the outside temperature is still low. It should be noted that the integrated model can be used with confidence to predict the cooling load needed for the HARBEMAN house even though it was not designed to be used with an absorption chiller. This case study was conducted to illustrate the validity of using the integrated model to predict the cooling load profile for a selected room within any given structure. 


\subsubsection{Case Study 3 - United States: Albuquerque (Mild/Dry), Madison}

(Cold/Damp), and Miami (Hot/Humid)

This case study was performed to show the cooling load requirements in selected locations and to further analyze the hourly cooling load profile for the month of July. A simulation of the 24-hour cooling load profile is summarized in Table 7.2 for three locations: Albuquerque (New Mexico), Madison (Wisconsin), and Miami (Florida). A comparison with

the 1-year cooling load simulation produced by Burch et al. (2004) is also presented in Figure 7.6. The results obtained by Burch et al. (2004) are carefully studied with the same collector area and storage tank capacity in order to approximate the cooling load requirements using the solar energy portion.

Table 7.2: Simulation Results Using Program Developed

\begin{tabular}{l|c|c}
\hline $\begin{array}{c}\text { Collector Area } \\
=23 \mathrm{~m}^{2}\end{array}$ & $\begin{array}{c}\text { Maximum } \\
\text { Cooling Load } \\
(\mathrm{Btu} / \mathrm{hr})\end{array}$ & $\begin{array}{c}\text { Average } \\
\text { Cooling Load } \\
(\mathrm{Btu} / \mathrm{hr})\end{array}$ \\
\hline Albuquerque & 158 & 90 \\
\hline Madison & 70 & 13 \\
\hline Miami & 151 & 125 \\
\hline
\end{tabular}

Burch et al. (2004) simulation focussed on the unglazed collector system for domestic water and space heating and cooling. However, this research predicts only the cooling load requirements portions. The load profile in Albuquerque is predicted to be approximately 2.1 GJ of the solar cooling load accumulated in 24 hours for this month. Burch et al. (2004) predicts that the solar cooling load for this month to be approximately $2.2 \mathrm{GJ}$ as 
plotted under "CLG Solar" category. This minor error shows that the developed program is capable of predicting various cooling load requirements at any locations.

The space cooling using solar energy is much more critical for Miami as compared to Madison since the cooling load is higher and approximately at the same rate over 24 hours. This is due to the hot and humid climate in Miami compared to the other two cities, where the air-conditioning unit has to be turned on all the time in order to reach a comfort level. Therefore, a higher capacity from the solar collector and storage tanks are needed to overcome the cooling load needs. Otherwise, the auxiliary unit from non-solar equipment has to be used as a back up system.

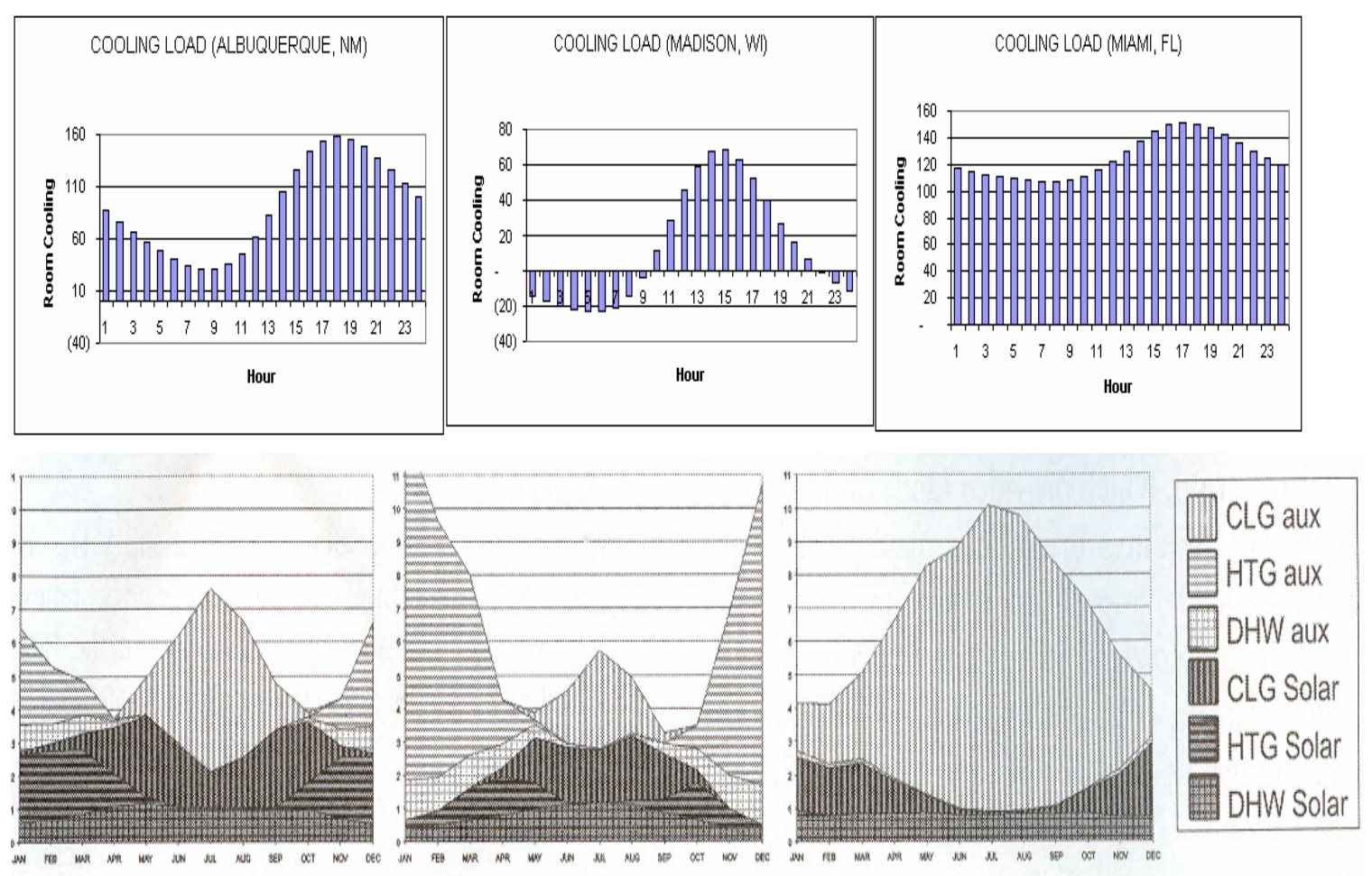

Figure 7.6 1- Day Cooling Load Simulation by Developed Program (top) vs. 1-Year Cooling Load Simulation by Burch et al. (2004) (bottom) Note: Comparison shown above for the July/summer month only. 


\section{Chapter 8 Conclusions and Recommendations}

\subsection{Conclusions}

The "Integrated Solar Absorption Cooling Model" software has been developed as a design tool that can simulate a building in a selected location and predict cooling load and design parameters. One of the goals of this software is to optimize the design components and to set a standard construction based on the designer's preferences. Furthermore, it is anticipated that it will aid the design engineer in understanding of the physical system and to enable advancement of capabilities in the system development.

The software is capable of computing and predicting the following design characteristics under dynamic operation.

1. Heat Load (solar, sensible, latent, conductive, convective, radiative)

2. Absorption Chiller Performance (sizing the desorber, absorber, condenser, evaporator)

3. Storage Tank Configuration (non-stratified, stratified model)

4. Solar Collector (flat plate)

5. Solar Load (solar energy availability) 
Based on the methodology and simulation results obtained in this research, the following conclusions could be made:

1. The program has the ability to calculate separate cooling loads for different rooms in the same building using multiple thermostat controllers.

2. Simulation of the absorption system, which is used as the cooling machines, has been optimized to suit the best design for integration with the building structure and the solar load availability.

3. The parametric studies clearly demonstrate that the computer simulation model is a useful tool for optimizing the system performance, which was traditionally done through a costly and time consuming experimental approach. The results also show that solar energy and the appropriate solar collector configuration could effectively replace the heating of absorption systems through conventional means.

4. Parametric studies also demonstrate that solar integrated absorption cooling systems are more capable in overall cost, maintenance and performance compared to conventional cooling devices. 


\subsection{Recommendations}

1. Since the response factors behave in a predictable fashion, the simulations can be expanded and plotted in a specific graphical format. Therefore future research should obtain every possible case of the cooling load of buildings. This will then serve as a "psychrometric-like" chart which the user is able to quickly use for the desired building configuration to determine the few options needed to approximate the cooling load.

2. An investigation of a passive design building, which is another feasible application for solar cooling, should be conducted. The material selection and configuration will play a role in the dampening effect of a building envelope. A more thorough study will have to be performed by incorporating the appropriate air circulation to cool the building without including cooling machines.

3. With higher computing power, construction of a 3-D CFD model should be considered to obtain a detailed study of the fluid and air behavior in a real absorption chiller and a building envelope. This will lead to a better design of complex absorption cooling systems in buildings. An improved Radiant Time Series (RTS) methodology to predict the cooling load with any given structure is achievable with a better design of the complex absorption chiller and building configurations.

4. A 3-D CFD model may also be a good approach for studying the fluid behavior inside a storage tank. Even though it was stressed that a 2-D CFD model is comparable to the stratified tank or the multi-node analysis, it may be useful to investigate other effects. 
Effects such as the internal behavior of the fluid may aid in further refinement of the energy storage system and could accomplished using a 3D model.

5. Since real solar data is available for major locations worldwide (http://www.nrel.gov), it may be preferable to have this information in the raw form of an input file such as wet bulb, dry bulb, etc. This will minimize the time needed to download weather data and run the code. Thus, the information required does not have to be "back calculated" with the simulation results obtained from specific data such as latitude, longitude, etc.

6. It will be very desirable to upgrade this software to include cost and cash flow analyses and to perform reliable cost basis comparisons with conventional gas compression systems, as well as powering the absorption cycle with conventional means such as the natural gas. 


\section{References}

1. Abu-Handeh, N.H. (2003) Simulation Study of Solar Air Heater. Solar Energy 74, 309317.

2. Amer, E.H. (1998) Development of Dynamic Test Procedures for Solar Flat-Plate Collectors. Ph.D. Thesis, IIT Bombay.

3. Amer, E.H., Nayak, J.K. and Sharma, G.K. (1998b) A Transient Method for Testing of Flat-Plate Solar Collectors. Energy Conversion and Management 40, 1-9.

4. Amer, E.H., Nayak, J.K. and Sharma, G.K. (1999) A New Dynamic Method for Testing Solar Flat-Plate Collectors Under Variable Weather. Energy Conversion and Management 40, 807-823.

5. Arranovitch, E. (1977) The Joint Solar Collector Testing Programme of the European Community. In Proceedings of UK/ISES Conference C11, Testing of Solar Collectors and Systems, pp. 49-70.

6. ASHRAE (1967). ASHRAE Handbook of Fundamentals. ATLANTA, GA: American Society of Heating, Refrigerating and Air-Conditioning Engineers, Inc.

7. ASHRAE (1972). ASHRAE Handbook of Fundamentals. ATLANTA, GA: American Society of Heating, Refrigerating and Air-Conditioning Engineers, Inc.

8. ASHRAE (1985). ASHRAE Handbook of Fundamentals. ATLANTA, GA: American Society of Heating, Refrigerating and Air-Conditioning Engineers, Inc. 
9. ASHRAE (1997). ASHRAE Handbook of Fundamentals. ATLANTA, GA: American Society of Heating, Refrigerating and Air-Conditioning Engineers, Inc.

10. ASHRAE (2001). ASHRAE Handbook of Fundamentals. ATLANTA, GA: American Society of Heating, Refrigerating and Air-Conditioning Engineers, Inc.

11. Bokhoven, T. P., Van Dam, J., and Kratz, P. (2001) Recent Experience with large solar thermal systems in the Netherlands. Solar Energy 71, 347-352.

12. Bosanac M., Brunotte A., Spirkl W. and Sizmann R. (1994) The Use of Parameter Identification for Flat-Plate Collector Testing Under Non-Stationary Conditions. Renewable Energy 4, 217-222.

13. BS 6757 (1986) British Standard Methods of Test for Thermal Performance of Solar Collectors, British Standard Institution, London.

14. Burch, J., Christensen, C., Salasovich, J., and Thornton, J. (2004) Simulation of an Unglazed Collector System for Domestic Hot Water and Space Heating and Cooling. Solar Energy 77, 399-406.

15. Chungpaibulpatana, S. and Exell R.H.B. (1988) The Effect of Using A One Node Heat Capacitance Model for Determining Solar Collector Performance Parameters by Transient Test Methods. Solar and Wind Technology 5, 411-421.

16. Chungpaibulpatana, S. and Exell R.H.B. (1990a) Transient Method for Testing FlatPlate Solar Collectors. In Proceedings of Energy and the Environment into the 1990s, Vol 2, Sayigh A.A.M. (Ed), pp. 699-703, Pergamon Press, New York. 
17. Chungpaibulpatana, S. and Exell R.H.B. (1990b) A Transient Method to Determine the Performance of Solar Collectors with Very Large Fluid Heat Capacities. Int. J. Ambient Energy 11, 83-98.

18. Consul, R., Rodriguez, I., Perez-Segarra, C. D. and Soria, M. (2004) Virtual prototyping of storage tanks by means of three-dimensional CFD and heat transfer numerical simulations. Solar Energy 77, 180-191.

19. Duffie J. A., and Beckman W. A. (1991). Solar Engineering of Thermal Processes. John Wiley, New York.

20. Eisenmann, W., Vajen, K., and Ackermann, H. (2004) On the Correlations Between Collector Efficiency Factor and Material Content of Parallel Flow Flat-Plate Solar Collectors. Solar Energy 76, 381-387.

21. Emery, M. and Rogers, B.A. (1984) On a Solar Collector Thermal Performance Test Method for Use in Variable Conditions. Solar Energy 33, 117-123.

22. Fischer, D.E. and Pedersen, C.O. (1997). Convective Heat Transfer in Building Energy and Thermal Load Calculations, ASHRAE transactions, 103 (2), pp. 137-148.

23. Frid, S.E. (1990) Multinode Models and Dynamic Testing Methods of Solar Collectors. Solar Wind Technol. 7, 655-661.

24. Furbo, F., Andersen, E., Knudsen, S., Vejen, N.K., and Shah, L.J. (2005) Smart Solar Tanks for Small Solar Domestic Hot Water Systems. Solar Energy 78, 269-279.

25. Grossman, G. (2002) Solar-Powered Systems for Cooling, Dehumidification and AirConditioning. Solar Energy 72, 53-62. 
26. Hawlader, M.N.A. and Wijeysundera, N.E. (1987) Solar Collector Testin. Renew. Energy Rev. J. 9, 11-28.

27. He, J., Okumura, A., Hoyano, A., and Asano, K. (2001) A Solar Cooling Project for Hot and Humid Climates. Solar Energy 71, 135-145.

28. Herold, K. E., Radermacer, R., and Klein, S. A. (1996) Absorption Chillers and Heat Pumps; New York: CRC Press Inc.

29. Hittle, D. C. (1979) Calculating building heating and cooling loads using the frequency response of multi layered slabs. Ph.D. Thesis. University of Illinois at UrbanaChampaign.

30. Igawa, N., Koga, Y., Matsuzawa, T. and Nakamura, H. (2004) Models of sky radiance distribution and sky luminance distribution. Solar Energy 77, 138-157.

31. Incropera, F.P. and DeWitt, D.P. (1996). Introduction to Heat Transfer, 3rd ed. Wiley, New York, NY.

32. Iu, I.S., Fischer, D.E., Chantrasrisalai, and Eldridge, D. Experimental Validation of Design Cooling Load Procedures: The Radiant Time Series Method. ASHRAE Transactions, Vol. 109, No 2, 2003.

33. Kamminga, W. (1985a) The Approximate Temperatures Within A Flat-Plate Solar Collector Under Transient Conditions. Int. J. Heat Mass Transfer 28, 433-440.

34. Kamminga, W. (1985b) Experiences of a Solar Collector Test Method Using Fourier Transfer Functions. Int. J. Heat Mass Transfer 28, 393-1404. 
35. Knudsen, S. (2002) Consumers' influence on the thermal performance of small SDHW systems -Theoretical investigations. Solar Energy 73, 33-42.

36. Li Z. F., and Sumathy K. (2001) Experimental studies on a solar powered air conditioning system with partitioned hot water storage tank. Solar Energy 71, 285-297.

37. Loudon, A.G. (1968). Summertime Temperatures in Buildings without Air Conditioning. Building Research Station, Current Paper 47/48.

37. Mather, D. W., Hollands, G. T., and Wright, J. L. (2002) Single and multi-tank energy storage for solar heating systems: Fundamentals. Solar Energy 73, 3-13.

38. McQuiston, F.C., and Spitler, J.D. (1992) Cooling and Heating Load Calculation Manual, 2nd Edition. Atlanta: ASHRAE.

40. McQuiston, F.C., Parker, J.D., and Spitler, J.D. (2000) Heating, Ventilating, And Air Conditioning. Analysis and Design. Wiley, 5th ed. New York: John Wiley \& Sons, Inc.

41. Mitalas, G.P., and Stephenson, D.G. (1967) Room Thermal Response Factors. ASHRAE Transactions 73(1): 2.1-2.10.

42. Munroe, M.M. (1983) Transient Tests for Flat-Plate Solar Collectors. In Proceedings of ISES Solar World Congress, Szokolay S.V. (Ed.), pp. 879-883, Pergamon Press, New York.

43. Muschaweck J. and Spirkl W. (1993) Dynamic solar collector performance testing. Solar Energy Materials and Solar Cells 30, 95-105. 
44. Nayak, J.K, and Amer, E.H. (2000) Experimental and Theoretical Evaluation of Dynamic Tesk Procedures for Solar Flat-Plate Collectors. Solar Energy 69, 377-401.

45. Pedersen, C.O., Fischer D.E. and R.J. Liesen (1997). Development of a heat balance procedure for calculating cooling loads. ASHRAE transactions 103 (2): 459-468.

46. Pedersen, C.O. (2001). Building loads calculation toolkit. Atlanta, GA: American Society of Heating, Refrigerating and Air-Conditioning Engineers, Inc.

47. Perers B. (1993) Dynamic method for solar collector array testing and evaluation with standard database and simulation programs. Solar Energy 50, 517-526.

48. Perers B. (1997) An improved dynamic solar collector test method for determination of non-linear optical and thermal characteristics with multiple regression. Solar Energy 59, $163-178$.

49. Rogers B. A. (1981) A Method of Collector Testing Under Transient Conditions. In Proceedings of ISES Solar World Forum, August, Brighton UK, Vol. 1, Hall D. O. and Morton J. (Eds.), pp. 898-902, Pergamon Press, New York.

50. Saitoh, T.S., and Fujino, T. (2001) Advanced Energy-Efficient House (HARBEMAN HOUSE) with Solar Thermal, Photovoltaic, and Sky Radiation Energies (Experimental Results). Solar Energy 70, 63-77.

51. Saunier G.Y. and Chungpaibulpatana, S. (1983) A New Inexpensive Dynamic Method of Testing to Determine Solar Thermal Performance. In Proceedings ISES Solar World Congress, Australia, Vol. 2, Szokolay S. V. (Ed.), pp. 910-916, Pergamon Press, New York. 
52. Schinner, E.N.Jr., and Radermacher, R. (1999) Performance Analysis of a Combined Desiccant/Absorption Air-Conditioning System. International Journal of Heating, Ventilating, Air-Conditioning and Refrigerating Research, 5(1), pp. 77-84.

53. Souproun, A.V. (1992) Dynamic method of solar collector testing. Trans. ASME: J. Solar Energy Eng. 2, 1149-1154.

54. Spirkl, W., Muschaweck J., Kronthaler P., Scholkopf W. and Spehr J. (1997) In Situ Characterization of SOlar Flat-Plate Collectors Under Intermittent Operation. Solar Energy 61, 147-152.

55. Spitler, J.D., Fisher, D.E., and Pedersen, C.O. (1997) The Radiant Time Series Cooling Load Calculation Procedure. ASHRAE Transactions 103(2): 503-515.

56. Spitler, J.D., and Fisher, D.E. (1999) On The Relationship between the Radiant Time Series and Transfer Function Methods for Design Cooling Load Calculations. International Journal of Heating, Ventilating, Air-Conditioning and Refrigerating Research, $5(2), 125-138$.

57. Spitler, J.D., and Fischer, D.E. (2000). Development of periodic response factors for use with the radiant time series method. ASHRAE Transactions.

58. Stephensen, D.G. and Mitalas, G.P. (1971) Calculation of Heat Transfer Functions for Multi-Layer Slabs. ASHRAE Transactions 77(2): 117-126.

59. Stronskii L.N., Shevchenko V.N. and Souproun A.V. (1996) Experimental Investigation of the Thermal Characteristics of a Solar Water Heater by a Dynamic Method. Appl. Solar Energy 22, 54-57. 
60. Vliet, G.C., Lawson, M.B., Lithgow, R.A. (1982) Water-Lithium Bromide DoubleEffect Absorption Cooling Cycle Analysis. ASHRAE Transactions 88(1): 811-823.

61. Wijeysundera, N.E., Hawlader, M.N.A. (1984) Indoor Transient Tests on Solar Collectors. In Proceedings of ENERGEX 84, Regina, Canada, May 14-19, pp. 181-185.

62. Wang, X.A., Xu, Y.F. and Meng, X.Y. (1987) A Filter Method for Transient Testing of Collector Performance. Solar Energy 38, 125-134.

63. Wijeysundera, N.E., Hawlader, M.N.A. and Foong K.Y. (1996) Estimation of Collector Performance Parameters from Daily System Tests. Trans. ASME.: J. Solar Energy Eng. 118, 30-36.

64. Zachar, A., Farkas, I. and Szlivka, F. (2003) Numerical analyses of the impact of plates for thermal stratification inside a storage tank with upper and lower inlet flows. Solar Energy 74, 287-302.

65. Zeroual A., Agouriane E. L., Ankrim M. and Wilkinson A. J. (1994) A New Method for Testing the Performance of Flat-Plate Solar Collectors. Renewable Energy 4, 825832. 


\section{Appendix A}

\section{(Building Cooling Model)}

\section{A.1 Wall Conduction Time Series - PART I}

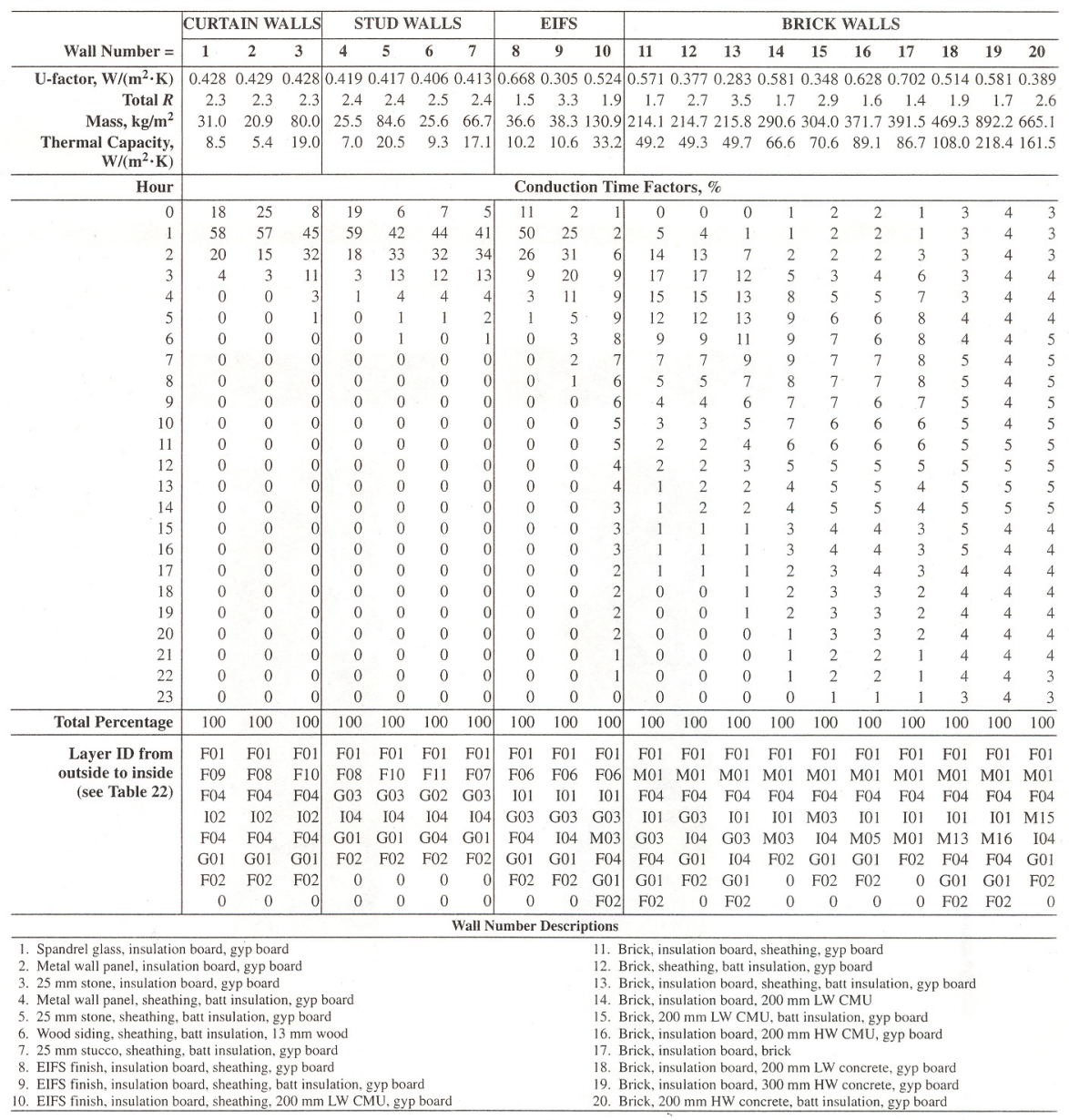

Table A.1 2001 ASHRAE Handbook - Fundamentals 


\section{A.2 Wall Conduction Time Series - PART II}

\begin{tabular}{|c|c|c|c|c|c|c|c|c|c|c|c|c|c|c|c|}
\hline \multirow[b]{2}{*}{ Wall Number $=$} & \multicolumn{6}{|c|}{ CONCRETE BLOCK WALL } & \multicolumn{9}{|c|}{ PRECAST AND CAST-IN-PLACE CONCRETE WALLS } \\
\hline & 21 & 22 & 23 & 24 & 25 & 26 & 27 & 28 & 29 & 30 & 31 & 32 & 33 & 34 & 35 \\
\hline U-factor, $\mathrm{W} /\left(\mathrm{m}^{2} \cdot \mathrm{K}\right)$ & 0.383 & 0.335 & 0.414 & 1.056 & 0.834 & 0.689 & 0.673 & 0.418 & 0.434 & 0.650 & 0.387 & 0.467 & 0.434 & 0.266 & 3.122 \\
\hline Total $R$ & 2.6 & 3.0 & 2.4 & 0.9 & 1.2 & 1.5 & 1.5 & 2.4 & 2.3 & 1.5 & 2.6 & 2.1 & 2.3 & 3.8 & 0.3 \\
\hline Mass, $\mathrm{kg} / \mathrm{m}^{2}$ & 108.8 & 108.8 & 224.3 & 94.3 & 107.1 & 168.9 & 143.9 & 144.6 & 262.5 & 291.8 & 274.7 & 488.1 & 469.9 & 698.9 & 683.2 \\
\hline $\begin{array}{r}\text { Thermal Capacity, } \\
W /\left(\mathrm{m}^{2} \cdot \mathrm{K}\right) \\
\end{array}$ & 27.4 & 27.4 & 57.0 & 23.1 & 26.9 & 42.0 & 34.5 & 34.6 & 61.3 & 68.9 & 64.9 & 122.7 & 118.3 & 175.7 & 171.0 \\
\hline Hour & \multicolumn{15}{|c|}{ Conduction Time Factors, \% } \\
\hline 0 & 0 & 1 & 0 & 1 & 1 & 0 & 1 & 2 & 1 & 3 & 1 & 2 & 1 & 0 & 1 \\
\hline 1 & 2 & 11 & 3 & 1 & 10 & 8 & 1 & 2 & 2 & 3 & 2 & 2 & 2 & 2 & 11 \\
\hline 2 & 8 & 21 & 12 & 2 & 20 & 18 & 3 & 3 & 3 & 4 & 5 & 3 & 4 & 8 & 21 \\
\hline 3 & 12 & 20 & 16 & 5 & 18 & 18 & 6 & 5 & 6 & 5 & 8 & 3 & 7 & 12 & 20 \\
\hline 4 & 12 & 15 & 15 & 7 & 14 & 14 & 8 & 6 & 7 & 6 & 9 & 5 & 8 & 12 & 15 \\
\hline 5 & 11 & 10 & 12 & 9 & 10 & 11 & 9 & 6 & 8 & 6 & 9 & 5 & 8 & 11 & 10 \\
\hline 6 & 9 & 7 & 10 & 9 & 7 & 8 & 9 & 6 & 8 & 6 & 8 & 6 & 8 & 9 & 7 \\
\hline 7 & 8 & 5 & 8 & 8 & 5 & 6 & 9 & 6 & 7 & 5 & 7 & 6 & 8 & 8 & 5 \\
\hline 8 & 7 & 3 & 6 & 8 & 4 & 4 & 8 & 6 & 7 & 5 & 6 & 6 & 7 & 7 & 3 \\
\hline 9 & 6 & 2 & 4 & 7 & 3 & 3 & 7 & 6 & 6 & 5 & 6 & 6 & 6 & 6 & 2 \\
\hline 10 & 5 & 2 & 3 & 6 & 2 & 2 & 7 & 5 & 6 & 5 & 5 & 6 & 6 & 5 & 2 \\
\hline 11 & 4 & 1 & 3 & 6 & 2 & 2 & 6 & 5 & 5 & 5 & 5 & 5 & 5 & 4 & 1 \\
\hline 12 & 3 & 1 & 2 & 5 & 1 & 2 & 5 & 5 & 5 & 4 & 4 & 5 & 4 & 3 & 1 \\
\hline 13 & 2 & 1 & 2 & 4 & 1 & 1 & 4 & 5 & 4 & 4 & 4 & 5 & 4 & 2 & 1 \\
\hline 14 & 2 & 0 & 1 & 4 & 1 & 1 & 4 & 4 & 4 & 4 & 3 & 4 & 4 & 2 & 0 \\
\hline 15 & 2 & 0 & 1 & 3 & 1 & 1 & 3 & 4 & 3 & 4 & 3 & 4 & 3 & 2 & 0 \\
\hline 16 & 1 & 0 & 1 & 3 & 0 & 1 & 2 & 4 & 3 & 4 & 3 & 4 & 3 & 1 & 0 \\
\hline 17 & 1 & 0 & 1 & 2 & 0 & 0 & 2 & 3 & 3 & 4 & 2 & 4 & 3 & 1 & 0 \\
\hline 18 & 1 & 0 & 0 & 2 & 0 & 0 & 1 & 3 & 2 & 4 & 2 & 4 & 2 & 1 & 0 \\
\hline 19 & 1 & 0 & 0 & 2 & 0 & 0 & 1 & 3 & 2 & 3 & 2 & 3 & 2 & 1 & 0 \\
\hline 20 & 1 & 0 & 0 & 2 & 0 & 0 & 1 & 3 & 2 & 3 & 2 & 3 & 2 & 1 & 0 \\
\hline 21 & 1 & 0 & 0 & 2 & 0 & 0 & 1 & 3 & 2 & 3 & 2 & 3 & 1 & 1 & 0 \\
\hline 22 & 1 & 0 & 0 & 1 & 0 & 0 & 1 & 3 & 2 & 3 & 1 & 3 & 1 & 1 & 0 \\
\hline 23 & 0 & 0 & 0 & 1 & 0 & 0 & 1 & 2 & 2 & 2 & 1 & 3 & 1 & 0 & 0 \\
\hline Total Percentage & 100 & 100 & 100 & 100 & 100 & 100 & 100 & 100 & 100 & 100 & 100 & 100 & 100 & 100 & 100 \\
\hline \multirow{6}{*}{$\begin{array}{r}\text { Layer ID from } \\
\text { outside to inside } \\
\text { (see Table 22) }\end{array}$} & $\mathrm{F} 01$ & $\mathrm{~F} 01$ & F01 & $\mathrm{FOI}$ & F01 & F01 & F01 & F01 & F01 & F01 & F01 & F01 & F01 & F01 & F01 \\
\hline & F07 & M08 & M08 & M09 & M11 & M11 & M11 & F06 & M13 & F06 & M15 & M16 & M16 & $\mathrm{F} 07$ & M08 \\
\hline & M05 & F02 & F04 & F04 & I0] & 104 & 102 & 101 & 104 & 102 & $\mathrm{I} 04$ & 105 & $\mathrm{~F} 02$ & M05 & F02 \\
\hline & 104 & - & G01 & $\mathrm{G} 01$ & F04 & G01 & M11 & M13 & G01 & M15 & G01 & G01 & - & $\mathrm{I} 04$ & - \\
\hline & G01 & - & F02 & F02 & G01 & F02 & $\mathrm{F} 02$ & G01 & $\mathrm{F} 02$ & $\mathrm{G} 01$ & F02 & F02 & - & G01 & - \\
\hline & F02 & - & - & - & F02 & - & - & F02 & - & F02 & - & - & - & $\mathrm{F} 02$ & - \\
\hline \multicolumn{16}{|c|}{ Wall Number Descriptions } \\
\hline \multicolumn{7}{|c|}{$\begin{array}{l}\text { 21. } 200 \mathrm{~mm} \text { LW CMU, batt insulation, gyp board } \\
\text { 22. } 200 \mathrm{~mm} \text { LW CMU with fill insulation, batt insulation, gyp board } \\
\text { 23. } 25 \mathrm{~mm} \text { stucco, } 200 \mathrm{~mm} \text { HW CMU, batt insulation, gyp board } \\
\text { 24. } 200 \mathrm{~mm} \text { LW CMU with fill insulation } \\
\text { 25. } 200 \mathrm{~mm} \text { LW CMU with fill insulation, gyp board } \\
\text { 26. } 300 \mathrm{~mm} \text { LW CMU with fill insulation, gyp board } \\
\text { 27. } 100 \mathrm{~mm} \text { LW concrete, board insulation, gyp board } \\
\text { 28. } 100 \mathrm{~mm} \text { LW concrete, batt insulation, gyp board }\end{array}$} & \multicolumn{9}{|c|}{$\begin{array}{l}\text { 29. } 100 \mathrm{~mm} \mathrm{LW} \text { concrete, board insulation, } 100 \mathrm{~mm} \mathrm{~L} \\
\text { 30. EIFS finish, insulation board, } 200 \mathrm{~mm} \mathrm{LW} \text { concree } \\
\text { 31. } 200 \mathrm{~mm} \mathrm{LW} \text { concrete, batt insulation, gyp board } \\
\text { 32. EIIS finish, insulation board, } 200 \mathrm{~mm} H \mathrm{HW} \text { concre } \\
\text { 33. } 200 \mathrm{~mm} \text { HW concrete, batt insulation, gWy board } \\
\text { 34. } 300 \mathrm{~mm} \text { HW concrete, batt insulation, gyp board } \\
\text { 35. } 300 \mathrm{~mm} \mathrm{HW} \text { concrete }\end{array}$} \\
\hline
\end{tabular}

Table A.2 2001 ASHRAE Handbook - Fundamentals 


\section{A.4 Radiant Time Series (Solar) - PART I}

\begin{tabular}{|c|c|c|c|c|c|c|c|c|c|c|c|c|c|c|c|c|c|c|c|c|c|c|c|c|}
\hline \multirow{4}{*}{$\begin{array}{c}\% \\
\text { Glass }\end{array}$} & \multirow{2}{*}{\multicolumn{6}{|c|}{ Light }} & \multirow{2}{*}{\multicolumn{6}{|c|}{ Medium }} & & & & & & & \multicolumn{6}{|c|}{ Interior Zones } \\
\hline & & & & & & & & & & & & & \multicolumn{6}{|c|}{ Heavy } & \multicolumn{2}{|c|}{ Light } & \multicolumn{2}{|c|}{ Medium } & \multicolumn{2}{|c|}{ Heavy } \\
\hline & \multicolumn{3}{|c|}{ With Carpet } & \multicolumn{3}{|c|}{ No Carpet } & \multicolumn{3}{|c|}{ With Carpet } & \multicolumn{3}{|c|}{ No Carpet } & \multicolumn{3}{|c|}{ With Carpet } & \multicolumn{3}{|c|}{ No Carpet } & \multirow{2}{*}{\multicolumn{2}{|c|}{ 点能 }} & \multirow{2}{*}{ 赔。 } & \multirow{2}{*}{ 产 } & & \multirow{2}{*}{ ż } \\
\hline & $10 \%$ & $50 \% 9$ & $90 \%$ & $10 \% 5$ & $\mathbf{5 0 \%}$ & $90 \%$ & $10 \%$ & $\mathbf{5 0 \%}$ & $90 \%$ & $10 \% 5$ & $50 \%$ & $90 \%$ & $10 \%$ & $\mathbf{5 0 \%}$ & $90 \%$ & $10 \%$ & $50 \%$ & $90 \%$ & & & & & & \\
\hline Hour & \multicolumn{24}{|c|}{ Radiant Time Factor, \% } \\
\hline 0 & 47 & 50 & 53 & 41 & 43 & 46 & 46 & 49 & 52 & 31 & 33 & 35 & 34 & 38 & 42 & 22 & 25 & 28 & 46 & 40 & 46 & 31 & 33 & 21 \\
\hline 1 & 19 & 18 & 17 & 20 & 19 & 19 & 18 & 17 & 16 & 17 & 16 & 15 & 9 & 9 & 9 & 10 & 9 & 9 & 19 & 20 & 18 & 17 & 9 & 9 \\
\hline 2 & 11 & 10 & 9 & 12 & 11 & 11 & 10 & 9 & 8 & 11 & 10 & 10 & 6 & 6 & 5 & 6 & 6 & 6 & 11 & 12 & 10 & 11 & 6 & 6 \\
\hline 3 & 6 & 6 & 5 & 8 & 7 & 7 & 6 & 5 & 5 & 8 & 7 & 7 & 4 & 4 & 4 & 5 & 5 & 5 & 6 & 8 & 6 & 8 & 5 & 5 \\
\hline 4 & 4 & 4 & 3 & 5 & 5 & 5 & 4 & 3 & 3 & 6 & 5 & 5 & 4 & 4 & 4 & 5 & 5 & 4 & 4 & 5 & 3 & 6 & 4 & 5 \\
\hline 5 & 3 & 3 & 2 & 4 & 3 & 3 & 2 & 2 & 2 & 4 & 4 & 4 & 4 & 3 & 3 & 4 & 4 & 4 & 3 & 4 & 2 & 4 & 4 & 4 \\
\hline 6 & 2 & 2 & 2 & 3 & 3 & 2 & 2 & 2 & 2 & 4 & 3 & 3 & 3 & 3 & 3 & 4 & 4 & 4 & 2 & 3 & 2 & 4 & 3 & 4 \\
\hline 7 & 2 & 1 & 1 & 2 & 2. & 2 & 1 & 1 & 1 & 3 & 3 & 3 & 3 & 3 & 3 & 4 & 4 & 4 & 2 & 2 & 1 & 3 & 3 & 4 \\
\hline 8 & 1 & 1 & 1 & 1 & 1 & 1 & 1 & 1 & 1 & 3 & 2 & 2 & 3 & 3 & 3 & 4 & 3 & 3 & 1 & 1 & 1 & 3 & 3 & 4 \\
\hline 9 & 1 & 1 & 1 & 1 & 1 & 1 & 1 & 1 & 1 & 2 & 2 & 2 & 3 & 3 & 2 & 3 & 3 & 3 & 1 & 1 & 1 & 2. & 3 & 3 \\
\hline 10 & 1 & 1 & 1 & 1 & 1 & 1 & 1 & 1 & 1 & 2 & 2 & 2 & 3 & 2 & 2 & 3 & 3 & 3 & 1 & 1 & 1 & 2 & 3 & 3 \\
\hline 11 & 1 & 1 & 1 & 1 & 1 & 1 & 1 & 1 & 1 & 2 & 2 & 2 & 2 & 2 & 2 & 3 & 3 & 3 & 1 & 1 & 1 & 2 & 2 & 3 \\
\hline 12 & 1 & 1 & 1 & 1 & 1 & 1 & 1 & 1 & 1 & 1 & 1 & 1 & 2 & 2 & 2 & 3 & 3 & 3 & 1 & 1 & 1 & 1 & 2 & 3 \\
\hline 13 & 1 & 1 & 1 & 0 & 1 & 0 & 1 & 1 & 1 & 1 & 1 & 1 & 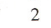 & 2 & 2 & 3 & 3 & 2 & 1 & 1 & 1 & 1 & 2 & 3 \\
\hline 14 & 0 & 0 & 1 & 0 & 1 & 0 & 1 & 1 & 1 & 1 & 1 & 1 & 2 & 2 & 2 & 3 & 2 & 2 & 1 & 0 & 1 & 1 & 2 & 3 \\
\hline 15 & 0 & 0 & 1 & 0 & 0 & 0 & 1 & 1 & 1 & 1 & 1 & 1 & ? & 2 & 2 & 2 & 2 & 2 & 0 & 0 & 1 & 1 & 2 & 3 \\
\hline 16 & 0 & 0 & 0 & 0 & 0 & 0 & 1 & 1 & 1 & 1 & 1 & 1 & 2 & 2 & 2 & 2 & 2 & 2 & 0 & 0 & 1 & 1 & 2 & 3 \\
\hline 17 & 0 & 0 & 0 & 0 & 0 & 0 & 1 & 1 & 1 & 1 & 1 & 1 & 2 & 2 & 2 & 2 & 2 & 2 & 0 & 0 & 1 & 1 & 2 & 2 \\
\hline 18 & 0 & 0 & 0 & 0 & 0 & 0 & 1 & 1 & 1 & 1 & 1 & 1 & 2 & 2 & 1 & 2 & 2 & 2 & 0 & 0 & 1 & 1 & 2 & 2 \\
\hline 19 & 0 & 0 & 0 & 0 & 0 & 0 & 0 & 1 & 0 & 0 & 1 & 1 & 2 & 2 & 1 & 2 & 2 & 2 & 0 & 0 & 1 & 0 & 2 & 2 \\
\hline 20 & 0 & 0 & 0 & 0 & 0 & 0 & 0 & 0 & 0 & 0 & 1 & 1 & 2 & 1 & 1 & 2 & 2 & 2 & 0 & 0 & 0 & 0 & 2 & 2 \\
\hline 21 & 0 & 0 & 0 & 0 & 0 & 0 & 0 & 0 & 0 & 0 & 1 & 1 & 2 & 1 & 1 & 2 & 2 & 2 & 0 & 0 & 0 & 0 & 2 & 2 \\
\hline 22 & 0 & 0 & 0 & 0 & 0 & 0 & 0 & 0 & 0 & 0 & 1 & 0 & 1 & 1 & 1 & 2 & 2 & 2 & 0 & 0 & 0 & 0 & 1 & 2 \\
\hline \multirow[t]{2}{*}{23} & 0 & 0 & 0 & 0 & 0 & 0 & 0 & 0 & 0 & 0 & 0 & 0 & 1 & 1 & 1 & 2 & 2. & 1 & 0 & 0 & 0 & 0 & 1 & 2 \\
\hline & 100 & 100 & 100 & 100 & 100 & 100 & 100 & 100 & 100 & 100 & 100 & 100 & 100 & 100 & 100 & 100 & 100 & $100^{\circ}$ & 100 & 100 & 100 & 100 & 100 & 100 \\
\hline
\end{tabular}

Table A.4 2001 ASHRAE Handbook - Fundamentals 


\section{A.5 Radiant Time Series (Non-Solar) - PART II}

\begin{tabular}{|c|c|c|c|c|c|c|c|c|c|c|c|c|c|c|c|c|c|c|}
\hline \multirow{3}{*}{$\begin{array}{l}\% \\
\text { Glass }\end{array}$} & \multicolumn{6}{|c|}{ Light } & \multicolumn{6}{|c|}{ Medium } & \multicolumn{6}{|c|}{ Heavy } \\
\hline & \multicolumn{3}{|c|}{ With Carpet } & \multicolumn{3}{|c|}{ No Carpet } & \multicolumn{3}{|c|}{ With Carpet } & \multicolumn{3}{|c|}{ No Carpet } & \multicolumn{3}{|c|}{ With Carpet } & \multicolumn{3}{|c|}{ No Carpet } \\
\hline & $10 \%$ & $50 \%$ & $90 \%$ & $10 \%$ & $50 \%$ & $90 \%$ & $10 \%$ & $50 \%$ & $90 \%$ & $10 \%$ & $50 \%$ & $90 \%$ & $10 \%$ & $50 \%$ & $90 \%$ & $10 \%$ & $50 \%$ & $90 \%$ \\
\hline Hour & \multicolumn{18}{|c|}{ Radiant Time Factor, \% } \\
\hline 0 & 53 & 55 & 56 & 44 & 45 & 46 & 52 & 54 & 55 & 28 & 29 & 29 & 47 & 49 & 51 & 26 & 27 & 28 \\
\hline 1 & 17 & 17 & 17 & 19 & 20 & 20 & 16 & 16 & 15 & 15 & 15 & 15 & 11 & 12 & 12 & 12 & 13 & 13 \\
\hline 2 & 9 & 9 & 9 & 11 & 11 & 11 & 8 & 8 & 8 & 10 & 10 & 10 & 6 & 6 & 6 & 7 & 7 & 7 \\
\hline 3 & 5 & 5 & 5 & 7 & 7 & 7 & 5 & 4 & 4 & 7 & 7 & 7 & 4 & 4 & 3 & 5 & 5 & 5 \\
\hline 4 & 3 & 3 & 3 & 5 & 5 & 5 & 3 & 3 & 3 & 6 & 6 & 6 & 3 & 3 & 3 & 4 & 4 & 4 \\
\hline 5 & 2 & 2 & 2 & 3 & 3 & 3 & 2 & 2 & 2 & 5 & 5 & 5 & 2 & 2 & 2 & 4 & 4 & 4 \\
\hline 6 & 2 & 2 & 2 & 3 & 2 & 2 & 2 & 1 & 1 & 4 & 4 & 4 & 2 & 2 & 2 & 3 & 3 & 3 \\
\hline 7 & 1 & 1 & 1 & 2 & 2 & 2 & 1 & 1 & 1 & 4 & 3 & 3 & 2 & 2 & 2 & 3 & 3 & 3 \\
\hline 8 & 1 & 1 & 1 & 1 & 1 & 1 & 1 & 1 & 1 & 3 & 3 & 3 & 2 & 2 & 2 & 3 & 3 & 3 \\
\hline 9 & 1 & 1 & 1 & 1 & 1 & 1 & 1 & 1 & 1 & 3 & 3 & 3 & 2 & 2 & 2 & 3 & 3 & 3 \\
\hline 10 & 1 & 1 & 1 & 1 & 1 & 1 & 1 & 1 & 1 & 2 & 2 & 2 & 2 & 2 & 2 & 3 & 3 & 3 \\
\hline 11 & 1 & 1 & 1 & 1 & 1 & 1 & 1 & 1 & 1 & 2 & 2 & 2 & 2 & 2 & 1 & 3 & 3 & 2 \\
\hline 12 & 1 & 1 & 1 & 1 & 1 & 0 & 1 & 1 & 1 & 2 & 2 & 2 & 2 & 1 & 1 & 2 & 2 & 2 \\
\hline 13 & 1 & 1 & 0 & 1 & 0 & 0 & 1 & 1 & 1 & 2 & 2 & 2 & 2 & 1 & 1 & 2 & 2 & 2 \\
\hline 14 & 1 & 0 & 0 & 0 & 0 & 0 & 1 & 1 & 1 & 1 & 1 & 1 & 2 & 1 & 1 & 2 & 2 & 2 \\
\hline 15 & 1 & 0 & 0 & 0 & 0 & 0 & 1 & 1 & 1 & 1 & 1 & 1 & 1 & 1 & 1 & 2 & 2 & 2 \\
\hline 16 & 0 & 0 & 0 & 0 & 0 & 0 & 1 & 1 & 1 & 1 & 1 & 1 & 1 & 1 & 1 & 2 & 2 & 2 \\
\hline 17 & 0 & 0 & 0 & 0 & 0 & 0 & 1 & 1 & 1 & 1 & 1 & 1 & 1 & 1 & 1 & 2 & 2 & 2 \\
\hline 18 & 0 & 0 & 0 & 0 & 0 & 0 & 1 & 1 & 1 & 1 & 1 & 1 & 1 & 1 & 1 & 2 & 2 & 2 \\
\hline 19 & 0 & 0 & 0 & 0 & 0 & 0 & 0 & 0 & 0 & 1 & 1 & 1 & 1 & 1 & 1 & 2 & 2 & 2 \\
\hline 20 & 0 & 0 & 0 & 0 & 0 & 0 & 0 & 0 & 0 & 1 & 1 & 1 & 1 & 1 & 1 & 2 & 2 & 2 \\
\hline 21 & 0 & 0 & 0 & 0 & 0 & 0 & 0 & 0 & 0 & 0 & 0 & 0 & 1 & 1 & 1 & 2 & 2 & 2 \\
\hline 22 & 0 & 0 & 0 & 0 & 0 & 0 & 0 & 0 & 0 & 0 & 0 & 0 & 1 & 1 & 1 & 2 & 1 & 1 \\
\hline \multirow[t]{2}{*}{23} & 0 & 0 & 0 & 0 & 0 & 0 & 0 & 0 & 0 & 0 & 0 & 0 & 1 & 1 & 1 & 2 & 1 & 1 \\
\hline & 100 & 100 & 100 & 100 & 100 & 100 & 100 & 100 & 100 & 100 & 100 & 100 & 100 & 100 & 100 & 100 & 100 & 100 \\
\hline
\end{tabular}

Table A.5 2001 ASHRAE Handbook - Fundamentals 


\section{A.6 Recommended Radiative and Convective Fractions}

\begin{tabular}{|c|c|c|c|}
\hline & \multirow[t]{2}{*}{ Heat Gain Type Occupants } & $\begin{array}{l}\text { Recommended } \\
\text { Radiative } \\
\text { Fraction }\end{array}$ & $\begin{array}{c}\text { Recommended } \\
\text { Convective } \\
\text { Fraction }\end{array}$ \\
\hline & & 0.7 & 0.3 \\
\hline \multirow[t]{5}{*}{ Lighting } & & & \\
\hline & $\begin{array}{l}\text { Suspended fluorescent: } \\
\text { unvented }\end{array}$ & 0.67 & 0.33 \\
\hline & $\begin{array}{l}\text { Recessed fluorescent: } \\
\text { vented to return air }\end{array}$ & 0.59 & 0.41 \\
\hline & $\begin{array}{l}\text { Recessed fluorescent: } \\
\text { vented to supply and return air }\end{array}$ & 0.87 & 0.81 \\
\hline & Incandescent & 0.8 & 0.2 \\
\hline \multirow[t]{3}{*}{ Equipmen } & & & \\
\hline & $\begin{array}{l}\text { General (applicable for equipment not } \\
\text { internally cooled with fans) }\end{array}$ & 0.7 & 0.3 \\
\hline & $\begin{array}{l}\text { Computers/electronic equipment with } \\
\text { internal fans }\end{array}$ & 0.2 & 0.8 \\
\hline \multicolumn{2}{|c|}{ Conduction heat gain through walls } & 0.63 & 0.37 \\
\hline \multicolumn{2}{|c|}{ Conduction heat gain through roofs } & 0.84 & 0.16 \\
\hline \multicolumn{2}{|c|}{ Transmitted solar radiation } & 1 & 0 \\
\hline \multicolumn{2}{|c|}{ Absorbed solar radiation } & 0.63 & 0.37 \\
\hline \multicolumn{2}{|c|}{ Infiltration } & 0 & 1 \\
\hline
\end{tabular}

Table A.6 2001 ASHRAE Handbook - Fundamentals 


\section{A.7 Periodic Response Factor (PRFs) Derivation (Iu and Fisher, 2004)}

Conduction heat gain is calculated for each multi layer wall and roof type with the use of 24 response factors. The response factor formulation gives a time series solution for transient, one-dimensional conductive heat transfer problem.

For any hour, $\theta$, the conductive heat gain for the surface, $q_{\theta}$ and $q^{\prime \prime}{ }_{\theta}$, are given by the summation of the response factors multiplied by the representative temperatures difference across the surface, as shown in equations (A-1) and (A-2). equation (A-1) is based on the temperature history versus constant room temperature, whereas equation $(\mathrm{A}-2)$ is expressed in terms of temperature history only.

$q_{\theta}=A \sum_{i=0}^{\iota \nu} Y_{P j}\left(t_{e, \theta-j \delta}-t_{r c}\right)$

where

$q_{\theta}=$ hourly conductive heat gain, Btu/hr $(\mathrm{W})$, for the surface

$A=$ surface area, $\mathrm{ft}^{2}\left(\mathrm{~m}^{2}\right)$

$Y_{P j}=$ response factor

$t_{e, \theta-j \delta}=$ sol-air temperature, $\mathrm{j}$ hours ago

$t_{r c}=$ presumed constant room air temperature

and;

$$
q_{\theta}^{\prime \prime}=-\sum_{i=0}^{n} Z_{j} T_{i, t-j \delta}+\sum_{i=0}^{n} Y_{j} T_{o, t-j \delta}
$$

where

$q_{\theta}{ }_{\theta}=$ heat flux at the inside surface of the wall at the current hour

$n=$ number dependent on the construction of the wall 
$Z_{j}, Y_{j}=$ response factor

$T_{i, t-j \delta}=$ inside surface temperature $\mathrm{j}$ hours ago, and

$T_{o, t-j \delta}=$ outside surface temperature $\mathrm{j}$ hours ago

To compute conduction heat gain for walls and roofs, a set of response factors is needed for each wall and roof that is used in the building of interest. The method described here uses a conventional method (Hittle and Bishop 1983) to calculate a set 120 response factor for a single pulse. The response factor can now be reduced to a set of 24 response factors that are appropriate for a steady periodic input. These will be called periodic response factors. (Spitler et al, 1997). If the boundary conditions are steady periodic within 24-hour period, it is useful to rearrange the summations as follows:

$$
\begin{aligned}
q^{\prime \prime} & =-\sum_{i=0}^{L J} Z_{j} T_{i, t-j \delta}+\sum_{\substack{i=0 \\
4 \prime}}^{L J} Z_{j} T_{i, t-j \delta} \\
& -\sum_{i=24}^{4 \prime} Z_{j} T_{i, t-j \delta}+\sum_{i=24} Z_{j} T_{i, t-j \delta}-\sum_{i=48}^{00} Z_{j} T_{i, t-j \delta}+\sum_{i=48}^{00} Z_{j} T_{i, t-j \delta}+\ldots
\end{aligned}
$$

If the first term of the $\mathrm{Z}$ summations is separated from the rest, one obtains:

$$
\begin{aligned}
q^{\prime \prime} & =-Z_{0} T_{i, t}-\sum_{i=1} Z_{j} T_{i, t-j \delta} \\
& +\sum_{i=0} Y_{j} T_{o, t-j \delta}+Z_{24} T_{t, t-24} \\
& -\sum_{i=25} Z_{j} T_{i, t-j \delta}+\sum_{i=24}^{4 /} Y_{j} T_{o, t-j \delta}-Z_{48} T_{t, t-48}
\end{aligned}
$$




$$
-\sum_{i=49}^{\text {os }} Z_{j} T_{i, t-j \delta}+\sum_{i=48}^{\text {os }} Y_{j} T_{i, t-j \delta}+\ldots
$$

For a steady periodic forcing function, the temperature $\mathrm{T}_{\mathrm{i}, \mathrm{t}}, \mathrm{T}_{\mathrm{i}, \mathrm{t}-24}, \mathrm{~T}_{\mathrm{i}, \mathrm{t}-48}$, etc., are all the same. The coefficients of these temperatures can be combined to give a new set of periodic response factors $\left(\mathrm{Z}_{\mathrm{Pj}}\right.$, and $\left.\mathrm{Y}_{\mathrm{Pj}}\right)$ :

$Y_{P 1}=Y_{0}+Y_{24}+Y_{48}+\ldots$

Similarly,

$Y_{P 2}=Y_{1}+Y_{25}+Y_{49}+\ldots$

and so on.

Thus, for the special case of a steady periodic forcing function, the generally large number of response can be replaced by 24 periodic response factors, and the heat flux can be expressed in terms of periodic response factors as

$$
q^{\prime \prime}{ }_{\theta}=-\sum_{i=0}^{2 s} Z_{P j} T_{i, t-j \delta}+\sum_{i=0}^{2 s} Y_{P j} T_{o, t-j \delta}
$$

where the wall heat gain coefficients are designated to be either inside coefficients $(Z)$ or cross-coefficients (Y), depending on the temperature by which they are multiplied.

As formulated in ASHRAE Loads Toolkit, the Radiant Time Series Method for design load calculations uses periodic response factors (PRFs) (also called "conduction time factors") rather than CTFs to calculate conductive heat transfer through walls and roofs. 
PRFs operate only on temperatures; the current surface heat flux is a function only of temperatures and does not rely on previous heat fluxes, as shown below:

$$
q_{\theta}^{\prime \prime}=\sum_{i=0}^{\infty \omega} Y_{P j}\left(t_{e, \theta-j \delta}-t_{r c}\right)
$$

This formulation is premised on the steady, periodic nature of the sol-air temperature over a 24-hour period (Spitler et al. 1997). Although the number of PRFs may vary, the 24 PRFs shown in the equation above corresponds to 24 hourly changes in the sol-air temperature for a single diurnal cycle. It is clear that the overall heat transfer coefficient, $\mathrm{U}$ is represented by the sum of the periodic response factors as shown below:

$$
U=\sum_{i=0}^{\infty} Y_{P j}
$$

The periodic response factor directly scales the contribution of previous fluxes (in the form of imperative gradients) to the current conductive heat flux. As a result, the periodic response factor series provides a visual representation of the thermal response of the wall. PRFs are directly related to CTFs as shown in equation (A-10) (Spitler and Fisher 1999a) and may be derived directly from CTFs. The toolkit uses this method to calculate periodic response factors.

$$
Y=d^{-1} b
$$

where 


$$
Y=\left[\begin{array}{ccccccc}
Y_{0} & \ldots & Y_{5} & Y_{4} & Y_{3} & Y_{2} & Y_{1} \\
Y_{1} & Y_{0} & \ldots & Y_{5} & Y_{4} & Y_{3} & Y_{2} \\
Y_{2} & Y_{1} & Y_{0} & \ldots & Y_{5} & Y_{4} & Y_{3} \\
Y_{3} & Y_{2} & Y_{1} & Y_{0} & \ldots & Y_{5} & Y_{4} \\
Y_{4} & Y_{3} & Y_{2} & Y_{1} & Y_{0} & \ldots & Y_{5} \\
\cdot & \cdot & \cdot & \cdot & \cdot & \cdot & \cdot \\
\cdot & \cdot & \cdot & \cdot & \cdot & \cdot & \cdot \\
\cdot & \cdot & \cdot & \cdot & \cdot & \cdot & \cdot \\
Y_{23} & & Y_{4} & Y_{3} & Y_{2} & Y_{1} & Y_{0}
\end{array}\right]
$$

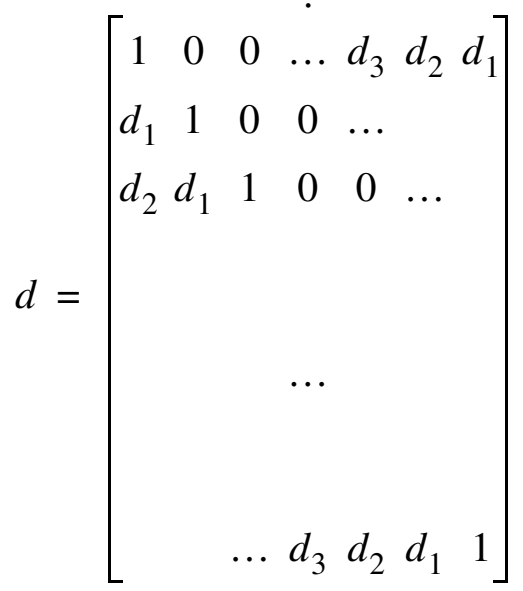

(A-12)

$$
b=\left[\begin{array}{ccccccc}
b_{0} & 0 & 0 & \ldots & b_{3} & b_{2} & b_{1} \\
b_{1} & b_{0} & 0 & 0 & \ldots & & b_{2} \\
b_{2} & b_{1} & b_{0} & 0 & 0 & \ldots & \\
& & & & & \\
& & & \ldots & & \\
& & & & & \\
& & & & & \\
& & \ldots & b_{3} & b_{2} & b_{1} & b_{0}
\end{array}\right]
$$


As shown in equation (A-10), the PRFs are related to the cross and flux CTF terms. The first column of the $\mathrm{Y}$ matrix is the resulting PRFs, $\mathrm{Y}_{0}, \mathrm{Y}_{1}, \mathrm{Y}_{2}, \ldots, \mathrm{Y}_{23}$. Since the sol-air temperature is used in RTS method conduction calculations, the $\mathrm{b}$ and $\mathrm{d}$ matrices must be filled with air-to-air CTFs. This eliminates the surface heat balance calculations in HB method. However, if conductive heat transfer is an isolated concern, the PRFs can be calculated from surface-to-surface CTFs. This reflects the actual conduction response of a construction without considering the outside and inside film. 


\section{Appendix B}

\section{(Absorption System Model)}

\section{B.1 Double Effect Absorption Chiller}

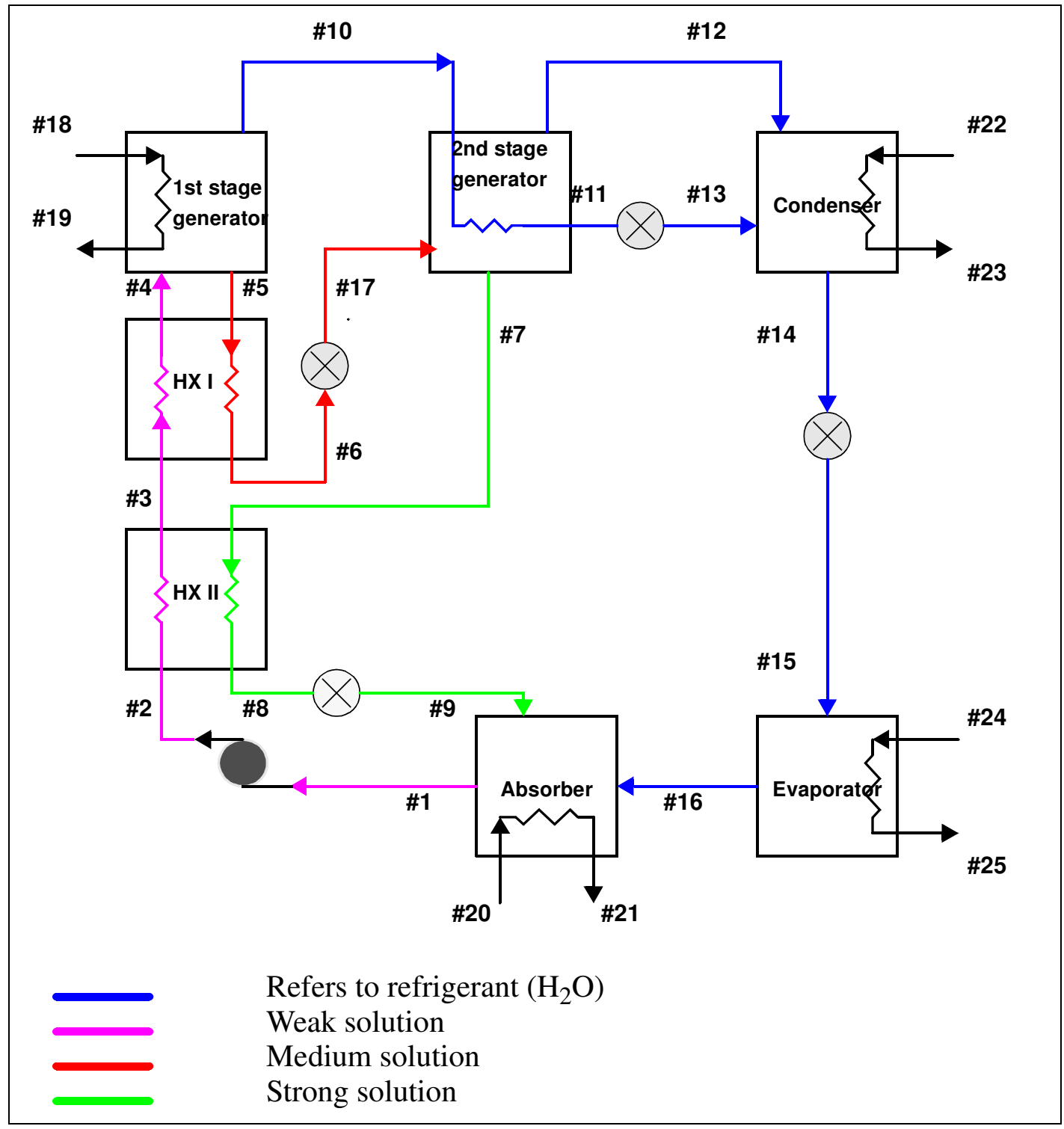

Figure B.1 Schematic diagram of the double-effect absorption cycle Series flow double-effect water/lithium bromide chiller

Dühring Chart Schematic (solution to high temperature) 


\section{B.2 Desorber/Generator/Concentrator}

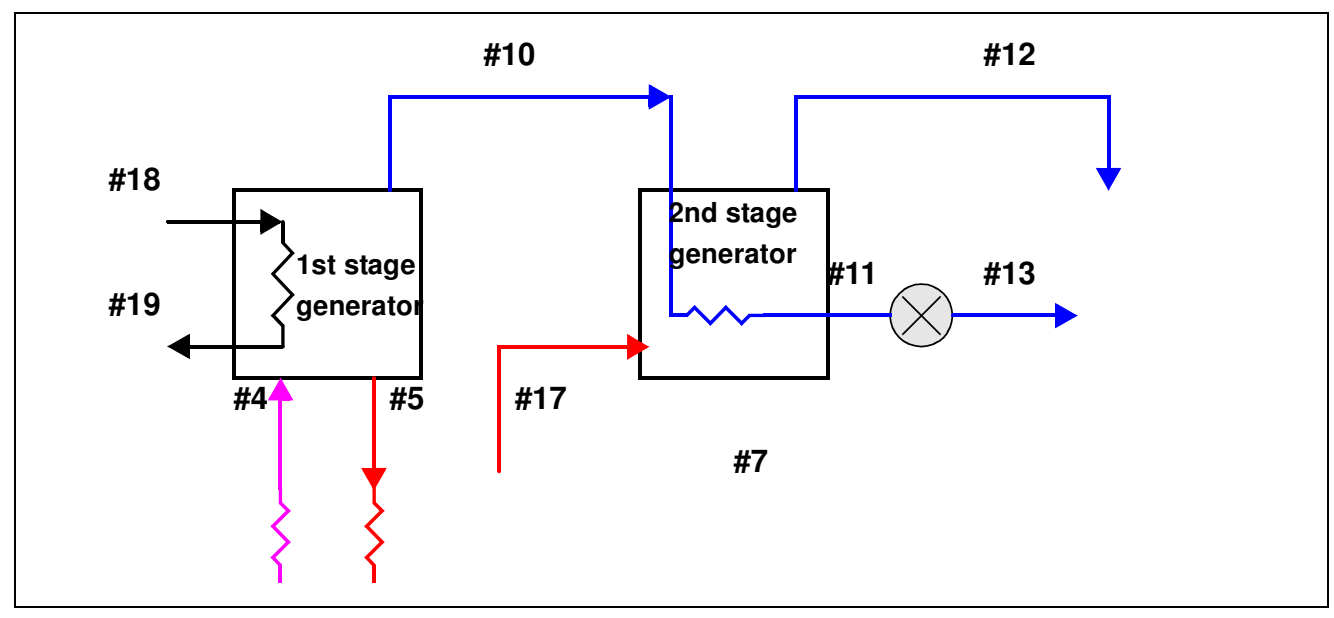

Figure B.2 Schematic diagram of the desorber/generator/concentrator

\section{Mass Balance}

$$
\begin{aligned}
& \dot{m}_{1}=\dot{m}_{5}+\dot{m}_{10} \\
& \dot{m}_{1} \times X_{4}=\dot{m}_{5} \times X_{5} \\
& \dot{m}_{5}=\dot{m}_{7}+\dot{m}_{12} \\
& \dot{m}_{5} \times X_{5}=\dot{m}_{7} \times X_{7}
\end{aligned}
$$

\section{Governing Equations}

$$
\begin{aligned}
& Q_{1 g}=\dot{m_{10}} h_{10}+\dot{m}_{5} h_{5}-\dot{m}_{4} h_{4} \\
& Q_{1 g}=\dot{m_{18}} C_{p, \text { water }}\left(T_{18}-T_{19}\right) \\
& Q_{1 g}=(U A)_{1 g} \frac{\left(T_{18}-T_{5}\right)-\left(T_{19}-T_{4}\right)}{\ln \left(\frac{T_{18}-T_{5}}{T_{19}-T_{4}}\right)} \\
& Q_{2 g}=\dot{m_{10}} h_{10}-\dot{m}_{11} h_{11}
\end{aligned}
$$




$$
\begin{aligned}
& Q_{2 g}=m_{12} h_{12}+m_{7} h_{7}-\dot{m}_{5} h_{17} \\
& Q_{2 g}=(U A)_{2 g} \frac{\left(T_{10}-T_{17}\right)-\left(T_{11}-T_{7}\right)}{\ln \left(\frac{T_{10}-T_{17}}{T_{11}-T_{7}}\right)}
\end{aligned}
$$

\section{Heat Transfer Correlations}

\section{-Tube side}

\section{Laminar Flow}

$N u=4.364$

\section{Turbulent Flow}

$$
N u=\frac{0.15 \operatorname{PrR} e^{0.9}}{f}\left[\frac{1}{X_{n}}+\frac{2.85}{X_{n}^{0.476}}\right]
$$

where $f$ is the friction factor of the tube,

$$
\begin{array}{lll}
f=0.707 \operatorname{PrR} e^{0.5} \text { if } 0 \leq R e \leq 50 & \text { if } & 0 \leq R e \leq 50 \\
f=5 \operatorname{Pr}+5 \ln \left[1+\operatorname{Pr}\left(0.0964 \operatorname{Re} e^{0.585}-1\right)\right] \quad \text { if } & 50 \leq R e \leq 1125 \\
f=5 \operatorname{Pr}+5 \ln 1+5 \operatorname{Pr}+2.5 \ln \left(0.0031 \operatorname{Re} e^{0.812}\right) & \text { if } & R e>1125
\end{array}
$$

\section{-Shell side}

$$
N u=0.16\left(\frac{q D_{H}}{\mu_{l} h_{f g}}\right)^{0.8588}\left(\frac{\rho_{v}}{\rho_{l}}\right)^{-0.7108}\left(\frac{q D_{H}}{\tau_{l} \rho_{v} h_{f g}}\right)^{-0.2104} \operatorname{Pr}\left(\frac{P}{P_{s}}\right) e^{-7.836 \times 10^{-2} x}
$$




\section{B.3 Condenser}

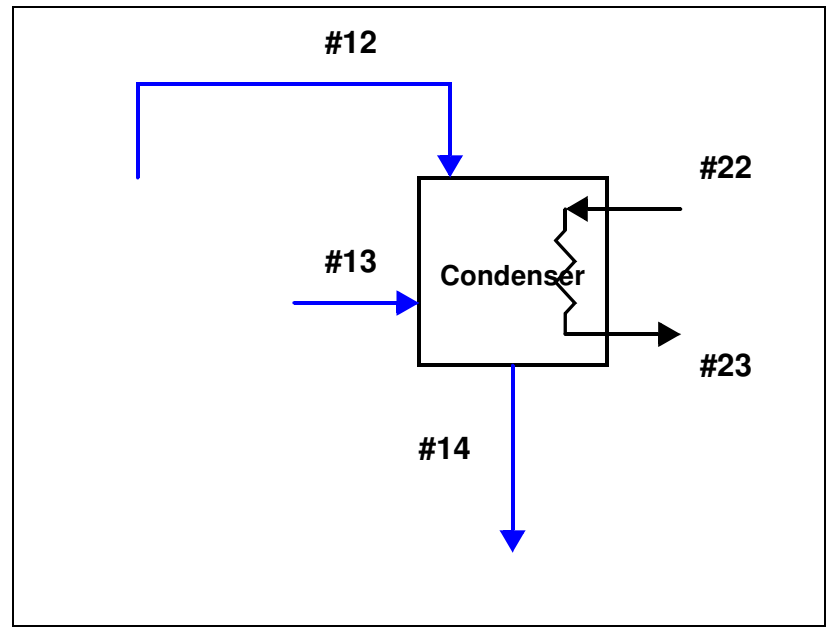

Figure B.3 Schematic diagram of the condenser

Mass Balance

$\dot{m_{14}}=\dot{m_{10}}+\dot{m}_{12}$

\section{Governing Equations}

$$
\begin{aligned}
& Q_{c}=\dot{m_{12}} h_{12}+\dot{m_{13}} h_{10}-\dot{m_{14}} h_{14} \\
& Q_{c}=\dot{m_{22}} C_{p, \text { water }}\left(T_{23}-T_{22}\right) \\
& N T U_{c}=(U A)_{c} /\left(\dot{m}_{22} C_{p, \text { water }}\right) \\
& \varepsilon_{c}=1-\exp \left(N T U_{c}\right) \\
& Q_{c}=\dot{m_{22}} C_{p, \text { water }} \varepsilon_{c}\left(T_{12}-T_{22}\right)
\end{aligned}
$$




\section{Heat Transfer Correlations}

-Tube side

\section{Laminar Flow}

$N u=4.364$

\section{Turbulent Flow}

$N u=\frac{\left(\frac{f}{8}\right)(\operatorname{Re}-1000) \operatorname{Pr}}{1+12.7\left(\frac{f}{5}\right)^{0.5}\left(\operatorname{Pr}^{2 / 3}-1\right)}$

where $f$ is the friction factor of the tube,

$f=(0.790 \ln R e-1.64)^{-2}$

-Shell side

$$
\begin{aligned}
& h_{c o}=0.729\left[\frac{\rho_{l}\left(\rho_{l}-\rho_{v}\right) g h_{f g} k^{3}}{\left(T_{s a t}-T_{w}\right) \mu_{l} D_{H}}\right] \\
& h_{f g}=\left(h_{l}-h_{v}\right)+\left(0.683-\frac{0.228}{P r_{l}}\right) c_{p}\left(T_{s a t}-T_{w}\right)
\end{aligned}
$$




\section{B.4 Evaporator}

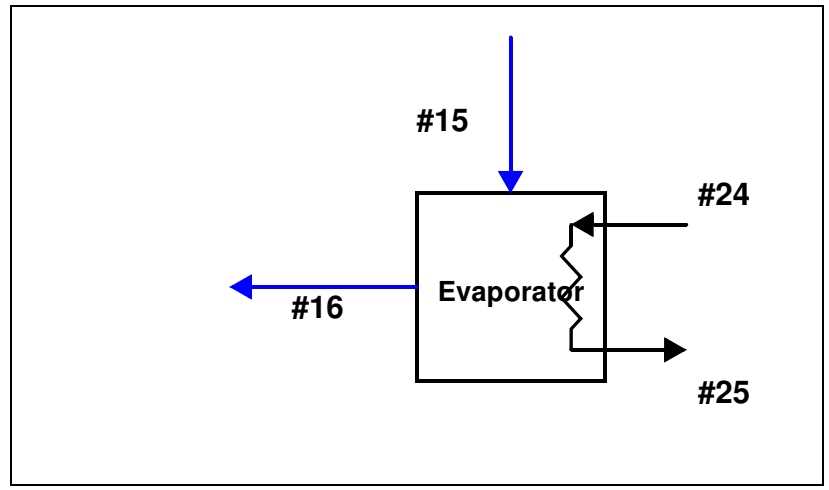

Figure B.4 Schematic diagram of the evaporator

Mass Balance

$\dot{m_{16}}=\dot{m_{14}}$

\section{Governing Equations}

$Q_{e}=\dot{m_{14}} h_{15}-\dot{m_{14}} h_{16}$

$Q_{e}=\dot{m_{24}} C_{p, w a t e r}\left(T_{24}-T_{25}\right)$

$N T U_{e}=(U A)_{e} /\left(\dot{m}_{24} C_{p}\right)$

$\varepsilon_{e}=1-\exp \left(N T U_{e}\right)$

$Q_{e}=\dot{m_{24}} C_{p} \varepsilon_{e}\left(T_{24}-T_{15}\right)$

\section{Heat Transfer Correlations}

\section{-Tube side}

Laminar Flow $h_{c o}=0.8221\left(\frac{k_{l}^{3} g}{v_{l}^{2}}\right)^{1 / 3} R e^{-0.22}$ 
Turbulent Flow $h_{c o}=0.0038 \operatorname{Re}^{-0.4} \operatorname{Pr}^{0.65}\left(\frac{k_{l}^{3} g}{v_{l}^{2}}\right)^{1 / 3}$

\section{-Shell side}

Laminar Flow $h_{c o}=0.8221\left(\frac{k_{l}^{3} g}{v_{l}^{2}}\right)^{1 / 3} R e^{-0.22}$

Turbulent Flow $h_{c o}=0.0038 \operatorname{Re}^{-0.4} \operatorname{Pr}^{0.65}\left(\frac{k_{l}^{3} g}{v_{l}^{2}}\right)^{1 / 3}$

$R e_{t r}=5800 \operatorname{Pr}_{l}^{-1.06} ; \operatorname{Re}=4 \frac{\Gamma}{\mu_{l}} ; \Gamma=\frac{\dot{m}}{l N^{2 / 3}}$

\section{B.5 Absorber}

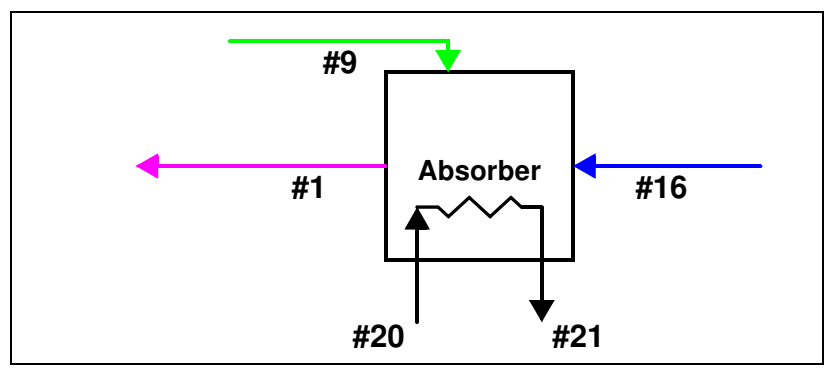

Figure B.5 Schematic diagram of the absorber

\section{Mass balance}

$$
\begin{aligned}
& \dot{m}_{1}=\dot{m}_{7}+\dot{m}_{14} \\
& \dot{m}_{1} \times X_{1}=\dot{m}_{7} \times X_{7}
\end{aligned}
$$




\section{Governing Equations}

$$
\begin{aligned}
& Q_{a}=\dot{m}_{7} h_{9}+\dot{m_{14}} h_{16}-\dot{m}_{1} h_{1} \\
& Q_{a}=\dot{m_{20}} C_{p, \text { water }}\left(T_{21}-T_{20}\right) \\
& Q_{a}=(U A)_{a} \frac{\left(T_{9}-T_{21}\right)-\left(T_{1}-T_{20}\right)}{\ln \left(\frac{T_{9}-T_{21}}{T_{1}-T_{20}}\right)}
\end{aligned}
$$

\section{B.6 Pump}

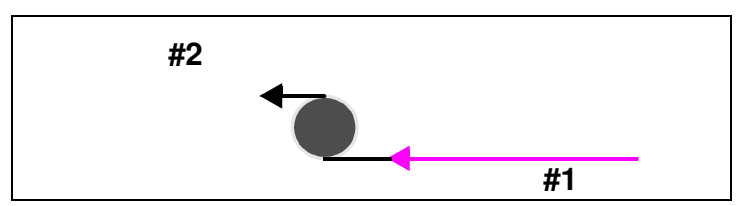

Figure B.6 Schematic diagram of the pump

\section{Mass Balance}

$\dot{m}_{1}=\dot{m}_{2}$

\section{Governing Equations}

$\dot{W}_{p}=\dot{m}_{1} v_{1}\left(P_{2}-P_{1}\right)$

$h_{2}=h_{1}+\dot{W}_{p} / \dot{m}_{1}$ 


\section{B.7 Heat-Exchangers}

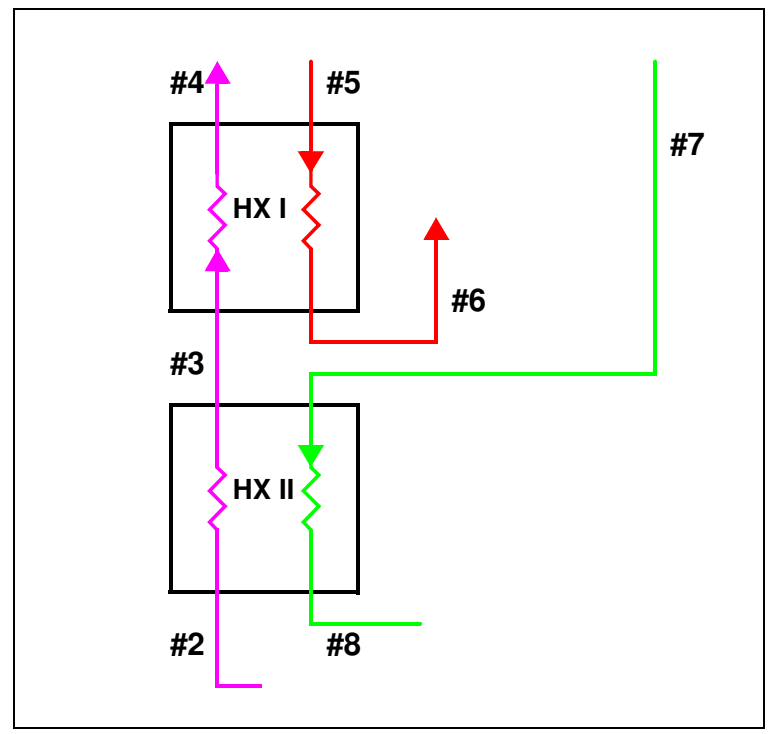

Figure B.7 Schematic diagram of the heat exchanger

\section{Mass Balance}

$$
\begin{aligned}
& \dot{m}_{1}=\dot{m}_{3}=\dot{m}_{4} \\
& \dot{m}_{5}=\dot{m}_{6} \\
& \dot{m_{1}}=\dot{m}_{2}=\dot{m_{3}} \\
& \dot{m_{7}}=\dot{m}_{8}
\end{aligned}
$$

\section{Governing Equations}

$$
\begin{aligned}
& Q_{h x I}=\dot{m}_{5} h_{5}-\dot{m}_{5} h_{6} \\
& Q_{h x I}=\dot{m}_{1} h_{4}-\dot{m}_{1} h_{3} \\
& C_{r}=C_{\min } / C_{\max } \\
& N T U_{h x I}=(U A)_{h x I} /(\dot{m} C)_{\min } \\
& \varepsilon=\frac{1-\exp \left[-N T U_{h x I}\left(1-C_{r}\right)\right]}{1-C_{r} \exp \left[-N T U_{h x I}\left(1-C_{r}\right)\right]}
\end{aligned}
$$


$Q_{h x I}=\left(\dot{m} C_{p}\right)_{\min } \varepsilon\left(T_{5}-T_{3}\right)$

$Q_{h x I I}=m_{7} h_{7}-\dot{m_{7}} h_{8}$

$Q_{h x I I}=\dot{m}_{1} h_{3}-\dot{m}_{1} h_{2}$

$C_{r}=C_{\text {min }} / C_{\max }$

$N T U_{h x I I}=(U A)_{h x I I} /(\dot{m} C)_{\min }$

$\varepsilon=\frac{1-\exp \left[-N T U_{h x I I}\left(1-C_{r}\right)\right]}{1-C_{r} \exp \left[-N T U_{h x I I}\left(1-C_{r}\right)\right]}$

$Q_{h x I I}=\left(\dot{m} C_{p}\right)_{\min } \varepsilon\left(T_{7}-T_{2}\right)$

\section{LMTD Method}

$q=\dot{m}_{h}\left(h_{h, i}-h_{h, o}\right)$

$q=\dot{m}_{h} C_{p, h}\left(T_{h, i}-T_{h, o}\right)$

$q=\dot{m}_{c}\left(h_{c, o}-h_{c, i}\right)$

$q=\dot{m}_{c} C_{p, c}\left(T_{c, o}-T_{c, i}\right)$

$q=(U A) \Delta T_{l m}$

where

$\Delta T=\frac{\Delta T_{i}-\Delta T_{o}}{\ln \left(\frac{\Delta T_{i}}{\Delta T_{o}}\right)}$

For Parallel flow heat exchangers

$$
\begin{aligned}
\Delta T_{i} & =T_{h, i}-T_{c, i} \\
\Delta T_{o} & =T_{h, o}-T_{c, o}
\end{aligned}
$$

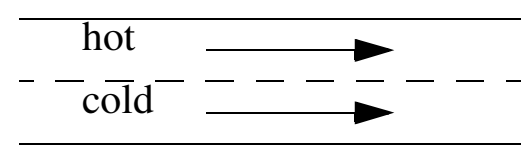




\section{For Counter flow heat exchangers}

$$
\begin{aligned}
\Delta T_{i} & =T_{h, i}-T_{c, o} \\
\Delta T_{o} & =T_{h, o}-T_{c, i}
\end{aligned}
$$

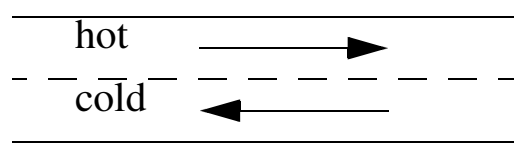

\section{NTU Method}

It is a simple matter to use the log mean temperature difference (LMTD) method of heat exchanger analysis when the fluid temperatures are known and the outlet temperatures are specified or readily determined from the energy balance equations. However, if only the inlet temperatures are known, then the LMTD method requires the iterative procedure. In such cases it is preferable to use the alternative approach, termed the effectiveness-NTU method.

$q_{\max }=C_{\min }\left(T_{h, i}-T_{c, i}\right)$

$C_{\text {min }}$ is the minimum of $C_{h}=\dot{m}_{h} C_{h}$ or $C_{c}=\dot{m}_{c} C_{c}$.

$q=\varepsilon q_{\max }$

where $\varepsilon=f\left(N T U, C_{\text {min }} / C_{\text {max }}\right)$.

$N T U=\frac{U A}{C_{\min }}$

\section{Counter flow heat exchanger}

$\varepsilon=\frac{1-\exp \left[-N T U\left(1-C_{r}\right)\right]}{1-C_{r} \exp \left[-N T U\left(1-C_{r}\right)\right]}$

where $C_{r}=C_{\text {min }} / C_{\text {max }}$.

For $C_{r}=0$

$\varepsilon=1-\exp [-N T U]$ 


\section{Appendix C}

\section{(Storage Tank Model)}

\section{C.1 Stratified Tank Mathematical Formulation}

\section{Stratified Tank}

$$
\begin{aligned}
& M_{i} C_{f} \frac{d T_{i}}{d t}=\left(\begin{array}{ll}
\left(\dot{m}_{1}-\dot{m}_{3}\right) C_{f}\left(T_{i-1}-T_{i}\right) & \dot{m}_{1} \geq \dot{m}_{3} \\
\left(\dot{m}_{3}-\dot{m}_{1}\right) C_{f}\left(T_{I+1}-T_{i}\right) & \dot{m}_{1}<\dot{m}_{3}
\end{array}\right) \\
& M_{i} C_{f} \frac{d T_{i}}{d t}=\alpha_{i} m_{c o l, \text { in }} C_{f}\left(T_{c o, \text { in }}-T_{i}\right)+\beta_{i} m_{\text {load, out }} C\left(T_{\text {load, in }}-T_{i}\right) \\
& +\delta_{i} \gamma_{i} C_{f}\left(T_{i-1}-T_{i}\right)+\left(1-\delta_{i}\right) \gamma_{i} C_{f}\left(T_{i}-T_{i+1}\right) \\
& +\varepsilon \dot{Q}_{a u x, i}-(1-\varepsilon) U A_{f l, i}\left(T_{i}-T_{f l}\right)-U A_{i}\left(T_{i}-T_{a m b}\right)
\end{aligned}
$$

where

$\alpha_{i}=1$, if fluid from collector enters node 1,0 otherwise

$\beta_{i}=1$, if fluid returning from load enters node $\mathrm{i}, 0$ otherwise

$$
\begin{aligned}
\gamma_{i} & =m_{\text {col, in }} \sum_{i=1}^{l-1} \alpha_{j}-m_{\text {load, out }} \sum_{i=i+1}^{N} \beta_{j} \\
\delta_{i} & =\left(\begin{array}{l}
1, \text { if } \gamma>0 \\
0, \text { if } \gamma \leq 0
\end{array}\right)
\end{aligned}
$$

The process is started with the node which has the largest entering flow stream and then throughout the tank. The average temperature over the time step is defined as

$$
\bar{T}_{i}=\frac{1}{\Delta t} \int_{0}^{\Delta t} T(t+\tau) d \tau=\frac{1}{\Delta t} \int_{0}^{\Delta t}\left(\left(T_{i}(t)+\frac{v}{w}\right) e^{u \tau}-\frac{v}{w}\right) d \tau
$$

